TECHNICAL PROGRESS REPORT:

TECHNICAL EVALUATION OF REMEDIATION TECHNOLOGIES FOR PLUTONIUM-CONTAMINATED SOILS AT THE NEVADA TEST SITE (NTS).

\author{
FINAL REPORT
}

REPORTING PERIOD START DATE: OCTOBER 1, 2000

REPORTING PERIOD END DATE: DECEMBER 31, 2003

Principal Aurthor: Steve Hoeffner

Date Issued: December 31, 2003

DOE AWARD \#: COOPERATIVE AGREEMENT \# DE-FC26-00NT40841

Submitting Organization:

Clemson Environmental Technologies Laboratory

100 Technology Drive

Anderson, SC 29625

POC: Steve Hoeffner

864-646-2413, ext. 264

Prepared on behalf of:

Clemson University Research Foundation

P.O. Box 946

Clemson, SC 29633

Subcontractor:

Waste Policy Institute

Savannah River Research Campus

227 Gateway Drive, Suite 223

Aiken, SC 29803

POC: Richard Smalley

(803) 652-8020, ext. 36 


\section{Disclaimer}

This report was prepared as an account of work sponsored by an agency of the United States Government. Neither the United States Government nor any agency thereof, nor any of their employees, makes any warranty, express or implied, or assumes any legal liability or responsibility for the accuracy, completeness, or usefulness of any information, apparatus, product, or process disclosed, or represents that its use would not infringe privately owned rights. Reference herein to any specific commercial product, process, or service by trade name, trademark, manufacturer or otherwise does not necessarily constitute or imply its endorsement, recommendation, or favoring by the United States Government or any agency thereof. The views and opinions of the authors expressed herein do not necessarily state or reflect those of the United States Government of any agency thereof. 


\begin{abstract}
The Clemson Environmental Technologies Laboratory (CETL) was contracted by the National Energy Technology Center to evaluate technologies that might be used to reduce the volume of plutonium-contaminated soil at the Nevada Test Site.
\end{abstract}

The project has been systematically approached.

A thorough review and summary was completed for:

1) The NTS soil geological, geochemical and physical characteristics

2) The characteristics and chemical form of the plutonium that is in these soils

3) Previous volume reduction technologies that have been attempted on the NTS soils

4) Vendors with technology that may be applicable

5) Related needs at other DOE sites

Soils from the Nevada Test Site were collected and delivered to the CETL. Soils were characterized for Pu-239/240, Am-241 and gross alpha. In addition, wet sieving and the subsequent characterization were performed on soils before and after attrition scrubbing to determine the particle size distribution and the distribution of Pu-239/240 and gross alpha as a function of particle size. Sequential extraction was performed on untreated soil to provide information about how tightly bound the plutonium was to the soil. Magnetic separation was performed to determine if this could be useful as part of a treatment approach.

Using the information obtained from these reviews, three vendors were selected to demonstration their volume reduction technologies at the CETL. Two of the three technologies, bioremediation and soil washing, met the performance criteria. Both were able to significantly reduce the concentration plutonium in the soil from around $1100 \mathrm{pCi} / \mathrm{g}$ to $200 \mathrm{pCi} / \mathrm{g}$ or less with a volume reduction of around $95 \%$, well over the target $70 \%$. These results are especially encouraging because they indicate significant improvement over that obtained in these earlier pilot and field studies. Additional studies are recommended. 


\section{TABLE OF CONTENTS}

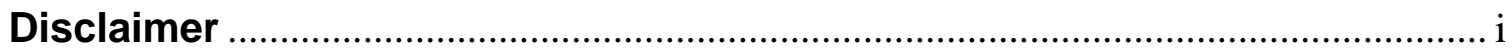

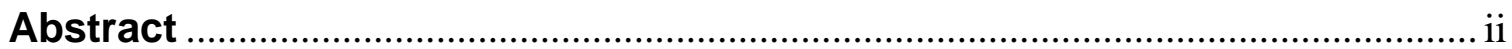

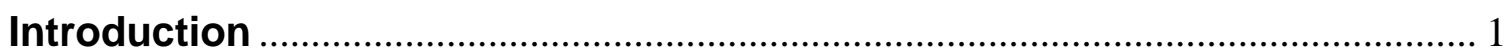

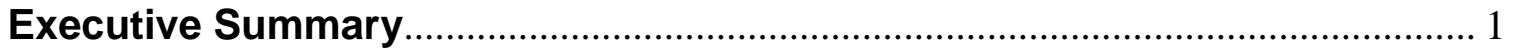

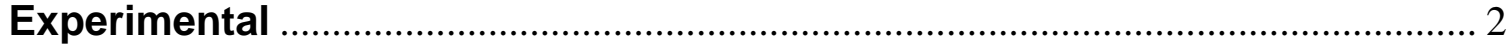

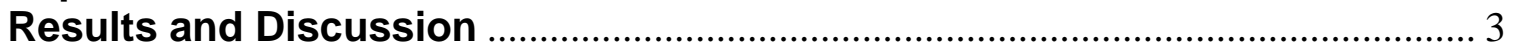

Note: Detailed Results and Discussion for each sub-task are provided in the attached volumes.

Conclusions

4

List of Acronyms and Abbreviations.

Cooperative Agreement Number DE-RA26-001NT40841 


\section{Introduction}

Soils contaminated with radionuclides are an environmental concern at most Department of Energy (DOE) sites. Clean up efforts at many of these sites are ongoing using conventional remediation techniques. These remediation techniques are often expensive and may not achieve desired soil volume reduction. Several studies using alternative remediation techniques have been performed on plutonium-contaminated soils from the Nevada Test Site. Results to date exhibit less than encouraging results, but these processes were often not fully optimized, and other approaches are possible. Clemson University and teaming partner Waste Policy Institute, through a cooperative agreement with the National Environmental Technologies Laboratory, are assisting the Nevada Test Site (NTS) in re-evaluating technologies that have the potential of reducing the volume of plutonium contaminated soil.

This efforts includes 1) a thorough literature review and summary of a) NTS soil characterization and b) volume reduction treatment technologies applied to plutonium-contaminated NTS soils, 2) an interactive workshop for vendors, representatives from DOE sites and end-users, and 3) bench scale demonstration of applicable vendor technologies at the Clemson Environmental Technologies Laboratory.

\section{Executive Summary}

Plutonium $\left({ }^{239 / 240} \mathrm{Pu}\right)$ contamination in soils is an environmental concern at many U.S. Department of Energy (DOE) sites. Remediation actions have been attempted using different technologies, and clean-up plans have been implemented at several sites, such as the Nevada Test Site (NTS). During the 1950's and early 1960's, nuclear weapons testing at and near the NTS resulted in soil contaminated with plutonium particles. Clean-up efforts are continuing using conventional remediation techniques. However, the DOE desires to obtain technologies that can further reduce risks, reduce clean-up costs, and reduce the volume of contaminated soil for disposal.

The Clemson Environmental Technologies Laboratory (CETL) through a cooperative agreement with the National Environmental Technologies Lab in Morgantown, West Virginia, are assisting the National Nuclear Security Administration Nevada Site Office (NNSA/NSO) in evaluating technologies that reduce the volume of plutonium-contaminated soil and that have the potential of reducing risks and clean-up costs.

The overall effort included the following, each of which are completely described in the referenced volume.

Literature Review, Volume 1

Cooperative Agreement Number DE-RA26-001NT40841

Final Report

December 2003 
A literature review was performed to recover and concisely summarize the vast amount of work that has been performed on the study of treatment of plutonium contaminated soils over a $20+$ year time period.

Receive and Characterize NTS Soils, Volume 2

To support vendor bench scale studies Clean Slate II site soils were shipped from the NTS to CETL and thoroughly characterized.

Workshop, Volume 3

A Remediation of Radioactive Surface Soils Workshop was held to determine if other sites has similar needs and to inform vendors about the pending solicitation at CETL.

Vendor Capabilities Survey, Volume 4

A list of vendors with applicable technology was prepared using several sources of information. From this list, several were invited to respond to the CETL solicitation.

Vendor Studies, Evaluation and Ranking, Volume 5

A total of 9 responses were obtained and three were selected: bioremediation, soil washing and flotation. The results of these vendor studies and CETL's independent evaluation and ranking are summarized in this volume.

References and Bibliography, Volume 6

Contains a thorough list of applicable references as well as a bibliography of resulting publications. Copies of may of the references have also been copied onto a CD-ROM disk.

The culmination of these efforts were the vendor bench scale treatability studies. Two of the three technologies, bioremediation and soil washing, met the performance criteria. Both were able to significantly reduce the concentration plutonium in the soil from around $1100 \mathrm{pCi} / \mathrm{g}$ to $200 \mathrm{pCi} / \mathrm{g}$ or less with a volume reduction of around $95 \%$, well over the target $70 \%$. These results are especially encouraging because they indicate significant improvement over that obtained in these earlier pilot and field studies. Additional studies are recommended.

\section{Experimental}

An extensive literature survey and market survey was performed to gather available information on the following topics:

- NTS Geological and Geochemical Soil Characteristics

- NTS Pu-contaminated Soil Characteristics

- NTS Soil Volume Reduction Approaches

- Identification of Potential Vendors

- Identification of DOE site needs

Cooperative Agreement Number DE-RA26-001NT40841

Final Report

December 2003 
The review/survey was accomplished by and iterative process of:

1) Review of two earlier studies (and their referenced documents),

2) Questioning and soliciting the core team about their recollection of other earlier studies,

3) On-line searches of DOE web sites, Environmental Remediation web site (such as www.techcom.com) and generic search engines,

4) Soliciting technology vendors for information about prior related studies,

5) Visiting to the University of Nevada-Reno, and

6) Hosting a Workshop

Soils from the Nevada Test Site, Clean Slate II soils, were collected and delivered to the CETL. Soils were characterized for Pu-239/240, Am-241 and gross alpha. In addition, wet sieving and the subsequent characterization were performed on soils before and after attrition scrubbing to determine the particle size distribution and the distribution of $\mathrm{Pu}-239 / 240$ and gross alpha as a function of particle size. Sequential extraction was performed on untreated soil to provide information about how tightly bound the plutonium was to the soil. Magnetic separation was performed to determine if this could be useful as part of a treatment approach.

Using the information obtained from these reviews, three vendors were selected to demonstration their volume reduction technologies at the CETL. The three technologies were bioremediation, soil washing, and flotation. Decision Analysis Software INEEL Quick Compare was used to rank vendor results.

\section{Results and Discussion}

Note: Detailed results and discussion for each of the following tasks are provided in the referenced attached volumes.

Literature Review, Volume 1

A literature review was performed to recover and concisely summarize the vast amount of work that has been performed on the study of treatment of plutonium contaminated soils over a $20+$ year time period.

Receive and Characterize NTS Soils, Volume 2

To support vendor bench scale studies Clean Slate II site soils were shipped from the NTS to CETL and thoroughly characterized.

Workshop, Volume 3

A Remediation of Radioactive Surface Soils Workshop was held to determine if other sites has similar needs and to inform vendors about the pending solicitation at CETL.

Vendor Capabilities Survey, Volume 4

Cooperative Agreement Number DE-RA26-001NT40841

Final Report

December 2003 
Potential vendors were identified through 1 ) review of vendors involved in previous studies, 2) input from other project participants, 3) library and internet search, 4) CETL previous experience with vendors, 5) CETL prior technology evaluations, 6) attendance of WM'01 symposium, 7) poster presentation at SCFA midyear review, 8) attendance of ER Tech ' 01 and other miscellaneous avenues. From this list, several were invited to respond to the CETL solicitation.

Vendor Studies, Evaluation and Ranking, Volume 5

A total of 9 responses were obtained and three were selected: bioremediation, soil washing and flotation. The results of these vendor studies and CETL's independent evaluation and ranking are summarized in this volume.

Based on the results of bench testing of technologies for the removal of Pu from soils at NTS, two technologies are considered to be viable treatment alternatives to the baseline approach of excavate, transport and dispose. Both the Shaw bioremediation technology and the Earthline soil washing technology met the criteria and goals established for the project, and preliminary testing demonstrates the potential for significant volume reduction of Pu contaminated soils at a substantial cost savings.

All three technologies tested exhibited strengths and weaknesses within the parameters at the NTS. The URS Flotation technology was not as streamlined as the others for NTS soils and the waste volume reduction was not demonstrated. The Shaw and Earthline technologies both demonstrated similar reduction percentages in waste volume. The Shaw bioremediation system will require a large volume of water and continuous operation. The Earthline soil washing system will require a large volume of water and will generate a secondary waste stream that will require treatment/disposal.

\section{Conclusions}

Conclusions specific to each sub-task are provided below:

Literature Review, Volume 1

Size separation helps as an initial step and is especially useful for smaller sized particles. But there can be significant variability in contaminant distribution in the soils and any successful treatment process must address this. Attrition scrubbing appears to help although there is limited data to compare results with and without scrubbing - most studies used either one or the other.

A system that could control the split or size range for the soil fraction based on near real time analysis of the Am-241 could prove to be especially useful. Often the majority $(+70 \%)$ of the plutonium contamination occurs in one or two soil fractions. The approximate lower limit of detection for Am-241 is around $10 \mathrm{pCi} / \mathrm{g}$. This equates to a detection limit of around $150 \mathrm{pCi} / \mathrm{g}$ for plutonium. With state of the art equipment it may be possible to perform near real time analysis of Am-

Cooperative Agreement Number DE-RA26-001NT40841

Final Report

December 2003 
241 as a way to monitor the levels of plutonium in the various soil fractions. (as long as the Am-241 count times are not too lengthy).

None of these volume reduction processes were fully optimized, so significant improvement may be realized by more in-depth studies. However, the varied soil size and plutonium activity distributions present throughout the NTS site proper would also have to be addressed for a treatment process to be robust enough to treat NTS and TTR soils.

Grouping a series of a unit operations together to further increase performance is possible, but it may not be cost effective especially if the increase is small (several of the magnetic separations techniques probably fall into this category).

This literature review indicates that the solution to remediation of the NTS soils is not as mature as one would hope - additional characterization and bench scale studies are warranted - and should aid vendors in developing a successful treatment approach.

Receive and Characterize NTS Soils, Volume 2

The average amount of $\mathrm{Pu}-239$ in the untreated soil from Drum \#1 of the Clean Slate II Site was determined to be $1100 \mathrm{pCi} / \mathrm{g}$. Wet sieving indicated that $35-40 \%$ of the soil is larger than 300 um and that there is very little plutonium activity $(<100 \mathrm{pCi} / \mathrm{g})$ in the $>300$ um fraction. Since $35-40 \%$ of the soil is greater than 300 um, the data indicate that size separation may be useful as part of a treatment process. Attrition scrubbing had no significant effect on particle size distribution. There does, however, appear to be a shift in activity from the 150-300 um fraction to the 38-75 um fraction. But the concentration of plutonium in the 150300 um fraction remains well above the $200 \mathrm{pCi} / \mathrm{g}$ target level.

Sequential extraction studies indicated that significant amounts of plutonium are soluble in the "organic" (HNO3/peroxide) and resistant (8 M HNO3) extracts. The solubility of plutonium in the $\mathrm{HNO} /$ peroxide is somewhat surprising because historical data indicated that the plutonium was present as plutonium dioxide and as fused plutonium silicate. These would usually be insoluble in the HNO3/peroxide and soluble in the resistant phase and any remaining residual phase. The results indicate that soil washing using acid/oxidant combinations may perform well and should be investigated.

Magnetic separation was able to reduce the amount of activity in the soil from 1200 down to $600 \mathrm{pCi} / \mathrm{g}$ (for wet separation) and $750 \mathrm{pCi} / \mathrm{g}$ (for dry separation). However, both of these remain well above the $200 \mathrm{pCi} / \mathrm{g}$ target level. As such, it does not appear to be a useful volume reduction technique.

Workshop, Volume 3

Cooperative Agreement Number DE-RA26-001NT40841

Final Report

December 2003 
In an effort to further make these studies as useful as possible to NTS and other sites, a soils workshop was held at the Nevada Operations Office in Las Vegas, Nevada on August 14 and 15, 2001. About 70 personnel from the government, private sector, and public participated. As a result of the workshop, needs from 10 sites assimilated into tables and the capabilities of 12 vendors were summarized into tables.

Vendor Capabilities Survey, Volume 4

A summary of 35 potential vendors were identified. Many of the vendors that were involved in earlier studies were no longer in business, or had merged with other companies. The survey indicated that the pool of qualified vendors is fairly dynamic and routinely changes.

As a result of the direct contacts:

- 35 vendors were identified and contacted

- 26 expressed an interest in the solicitation

- $\quad$ About a dozen attended the soils remediation workshop (see Volume 3)

- 9 vendors responded to the Request for Qualifications.

The responses were reviewed and, according to CETL's review, three of the submittals met the RFQ criteria. These are IT Corp (bioremediation), Earthline Technolgies (physical/chemical soil washing) and URS Corp. (flotation). Awards were issued to these vendors to perform bench scale studies at CETL.

Vendor Studies, Evaluation and Ranking, Volume 5

It is recommended that, pending review of more detailed information to support the cost estimate, the Shaw system be considered for a pilot scale demonstration at the NTS. Parallel with or prior to this effort, it would also be useful to perform laboratory studies to determine if sulfuric acid leaching can perform as well as the bioremediation process. A chemical based process would be much simpler than the biological based Shaw process. The Earthline system should first demonstrate effective Pu removal from recycled leachate prior to advancing to a pilot scale test. And concerns raised by technical team members should be addressed and resolved prior to a pilot scale test. Larger scale testing under true site conditions will reduce technology deployment uncertainties and allow a sitespecific evaluation of system requirements. No further studies are recommended for the URS flotation technology.

\section{References and Bibliography}

Volume 6 contains a list of applicable references as well as a bibliography of resulting publications.

\section{List of Acronyms and Abbreviations}

CETL - Clemson Environmental Technologies Laboratory

NETL - National Energy Technology Laboratory

Cooperative Agreement Number DE-RA26-001NT40841

Final Report

December 2003 
NTS - Nevada Test Site

TTR - Tonopah Test Range

Appendices

Appendices, where applicable, are included with each Volume. 


\title{
Evaluation of Remediation Technologies for Plutonium Contaminated Soils at the Nevada Test Site (NTS)
}

\section{Cooperative Agreement \#DE-FC26-00NT40841}

\author{
Volume I
}

\section{Literature Review}

Date Issued October 13, 2003 


\section{TABLE OF CONTENTS}

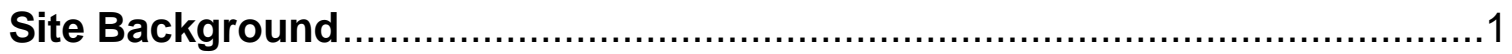

Description of the NTS Plutonium-Contaminated Soils ..............................

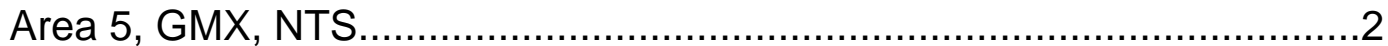

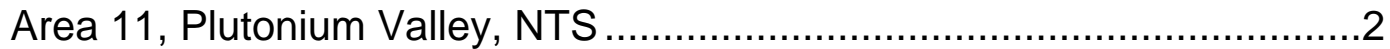

Area 13, Project 57, near NTS........................................................

Area 52, Clean Slate I, II and III, Double Tracks....................................

Previous Technology Assessments ...................................................

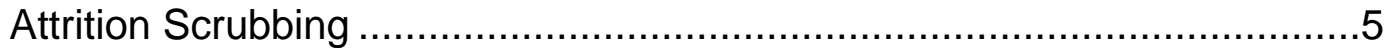

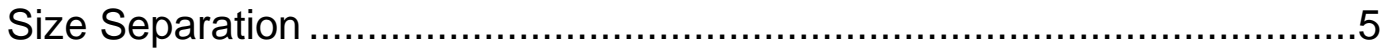

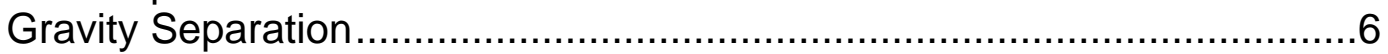

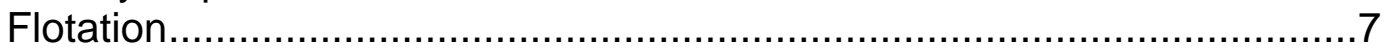

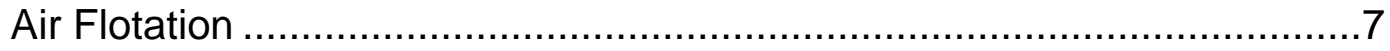

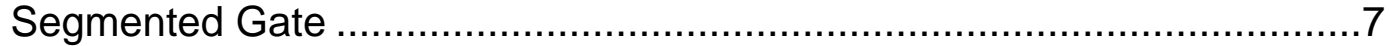

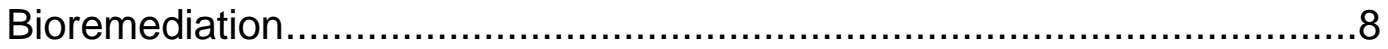

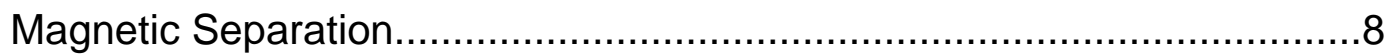

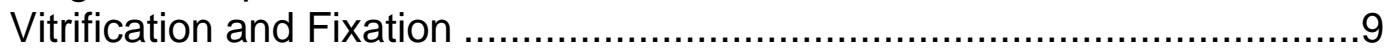

Logistical Considerations That Are Unique to the Nevada Test Site.............

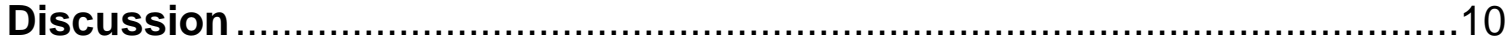




\section{LIST OF FIGURES}

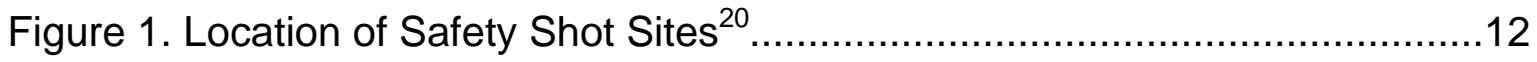

Figure 2. Plutonium Distribution-Clean Slate III...........................................13

Figure 3. Plutonium and Mass Distribution in Clean Slate I Soil.........................14

Figure 4. Mass Distribution-Clean Slates II Soils...........................................15

Figure 5. Plutonium Distribution-Clean Slates II Soils ...................................16

Figure 6. Relative Activity as a Function of Particle Size-Clean Slate II Soils .......17

Figure 7. Plutonium and Mass Distribution in Clean Slate II Soil-PCMR2-B1 .......18

Figure 8. Plutonium and Mass Distribution in Clean Slate II Soil-PCMR2-B3 .......19

Figure 9. Plutonium and Mass Distribution in Clean Slate II Soil-PCMR2-B3 .......20

Figure 10. Mass Distribution-Clean Slate III Soils .........................................21

Figure 11. Plutonium Distribution-Clean Slate III Soils ....................................22

Figure 12. Relative Activity as a Function of Particle Size-Clean Slate III Soils ....23

Figure 13. Plutonium and Mass Distribution in Clean Slate III Soil-PCMR2-C1 ....24

Figure 14. Plutonium and Mass Distribution in Clean Slate III Soil-F-034 ............25

Figure 15. Plutonium and Mass Distribution in Clean Slate III Soil-PCMR2-C1 ....26 


\section{Site Background}

In December of 1950 President Harry Truman established the NTS as the continental test site for research and development of nuclear weapons ${ }^{1}$. The site is located in the south central portion of Nevada and has been used by the Atomic Energy Commission and the Department of Energy (DOE) for 982 of the 1100 nuclear weapons tests conducted since World War ${ }^{2}$. The site was chosen for nuclear testing because of the remoteness and climatology of the site $^{1}$. From 1951 until the establishment of the Limited Test Ban Treaty in 1963, many atmospheric, tower, nuclear rocket, borehole, and underground tests were conducted at the NTS ${ }^{3}$.

The series of tests pertinent to this project are known as "Safety Shots" or "Safety Tests." Safety Tests were conducted between 1954 and 1963. The purpose of the tests was to investigate and evaluate the safety of nuclear weapon designs ${ }^{4}$. The sub-critical tests, which used depleted uranium (U) and plutonium $(\mathrm{Pu})$ as tracer material, were conducted to investigate the physical and chemical reaction of plutonium materials when subjected to detonations of conventional chemical explosions in accidental or terrorist scenarios. An example of this kind of testing is the detonation of explosives on an open concrete pad or in an enclosed simulated storage facility. The Safety Tests were performed at several sites at the NTS as well as at the Nellis Air Force Range and the Tonopah Test Range $(\mathrm{TTR})^{4}$.

\section{Description of the NTS Plutonium-Contaminated Soils}

The Department of Energy conducted safety shots at several locations on the Nellis Air Force Range, TTR (Double Tracks; Clean Slates 1, 2, and 3; and Area 13); at Plutonium Valley in Area 11 of the NTS; and the GMX site in Area 5 of the NTS. The safety tests did not result in significant nuclear yield, but did disperse contaminants in excess of 40 picocuries per gram in surficial soils over more than 1,200 hectares $(3,000 \text { acres })^{5}$. Detailed information on the extent of contamination is provided in a recent Cost/Risk/Benefit analysis ${ }^{6}$.

Soils for the region are classified as sands, loamy sands or sandy clay loams ${ }^{7}$. Plutonium and its daughter isotopes, primarily americium, were dispersed from the source of detonations in a widening plume dependent on prevailing environmental conditions at the time of the test shots. Fine plutonium particles became airborne and were either transported off-site by the wind currents or were deposited downwind of the point of detonation as a result of fusing with silica particles. Over the years, the plutonium became integrated with the gravel, sand and silt particles at the site and with varying degrees of cementation caused by environmental weathering, the plutonium became incorporated into the surface hardpan typical of such arid areas. The bulk of the activity typically resides within the top few centimeters of the soil. The plutonium particles have become relatively immobile over the past 30 years and will remain so until disturbed $^{3}$. Contaminant concentrations range from 200 to 12,800 picocuries per 
gram (pCi/g) over the 3,000 acres of land ${ }^{3}$. An estimated 20-25 million cubic feet of plutonium-contaminated soil exists at the NTS and the adjacent TTR ${ }^{8}$.

The surface chemistry and physical properties of radionuclides are significantly different from that of the host soil. For example, the density, magnetic susceptibility, surface wetability and electrical charge of certain transuranic elements are markedly different from that of quartz, clay and other minor constituents ${ }^{9}$.

For the purpose of this study, there are 5 sites that have been targeted for remediation (See Figure 1):

GMX (Area 5, NTS)

Plutonium Valley (Area 11, NTS)

Project 57 (Area 13, slightly outside the Northeast corner of the NTS)

Clean Slates II (Area 52, TTR)

Clean Slates III (Area 52, TTR)

Information for each, if available, is provided below.

\section{Area 5, GMX, NTS}

No information is available on this area. The assumption is that the soil would be similar to other nearby areas.

\section{Area 11, Plutonium Valley, NTS}

A study was performed by Misra on an Area 11 soil from the NTS ${ }^{9}$. More than $75 \%$ of the total radionuclides are dispersed in the minus 40 -micron size soil fractions $^{9,10}$. Thirty-one percent (weight) of soil is minus 20 microns, $95 \%$ is minus 125 microns. The radionuclides are present as particles and/or are partially attached to clay particles. SEM indicates that fine clay and silt attach to relatively large particles and agglomeration of fine clays is also observed. This information, along with the wet screening results, suggests that the soil pretreatment steps are necessary to disintegrate the lumped particles for effective separation. Scanning Electron Microscope/Energy Dispersive X-ray Spectroscopy (SEM/EDX) and petrographic analyses have shown that the major mineralogical constituents of the soil are clay, quartz, magnetite, titanomagnetite and limestone. The mineralogical analysis of the coarse size NTS soil indicates the presence of magnetite, sanidine, titanomagnetite and biotite. The fine fraction contains clay, quartz and feldspar. In some instances radionuclides are bonded to magnetite (which is magnetic) and clay particles ${ }^{9}$.

In a study performed by Lockheed Environmental Systems and Technologies (LESAT), only about $45 \%$ of the total curie activity was contained in the soil smaller than 20 microns (soil was wet sieved) ${ }^{7}$. This increases to just under $60 \%$ for soil that is smaller than 75 microns. In comparing these results to those in the previous paragraph, some variability in plutonium distribution as a function of particle size is indicated for Area 11 soils. Photo-optical microscopy and 
scanning electron microscope analyses indicated the presence of discrete, agglomerated, fused and mixed matrix soil particles.

Work by Murarik ${ }^{11}$ has shown that the activity of plutonium increased in the wet size fractions as compared to the dry size fraction. This may indicate that the transuranics are finely dispersed and loosely bound to clay particles. In such instances it should be easy to separate much of the plutonium from the soil using pretreatment techniques.

In another study by Misra ${ }^{12}$, particle size and activity distributions were determined for an Area 11 soil and for a Clean Slate I soil. A graphical presentation of Misra's tabular data is shown in Figure 2. This Area 11 soil appears to be significantly different from the first Area 11 soil mentioned above. In general the data indicate a courser soil. Figure 2 shows the mass distribution of the soil as a function of the soil particle size, as determined by wet and dry sieving. As might be expected, the percent of fine material increases when the soil is wet sieved. Only about $10 \%$ of the soil is minus 150 microns. This graph also shows the plutonium distribution (percent of total curie content) as a function of the soil particle size. The figure indicates that the minus 150-micron fraction contains less than $20 \%$ of the total plutonium when dry sieved and nearly $70 \%$ when wet sieved. The graph also shows the plutonium activity distribution $(\mathrm{pCi} / \mathrm{g})$ as a function of the soil particle size. Similar to the above soil, the highest concentrations of plutonium occur in the smaller sized fractions.

The limited data indicate that the size distribution and plutonium distribution may vary significantly for Area 11 soils. Available data for the Area 11 soils show increasing plutonium activity with decreasing particle size. This may or may not be the case for other Area 11 soils, as the following data for some other Area soils indicates significant variability within a given Area.

\section{Area 13, Project 57, near NTS}

A limited amount of data is available for the Area 13 soils $^{10}$. Most of the plutonium contamination was associated with smaller particles $(<40 \mathrm{~mm})$. These data suggest that even in soils with very low average plutonium activity, such as the soil of Area 13, specific activities in smaller size fractions may be orders of magnitude higher ${ }^{10}$.

\section{Area 52, Clean Slate I, II and III, Double Tracks}

In contrast to Area 11 and 13 soils, almost all the plutonium activity was found in medium size fractions (83\% of the soil mass was between 75 and 250 microns) for an Area 52 soil (see Misra ${ }^{10}$, source of the soil was not more specifically identified). It is possible that the mineralogy of the area in combination with the specific history of the plutonium test and nuclear devices used in area 52 resulted in association of the plutonium with a coarser size fraction (larger than $125 \mathrm{um}$ ). The shot in Area 52 was exploded in a bunker, whereas the shots in areas 11 and 13 were above ground detonations. This may explain why 
plutonium in area 52 was deposited as a fused plutonium-silicate, whereas in areas 11 and 13 it was deposited as a plutonium oxide ${ }^{10}$.

In another study by Misra ${ }^{12}$, particle size and activity distributions were determined for a Clean Slate I soil. Figure 3 shows the mass distribution of the soil as a function of the soil particle size, as determined by wet and dry sieving. The percent of fine material increases slightly when the soil is wet sieved. The graph of plutonium distribution (percent of total curie content) as a function of the soil particle size indicates that the minus 150-micron fraction contains less than $5 \%$ of the total plutonium when dry or wet sieved. The highest concentrations of plutonium occur in the mid-sized fraction (300-850 microns).

An extensive amount of soil characterization work was done by University of Nevada-Reno and by the IT Corporation in support of pilot-scale demonstrations for soils from Double Tracks, Clean Slate I, Clean Slate II and Clean Slate III ${ }^{13}$. Data for the Clean Slate II and Clean Slate III soils are presented in Figures 3 through 15.

Clean Slate II - Figure 4 shows the mass distribution of the soil as a function of the soil particle size. It is not known if these results were obtained by wet or dry sieving. Data are summarized for nine different Clean Slate II soils. The amount of soil passing a particular sieve size varies up to around $20 \%$. Figure 5 shows the plutonium distribution (percent of total curie content) as a function of the soil particle size. The figure indicates very large differences in the plutonium distribution. As a result, the amount of plutonium that can be removed by size separation is going to vary significantly for Clean Slate II soils. Figure 6 shows the plutonium activity distribution ( $\mathrm{pCi} / \mathrm{g}$ ) as a function of the soil particle size. The soil size fraction containing the highest concentration of plutonium varies significantly from soil to soil, ranging from 74-295 microns to $9-13$ microns. A summary of the mass and plutonium distribution for three of the Clean Slate II soils is shown in Figures 7,8 and 9. The data clearly show the variability in soil mass distribution, plutonium mass distribution and plutonium specific activity as a function of particle size.

Clean Slate III - Figure 10 shows the mass distribution of the soil as a function of the soil particle size. It is not known if these results were obtained by wet or dry sieving. Data are summarized for nine different Clean Slate III soils. The amount of soil passing a particular sieve size varies around $25-30 \%$. Figure 11 shows the plutonium distribution (percent of total curie content) as a function of the soil particle size. The figure indicates very large differences in the plutonium distribution. As a result, the amount of plutonium that can be removed by size separation is going to vary significantly for Clean Slate III soils. Figure 12 shows the plutonium activity distribution ( $\mathrm{pCi} / \mathrm{g}$ ) as a function of the soil particle size. The soil size fraction containing the highest concentration of plutonium varies significantly from soil to soil, ranging from $>4700$ microns to $9-13$ microns. A summary of the mass and plutonium distribution for three of the Clean Slate III soils is shown in Figures 13,14 and 15. The data clearly show the variability in 
soil mass distribution, plutonium mass distribution and plutonium specific activity as a function of particle size.

\section{Previous Technology Assessments}

The removal of plutonium from NTS Area soils has been attempted using various combinations of attrition scrubbing, size classification, gravity based separation, flotation, air flotation, segmented gate, bioremediation, magnetic separation and vitrification. A brief summary of the effectiveness of each is provided below.

In addition, the manner in which the soil is removed has a direct impact on the total volume of soil that will need to be treated. Most of the plutonium activity typically resides within the top few centimeters of soil ${ }^{6}$, but most soil removal techniques cannot be controlled to this degree. As a result more soil is usually removed than is necessary to meet cleanup criteria. Typically on the order of a couple of inches of soil is removed using equipment such as a road grader. Alternative approaches have been such as a scabbler-type tool designed by JVI Environmental that has been used to remove asbestos and that may have application to removal of plutonium from soils ${ }^{14}$.

\section{Attrition Scrubbing}

Attrition scrubbing was used extensively as a pretreatment step to break up agglomerated materials, to remove surficial coatings from larger soil particles, and hopefully to make the contaminated soil more amenable to processing. As data in Figures 2 and 3 indicate, the result is often but not always a shift to more of the plutonium activity residing in the smaller sized particles.

SEM indicates that fine clay and silt attach to relatively large particles and agglomeration of fine clays is also observed. This information, along with the wet screening results, suggests that the soil pretreatment steps are necessary to disintegrate the lumped particles for effective separation.

\section{Size Separation}

It was found, based on wet sieving of the contaminated soil and plutonium determination in each size fraction, that for a soil from Areas 11 and 13 (but not Area 52), most of the plutonium contamination was associated with the smaller particles, typically smaller than approximately 40 microns $^{10}$. A spiral classifier that had a 75 -micron cutoff was used to treat Area 11 soil $^{10}$. The classifier worked very well since the soil less than 73 microns in diameter (about $1 / 3$ of the total soil) contained most of the plutonium. Note, however, that data for Area 11 and 13 are fairly limited and that these conclusions may not apply to all of the contaminated soil from these two areas. Attrition scrubbing and wet sieving of Area 11 soil was able to achieve a $70 \%$ volume reduction ${ }^{10}$. 
The dispersion of the plutonium oxide contaminant in the NTS soil is unique and completely different from the way mineral is naturally dispersed in an ore to be processed by mineral processing plants. Most of the plutonium oxide in the NTS soil is dispersed in a size range of minus 120 microns that also includes $40-50 \%$ of the nominal soil fraction in this size range. Compounding the problem, the content of plutonium oxide in the NTS soil is less than $0.001 \%$, which is well below the average mineral content (normally several percent) of an ore to be processed in a typical mineral processing plant. This unique situation at NTS makes the separation of plutonium oxide by physical methods extremely difficult or impossible from the standpoint of scientific concepts. For example, sizing with a 120 micron screen will recover most of the plutonium oxide, but the soil volume reduction will be very low, approximately $2-2.5$. However, sizing with a smaller screen size will achieve a high volume reduction but will recover only a small fraction of the contaminant. Thus, screening of the soil alone is not a primary choice for separation of plutonium oxide from the NTS soil ${ }^{3}$.

\section{Gravity Separation}

Gravity-based processes work on the principle of Stokes' law. Heavy particles settle faster than light particles. However, the size of the particle also influences the rate of settling. The result is that gravity based separation is not very effective for fine particles ${ }^{9}$. Many of the NTS soils contain a significant amount of fines.

For these reasons the mineral jig did not work well. Very small plutonium particles are carried away by water flow instead of settling downward ${ }^{10}$.

The Multigravity system (MGS), a system based on gravity separation, enhances the performance of a conventional vibrating table by enclosing the horizontal concentrating surface into a rotating cylindrical drum. The MGS did an excellent job for the $<44$-micron soil ${ }^{10}$. The efficiency of the process appeared to depend on particle size and particle size uniformity. Although the ratio of concentrate-totailings specific activities reached an encouraging 16.3:1 for the finer particles, this ratio was not consistently maintained, suggesting that the overall process performance depends on parameters which are not well understood. With particles of less uniform size (all particles smaller than 75 microns), the results were less encouraging.

Gravity separators (mineral jig and Wilfley shaking table) and centrifugal separators (hydrocyclones and Falcon concentrator) will not effectively separate the contaminant ${ }^{3,}{ }^{10}$. Thermal drying and air classification has also been proposed to treat the NTS soils ${ }^{3}$. Gravity and centrifugal separators utilize the terminal velocity of a particle for the basis of separation, which depends on the combination of density and size. Thus, the fine (size) and heavy (density) plutonium oxide particles will be separated and report together to the same concentrate product stream with the large (size) and light (density) soil matrix particles. As an example, a roughly 50-micron plutonium oxide particle with a density of $11.6 \mathrm{~g} / \mathrm{cm}^{3}$ would end up in the same concentrate stream as a 20micron soil matrix particle with a $2.65 \mathrm{~g} / \mathrm{cm}^{3}$ density. Thus, the separation of only

6

Volume I Literature Review

Cooperative Agreement \#DE-FC26-00NT40841

October 13, 2003 
plutonium oxide particles from the soil matrix particles is not possible using only gravity/centrifugal separators. In addition, during the separation process, the plutonium oxide particle is surrounded by several thousand soil matrix particles, making it difficult to liberate and to allow the particle to respond to gravity separation forces ${ }^{3}$. But the primary reason why processes that rely on the dependence of settling velocity on density differences failed was the very fine grain size of the plutonium-rich particles ${ }^{10}$.

\section{Flotation}

From a scientific perspective froth flotation looks promising (zeta potential between soil and plutonium oxide is significantly different $)^{9}$. A technology based on carrier flotation appears to offer some promise ${ }^{3}$. More than $90 \%$ of two surrogates $\left(\mathrm{CeO}_{2}\right.$ and $\left.\mathrm{TiO}_{2}\right)$ can be separated from NTS soil with flotation using oleic acid at an alkaline $\mathrm{pH}^{9}$. Lab tests using cerium dioxide surrogate and calcium carbonate carrier provided impressive recovery and volume reduction results ${ }^{3}$.

Over $70 \%$ of the activity were found in the dense liquid float for an Area 11 soil $^{7}$. Mechanical flotation resulted in $90 \%$ of the total soil mass in the lean stream for an Area $11 \mathrm{soil}^{12}$. Plutonium concentration was decreased from $150 \mathrm{pCi} / \mathrm{g}$ in the feed to $33 \mathrm{pCi} / \mathrm{g}$ in the lean stream for an Area 11 soil $^{12,15}$.

Flotation separation is highly dependent on using the correct reagent in the slurry, which would permit air bubbles to attach to plutonium mineral grains. The best reagent may not have been identified to produce an optimal separation so even improved separations could potentially be achieved ${ }^{10}$. Carrier flotation has the advantage over air flotation of use of a carrier, which is especially important if the contaminant of interest is present at very low concentration, such as it is for plutonium (present at $<0.001 \%$ ).

\section{Air Flotation}

For both Area 13 and 52 soils, the overflow (concentrate) actually had less plutonium than the underflow material. This indicates that air flotation was not capable of separating the plutonium from the bulk soil slurry for this soil. These results also show that air flotation was not as successful in removing the fine ( $<38$ micron) plutonium particles as it was with the larger plutonium particles ${ }^{10}$. Some factors that may partially explain the poor results are 1) a surrogate was used to determine the optimum reagents and other experimental variables, and 2) an attrition scrubber was not used to break down plutonium-soil particle aggregates ${ }^{10}$. The process does, however, work well with fine particles $(<10$ micron). Being a flotation technique, the results are dependent on surface chemistry, which can be used to improve separations.

\section{Segmented Gate}

The segmented gate system separates contaminated soil from clean soil according to a preset radioactivity criterion. Field surveys show that there can be significant differences in surface activity within a foot or two ${ }^{6}$. But mixing of the 
soil occurs with the methods that have been used to remove the top few inches of contaminated soil (usually a road grader that pushes the soil into wind rows, followed by equipment to pick up the row of soil). This, coupled with the wide dispersion and low concentration of the plutonium oxide particles, restrains this technology from attaining the targeted goals in terms of volume reduction and recovery of plutonium oxide ${ }^{3}$. Poor results were obtained in a recent field test performed at the Clean Slate 2 site: only $61 \%$ of the plutonium activity ended up in the "concentrate" with a volume reduction of 2:1 (weight of feed to weight of clean $)^{3,16}$.

\section{Bioremediation}

Bio-leaching of plutonium oxide occurs with sulfuric acid produced from elemental sulfur in the presence of sulfur oxidizing bacteria. This technology is also based on a precipitation of plutonium sulfate complex $\left(\mathrm{PuO}_{2}\left(\mathrm{SO}_{4}\right)_{3}{ }^{4-}\right)$ as plutonium oxide sulfur $\left(\mathrm{PuO}_{2} \mathrm{~S}\right)$ in the presence of sulfate reducing bacteria. Good results of field testing at NTS were obtained and the technology has been evaluated as promising ${ }^{3}$. The unit processes are based on sound scientific concepts that have been proven in the acid leaching of uranium oxides with sulfuric acid and oxygen, and in the precipitation of metal ions in wetlandtreatment of acid-mine drainage. Preliminary conversations with Carl Fliermans ${ }^{17}$ indicate that the soil would need to be kept moist and could be covered with plastic sheeting to retain moisture. Elevated temperatures up to 50 or 60 degrees Celsius are not detrimental and could be beneficial. These factors indicate that it may be possible to treat using a heap leaching approach.

\section{Magnetic Separation}

Early studies with magnetic separation indicated that the magnetic susceptibility of fine soil is very low. Wet magnetic separation was being tested and indications were that wet magnetic separation might work ${ }^{9}$.

More recently, a more in-depth study was performed using two magnetic processes on three NTS soils from Areas 11,13 and $52^{10}$. One process used a Kolm separator and the second a rare earth conveyor. The results were highly variable, and for the Area 52 soil, the specific activity of the plutonium in the "decontaminated" stream was higher than either the feed or the "contaminated stream. These results are for the feed into the magnetic separator. There was some preliminary separation of the NTS soils based on size. Mass balances were poor. Many potential explanations were advanced to explain these discouraging results:

1) The magnetic intensity setting and flow rate may not have been optimal.

2) A large fraction of the slurry was retained by the magnet (26\%), possibly a result of the initial deposit of magnetic material trapping non-magnetic material.

3) Incorrect frequency of shutdown and cleanup of the magnet could have resulted in excessive buildup of retained material. 
4) The relatively high clay content of the soil could be responsible for "masking" the paramagnetic behavior of plutonium particles resulting in poor separation.

5) The exact plutonium distribution as a function of particle size was not known before the record runs and process optimization was based on preliminary plutonium activity estimates from ${ }^{241} \mathrm{Am}$ spectroscopy measurements ${ }^{10}$.

The major reason seems to be that fine particles of plutonium oxide are attached to large matrix particles by Van der Waals type of forces and the magnetic separator is not strong enough to pull paramagnetic plutonium oxide particles, especially when the particles are shrouded by many matrix particles.

In another study by Los Alamos ${ }^{18}$, about $85 \%$ of the plutonium were removed from the flow stream. However, about $30 \%$ of the soil mass was also caught up in the separator. Results then are similar to those mentioned above. The results indicate that the NTS residue is highly magnetic and the activity is probably tied up with the magnetic minerals such as magnetite.

Although results to date have not been encouraging, there is the potential to further optimize treatment and reduce the amount of material that is held up.

\section{Vitrification and Fixation}

This technology is expensive and does not achieve soil volume reduction. It does not meet DOE programmatic goals of volume reduction; instead, it provides only immobilization of the contaminant ${ }^{3}$. However, it is possible that vitrification may be an acceptable form of treatment on certain locations.

Recent work has shown that radionuclides can also be "fixed" to soil and minerals by heating the soil up to around $1000 \mathrm{C}^{19}$. Although less expensive than vitrification, the technology does not meet DOE programmatic goals of volume reduction; instead, it provides only immobilization of the contaminant. However, it is possible that fixation may be an acceptable form of treatment on certain locations.

\section{Logistical Considerations That Are Unique to the Nevada Test Site}

Successful treatment of soils at the NTS and TTR will have to overcome the following challenges:

- $\quad$ The distribution of plutonium and soil mass as a function of soil particle size varies significantly from test site to test site, and even within a test site.

- $\quad$ The site is an active bombing and gunnery range operation of the United States Air Force

- $\quad$ The site is remote; there are no readily available services such as electricity, water, or service facilities ${ }^{3}$. 
- The area is exceptionally arid with no readily available water resources, i.e., there are no surface river systems; underground reserves are deep and the area receives little precipitation.

- The plutonium-contaminated particles are very small diameter. Most of the plutonium oxide particles are less than 120 microns in size ${ }^{3}$. Often a large percentage of the soil particles are in this same size range. Thus, a sharp separation cannot be theoretically achievable using gravity separation because the fine-heavy plutonium oxide particles and the coarse-light matrix particles will be separated and report together in the same process stream. Static forces may hinder separation.

- The content of plutonium oxide in the NTS soil is less than $0.001 \%$, which is well below the average mineral content (normally several percent) of an ore to be processed in a typical mineral processing plant.

\section{Discussion}

Early reports were very positive and data indicated increasing plutonium concentration with decreasing particle size for the NTS soils ${ }^{10}$. While this may be true for some soils at the NTS proper, as the Figures 2 through 15 have shown, it is by no means the case for all of the Safety Shot soils. Preliminary studies also indicated that the plutonium might be in a readily extractable form. But later studies have shown that this is not usually the case, and that there are at least two forms of plutonium present at the site: plutonium oxide and fused plutoniumsilicate. In addition, weathering has taken its toll and made the plutonium less amenable to extraction.

Many different treatment techniques have been investigated. Unfortunately, the interpretations of the results from several of these studies were hampered by low activity, small sample size for treatability test and small analytical sample size for determining the results of the treatability test.

Physical separation technologies were found to be intrinsically difficult to use on the NTS soil due to the dispersion and size of the plutonium dioxide particles within the soil matrix ${ }^{3}$. Another problem that may have complicated all of the tests is the inability to totally dislodge the plutonium from the other soil particles ${ }^{10}$.

The significant variability in soil composition within a given area can pose additional challenges to successfully treating the soil. And how the soils are processed can also influence these size and activity distributions. Blending may be helpful within a given area, especially if size separation is one of the unit operations selected for the overall treatment scheme. But in other instances blending of the soil would be disadvantageous. For example, segmented gate would work best when minimal mixing of the soil has occurred. If an improved method of collecting the soil could be developed, segmented gate may be much more effective. 
Use of magnets to remove the plutonium from the soil has been tried repeatedly, with little or no success. Part of the problem appears to be that lots of other materials get held up on the magnets besides the plutonium. Reagents can be used to try and minimize this.

In summary, size separation helps as an initial step and is especially useful for smaller sized particles. But there can be significant variability in contaminant distribution in the soils and any successful treatment process must address this. Attrition scrubbing appears to help although there is limited data to compare results with and without scrubbing - most studies used either one or the other. A system that could control the split or size range for the soil fraction based on near real time analysis of the Am-241 could prove to be especially useful. Often the majority $(+70 \%)$ of the plutonium contamination occurs in one or two soil fractions. The approximate lower limit of detection for Am-241 is around $10 \mathrm{pCi} / \mathrm{g}$. This equates to a detection limit of around $150 \mathrm{pCi} / \mathrm{g}$ for plutonium. With state of the art equipment it may be possible to perform near real time analysis of Am241 as a way to monitor the levels of plutonium in the various soil fractions. (as long as the Am-241 count times are not too lengthy).

None of these processes were fully optimized, so significant improvement may be realized by more in-depth studies. However, the varied soil size and plutonium activity distributions would also have to be addressed for a treatment process to be robust enough to treat NTS and TTR soils.

Series of a given unit operation could be performed to further increase performance, although it may not be cost effective especially if the gain is small (several of the magnetic separations techniques probably fall into this category).

This summary shows that the solution to remediation of the NTS soils is not as mature as one would hope - additional characterization and bench scale studies are warranted - and should aid vendors in developing a successful treatment approach.

Note that any plan to return cleaned soil to the site requires stakeholder buy in. 


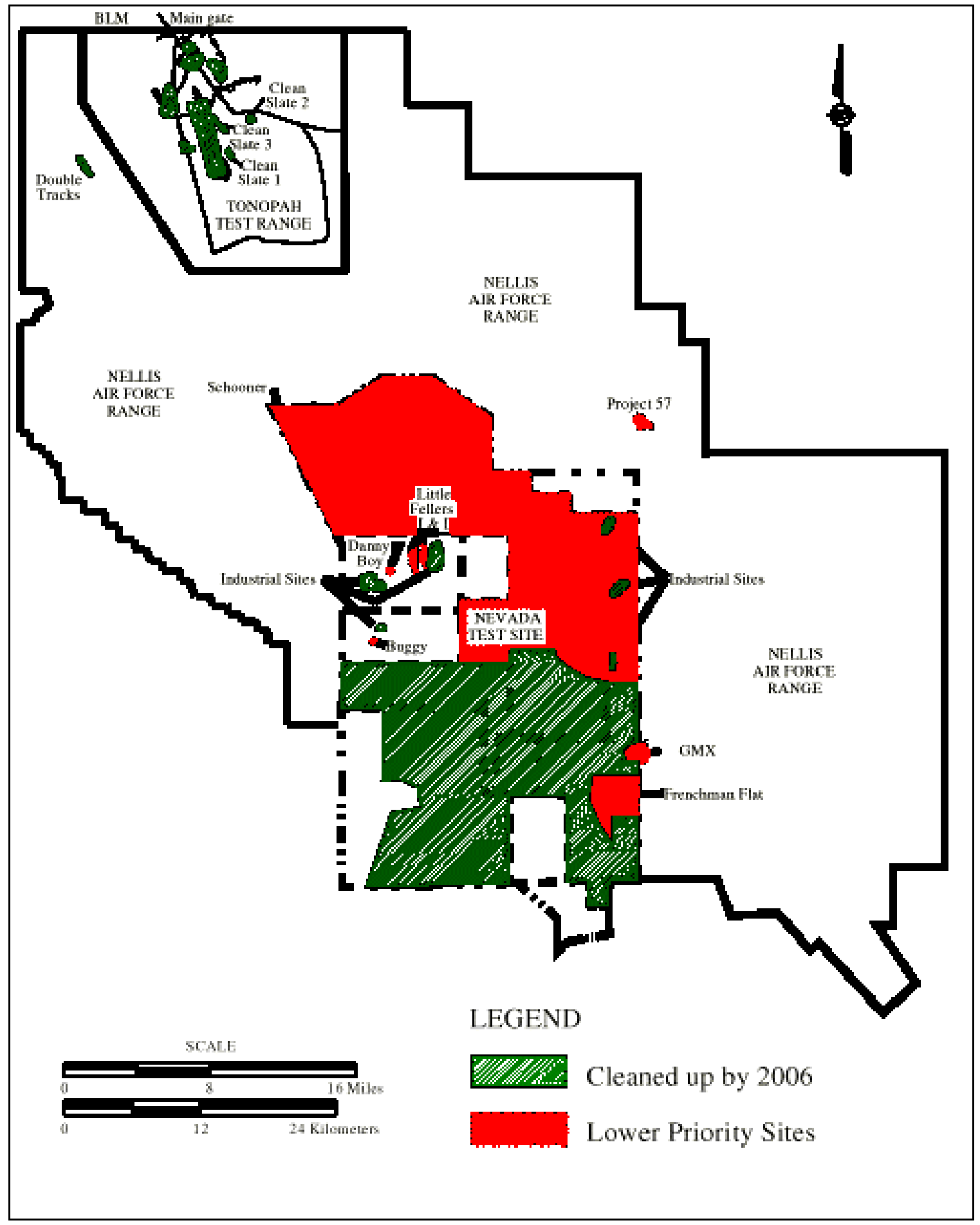

\begin{tabular}{|l|l|l|}
\hline \multirow{3}{*}{ TTS } & GMX & Area 5 \\
\cline { 2 - 3 } & Plutonium Valley & Area 11 \\
\cline { 2 - 3 } & Project 57 & Area 13 \\
\hline \multirow{2}{*}{ TTR } & Clean Slates II & Area 52 \\
\cline { 2 - 3 } & Clean Slates III & \\
\hline
\end{tabular}

Figure 1. Location of Safety Shot Sites ${ }^{20}$ 
Figure 2. Plutonium and Mass Distribution in Area 11 Soil

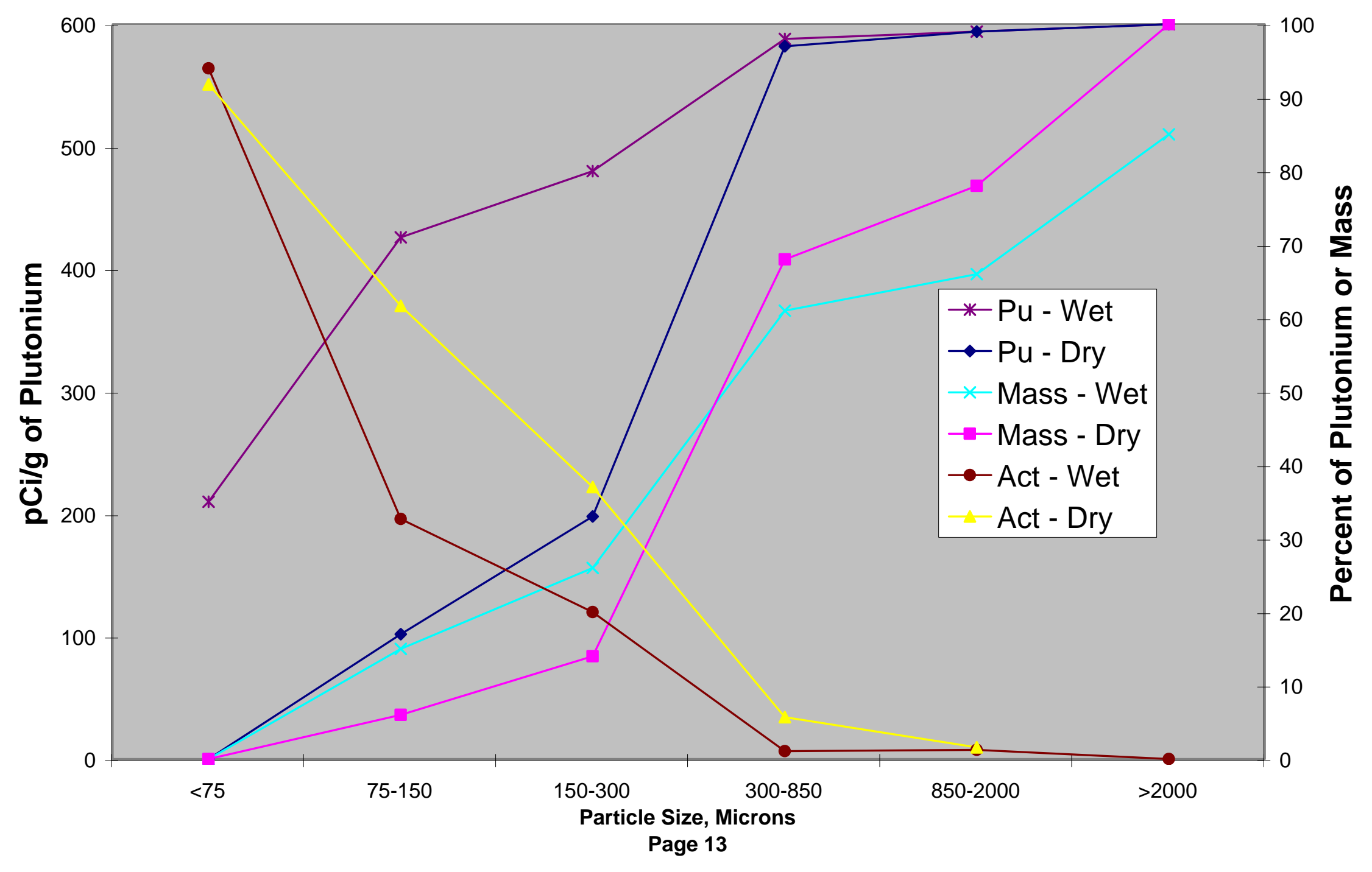


Figure 3. Plutonium and Mass Distribution in Clean Slate I Soil

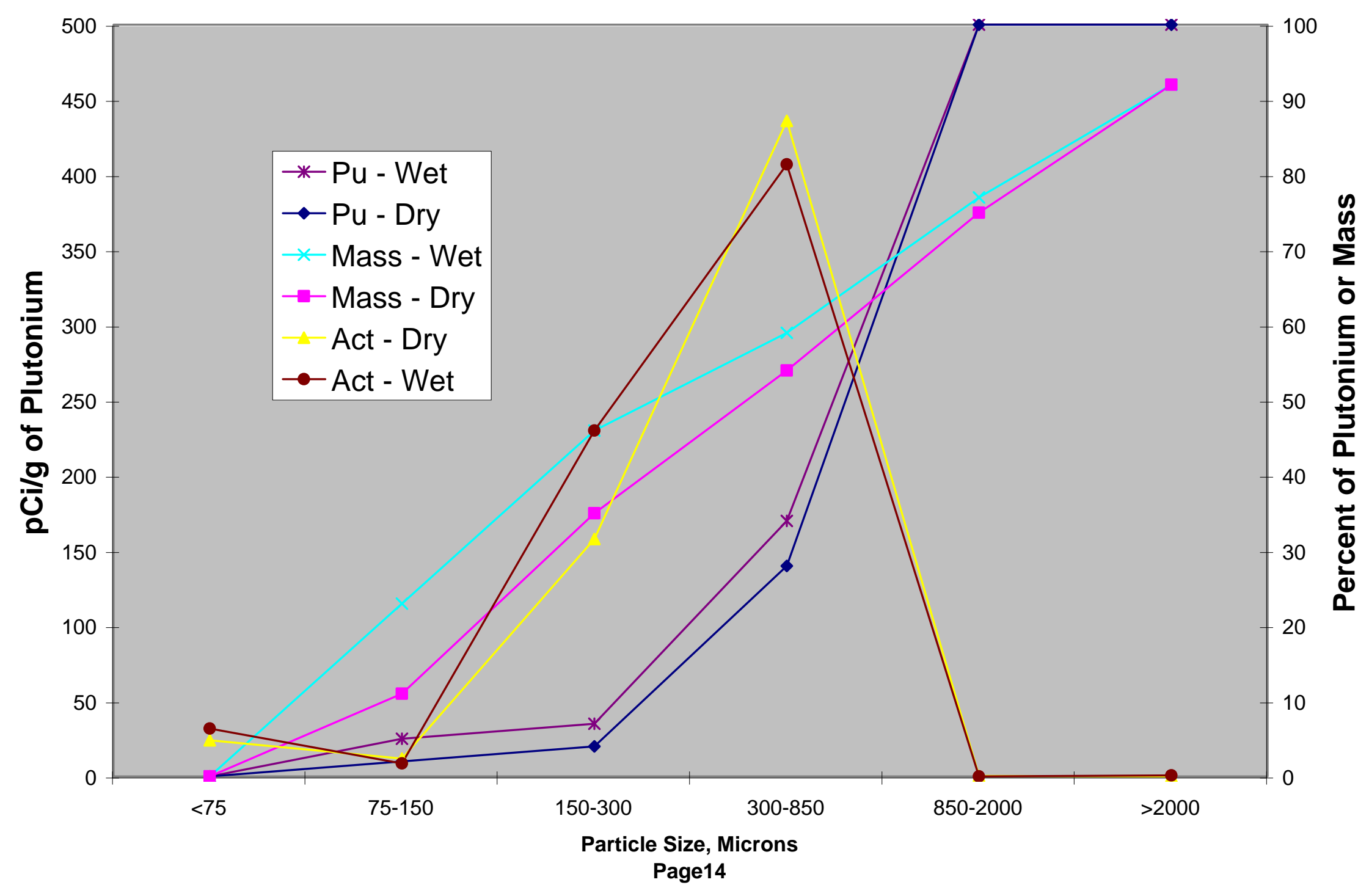


Figure 4. Mass Distribution - Clean Slates II Soils

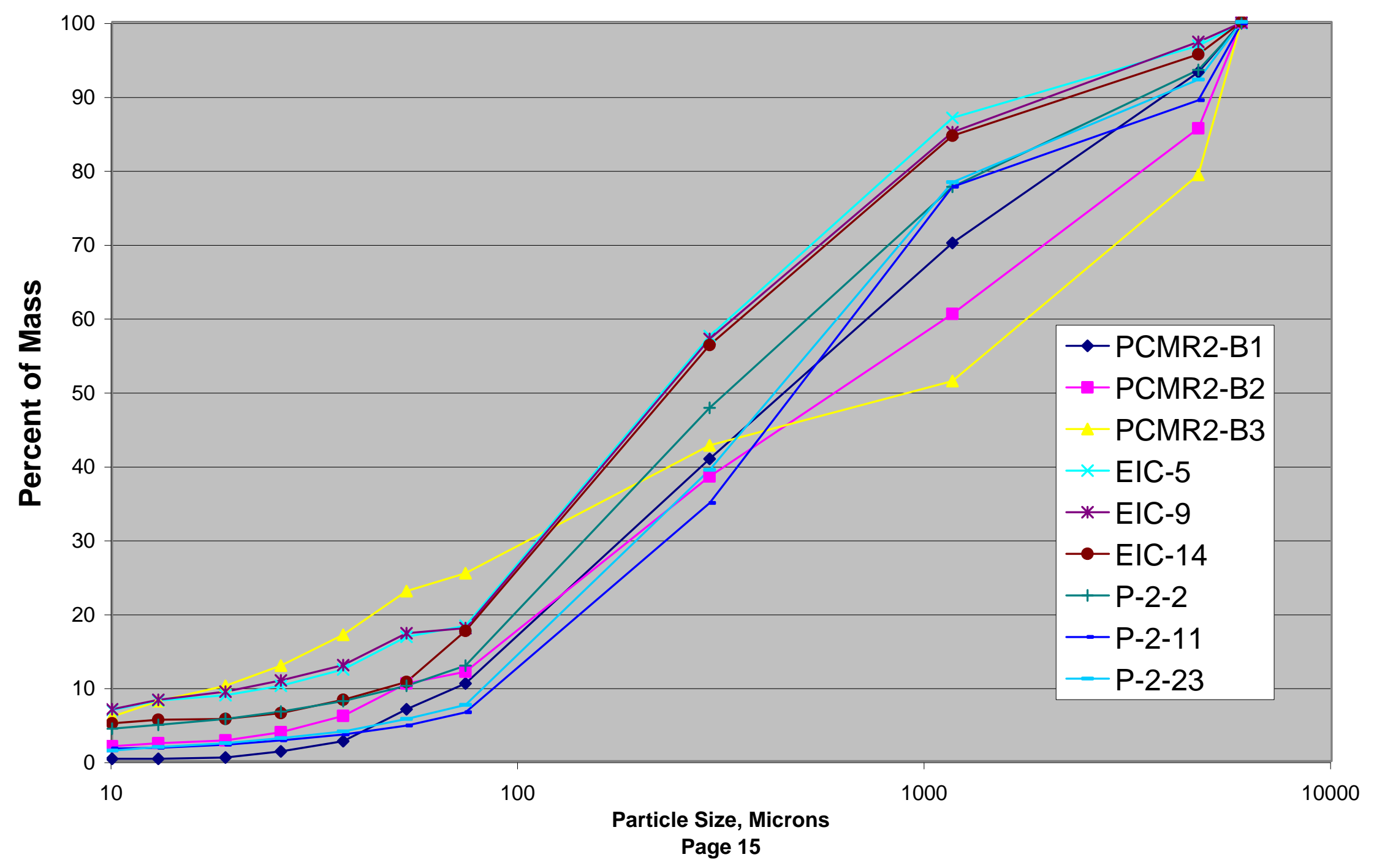


Figure 5. Plutonium Distribution - Clean Slates II Soils

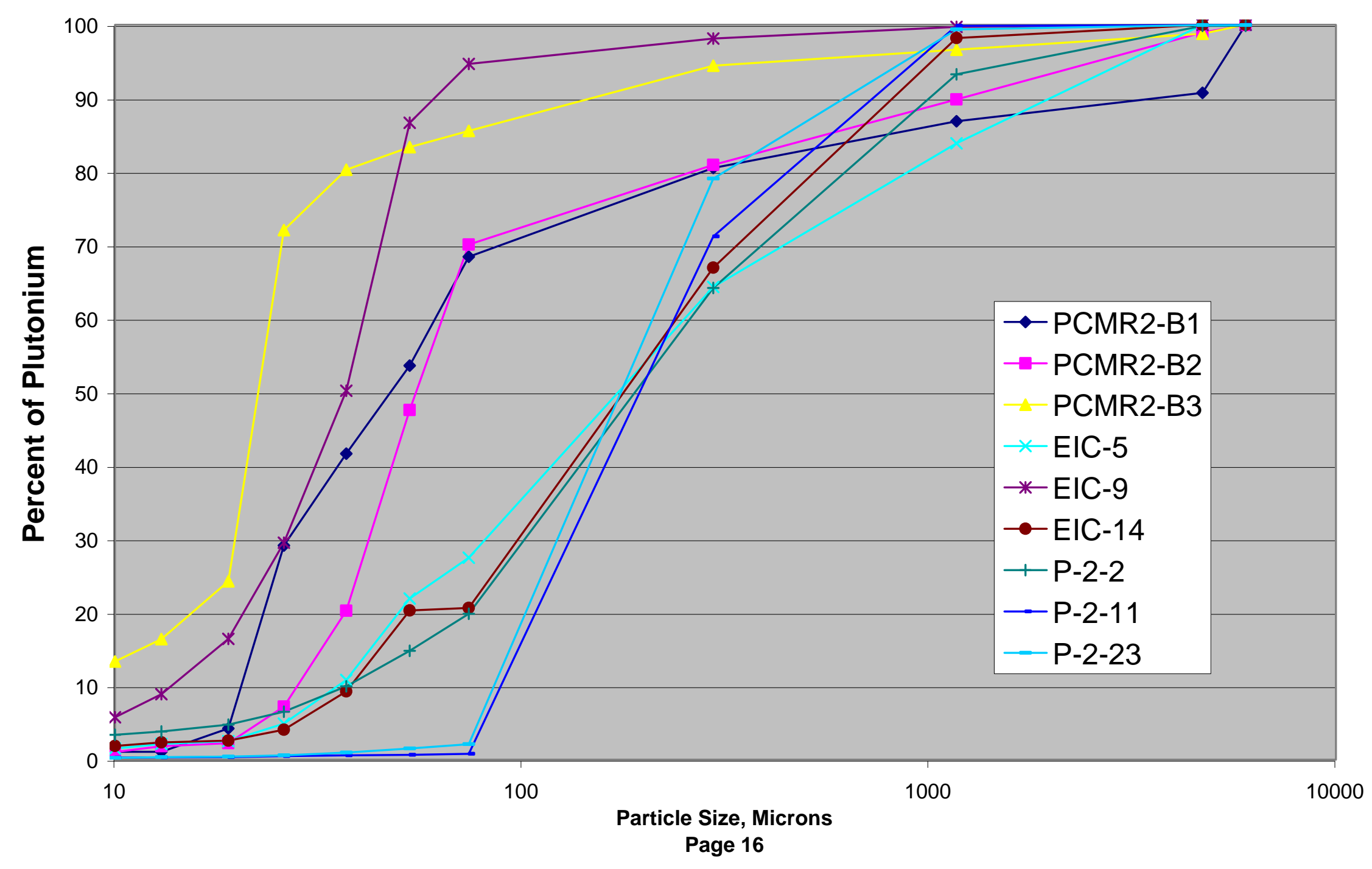


Figure 6. Relative Activity as a Function of Particle Size - Clean Slate II Soils

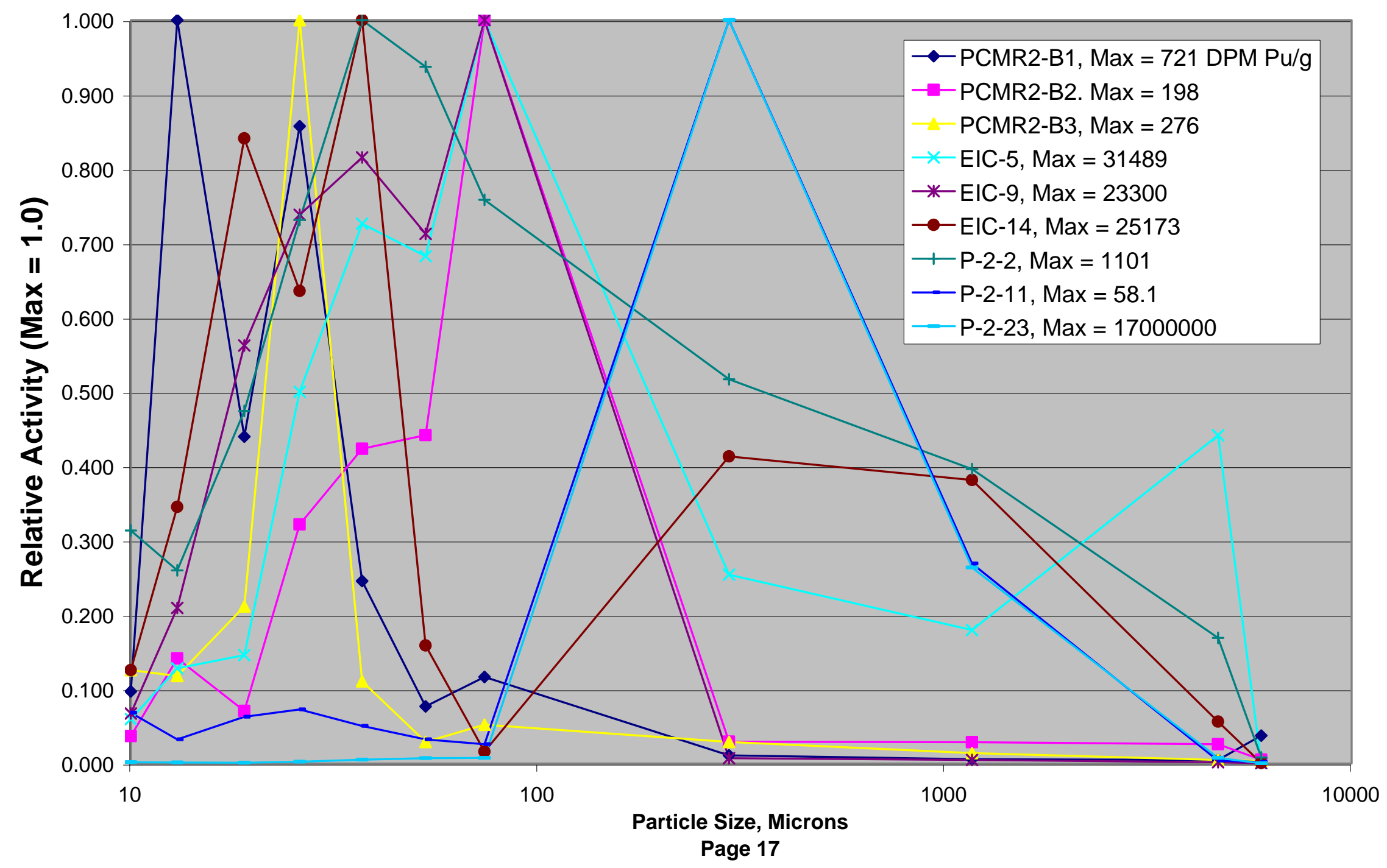


Figure 7. Plutonium and Mass Distribution in Clean Slate II Soil - PCMR2-B1

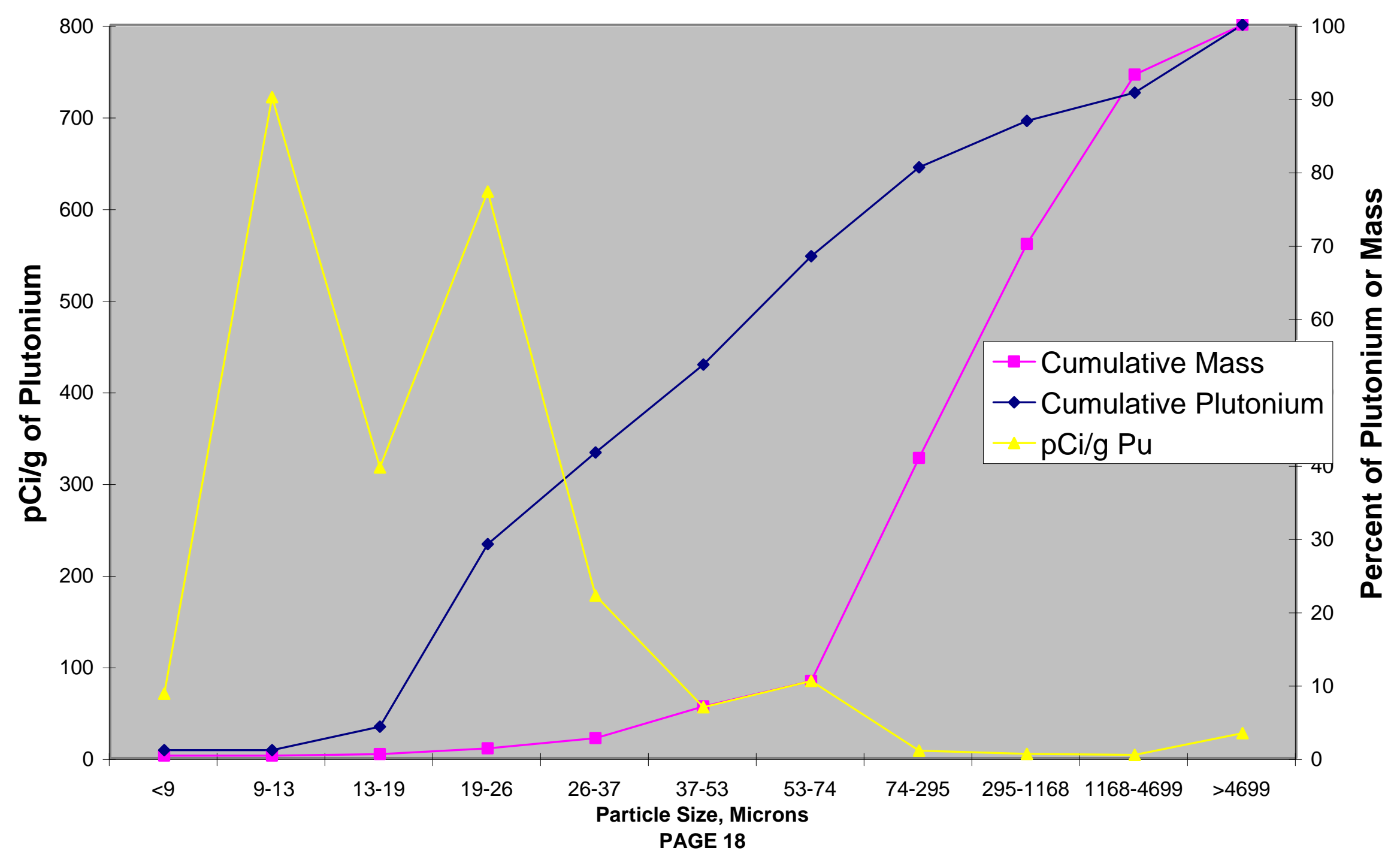


Figure 8. Plutonium and Mass Distribution in Clean Slate II Soil - PCMR2-B3

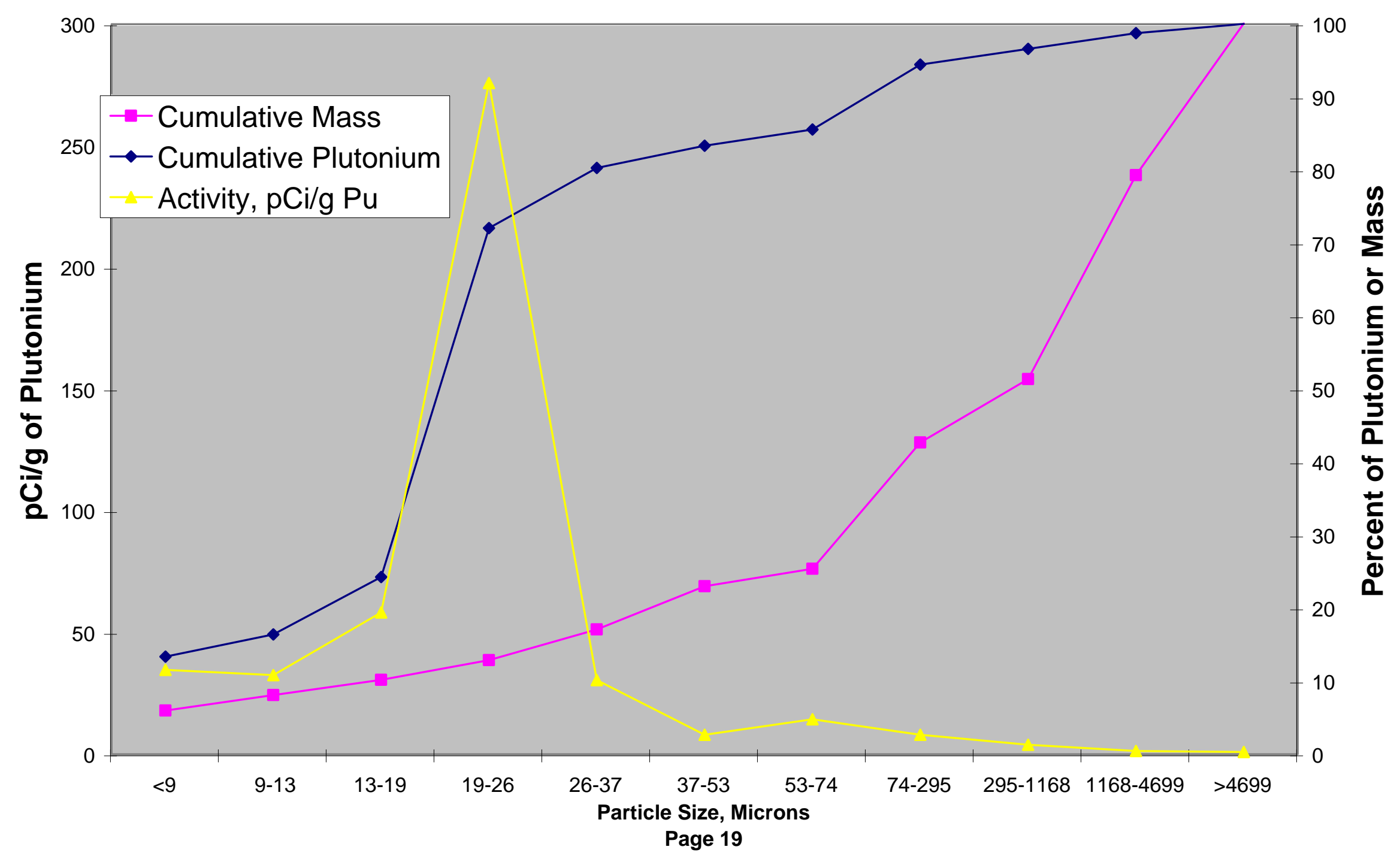


Figure 9. Plutonium and Mass Distribution in Clean Slate II Soil - P2-23

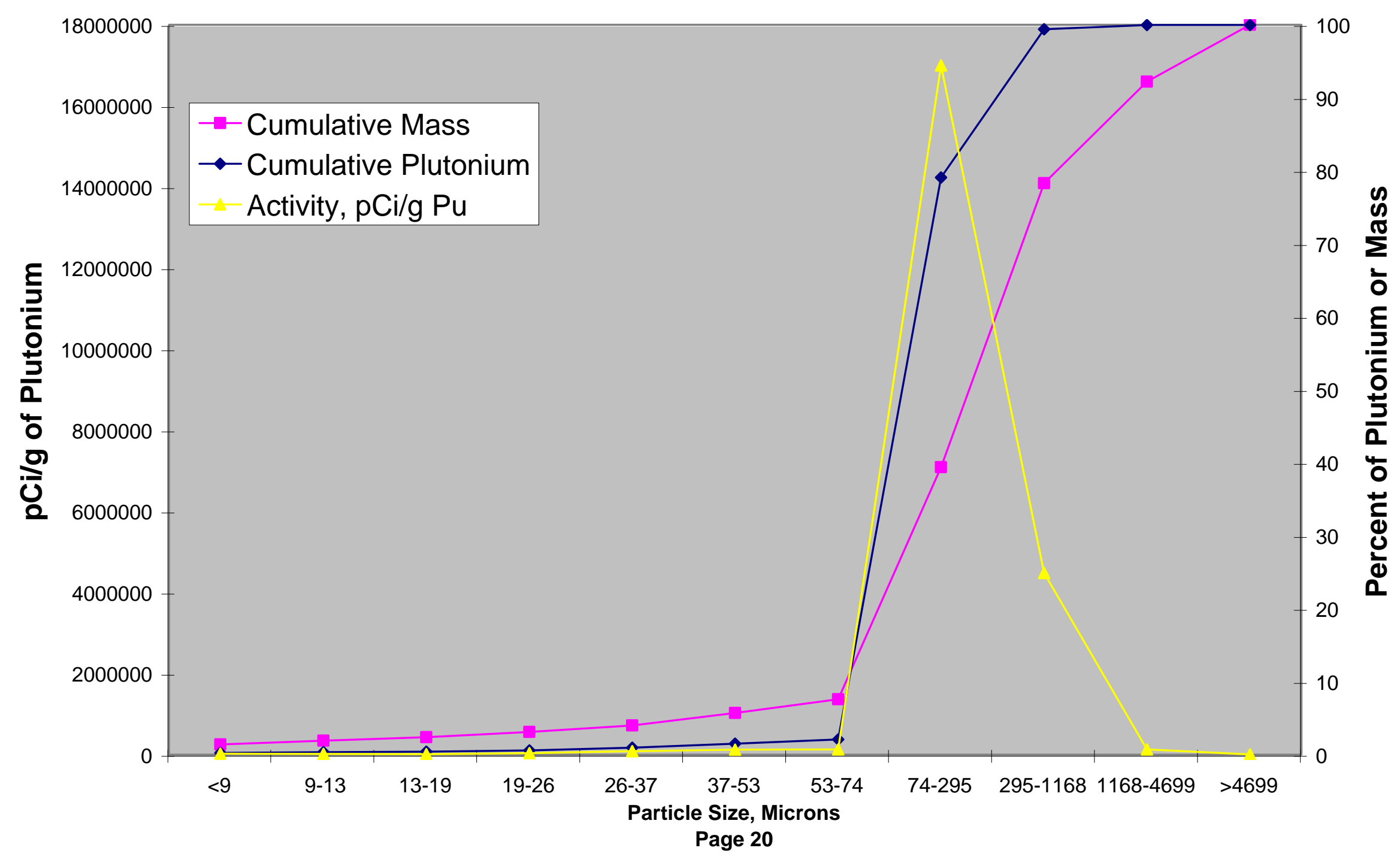


Figure 10. Mass Distribution - Clean Slate III Soils

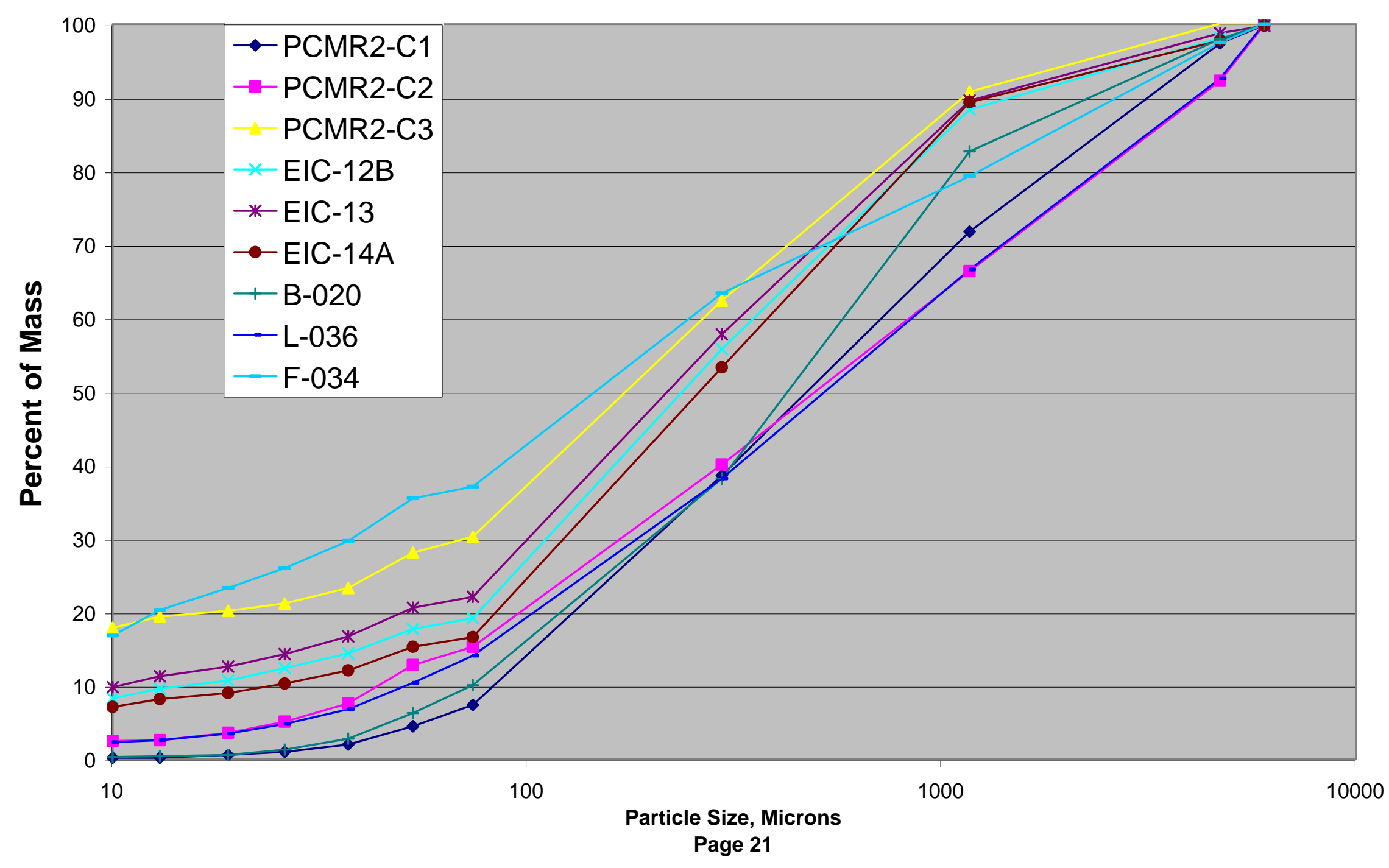


Figure 11. Plutonium Distribution - Clean Slate III Soils

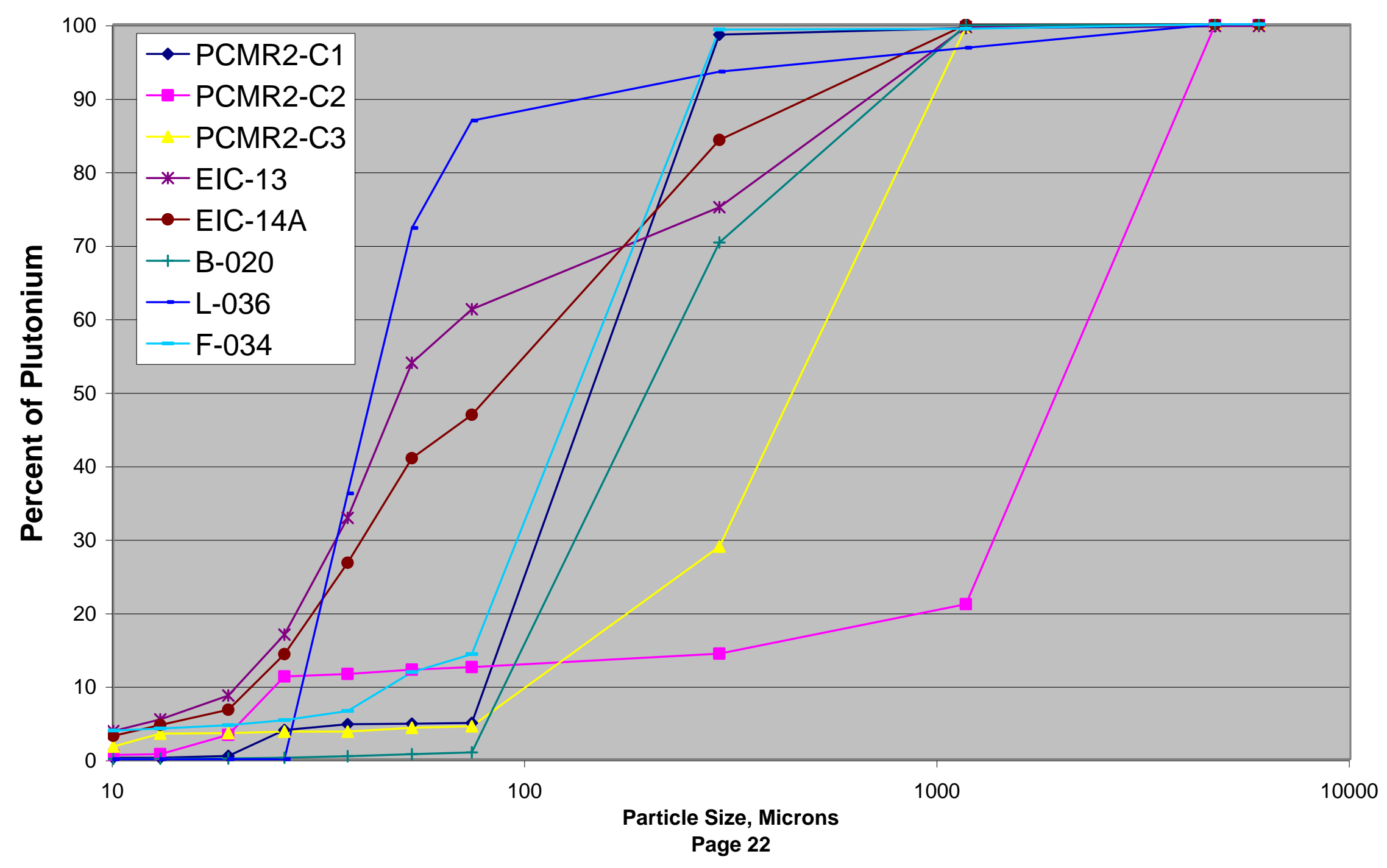


Figure 12. Relative Activity as a Function of Particle Size - Clean Slate III Soils

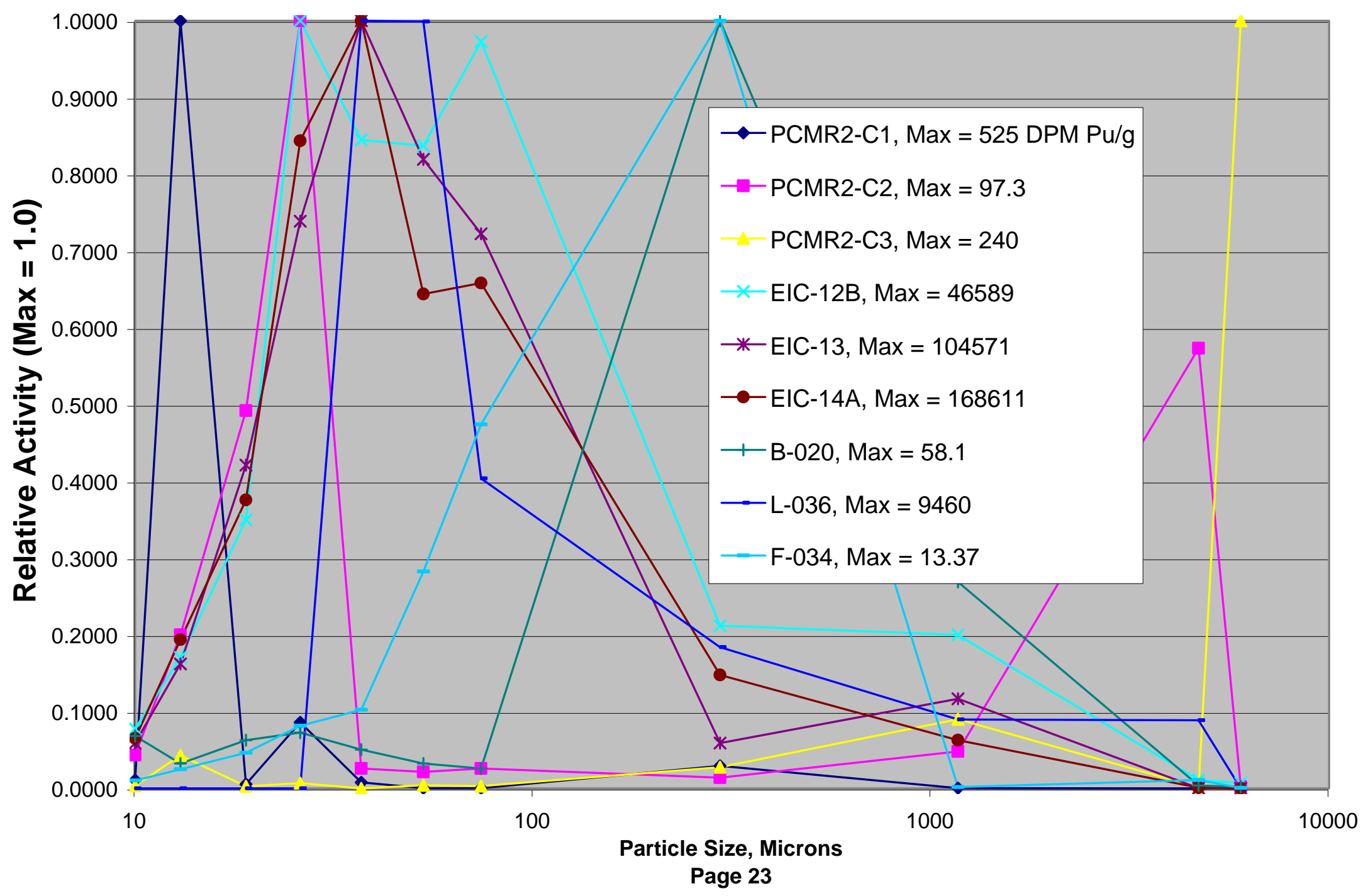


Figure 13. Plutonium and Mass Distribution in Clean Slate III Soil - PCMR2-C1

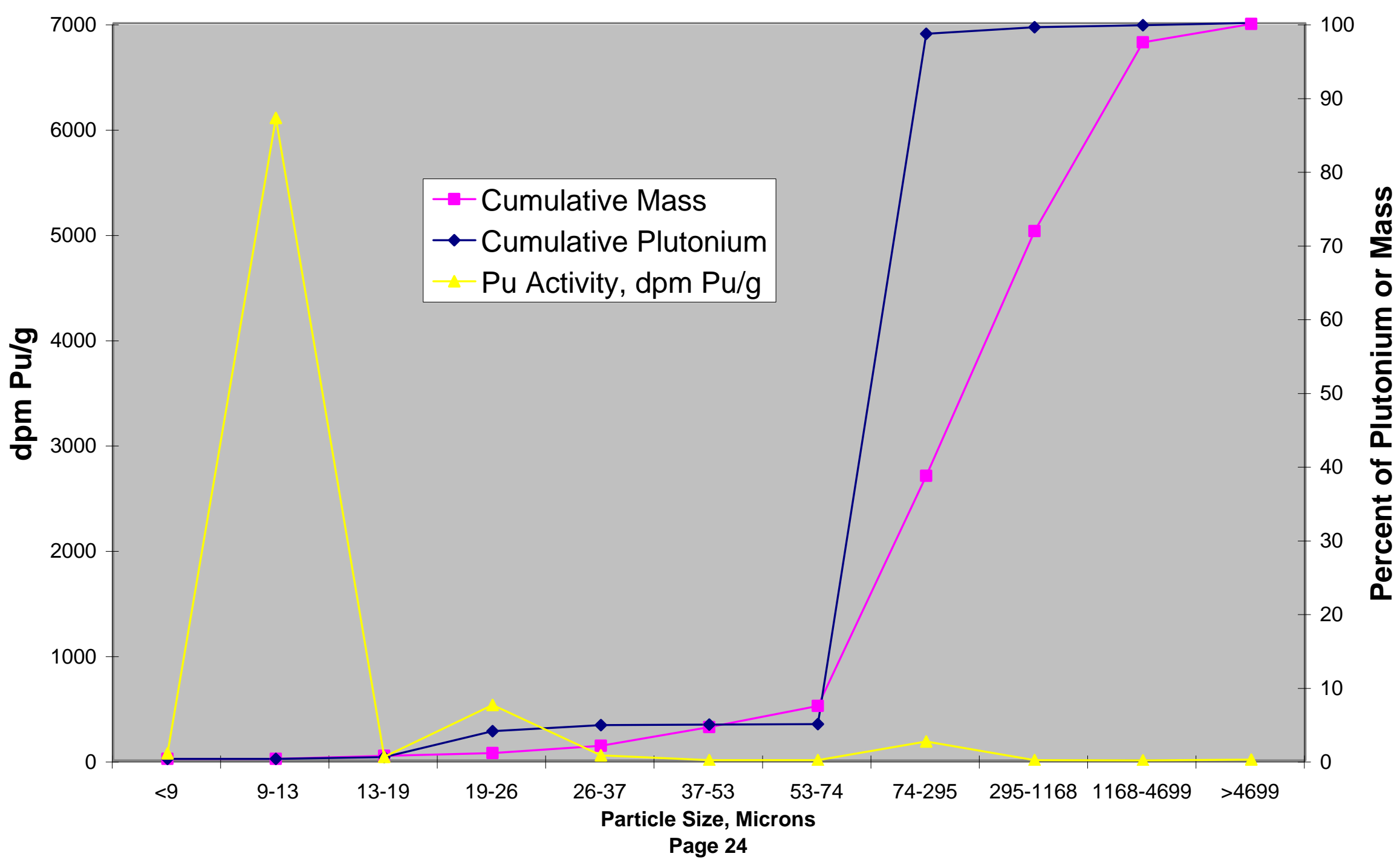


Figure 14. Plutonium and Mass Distribution in Clean Slate III Soil - F-034

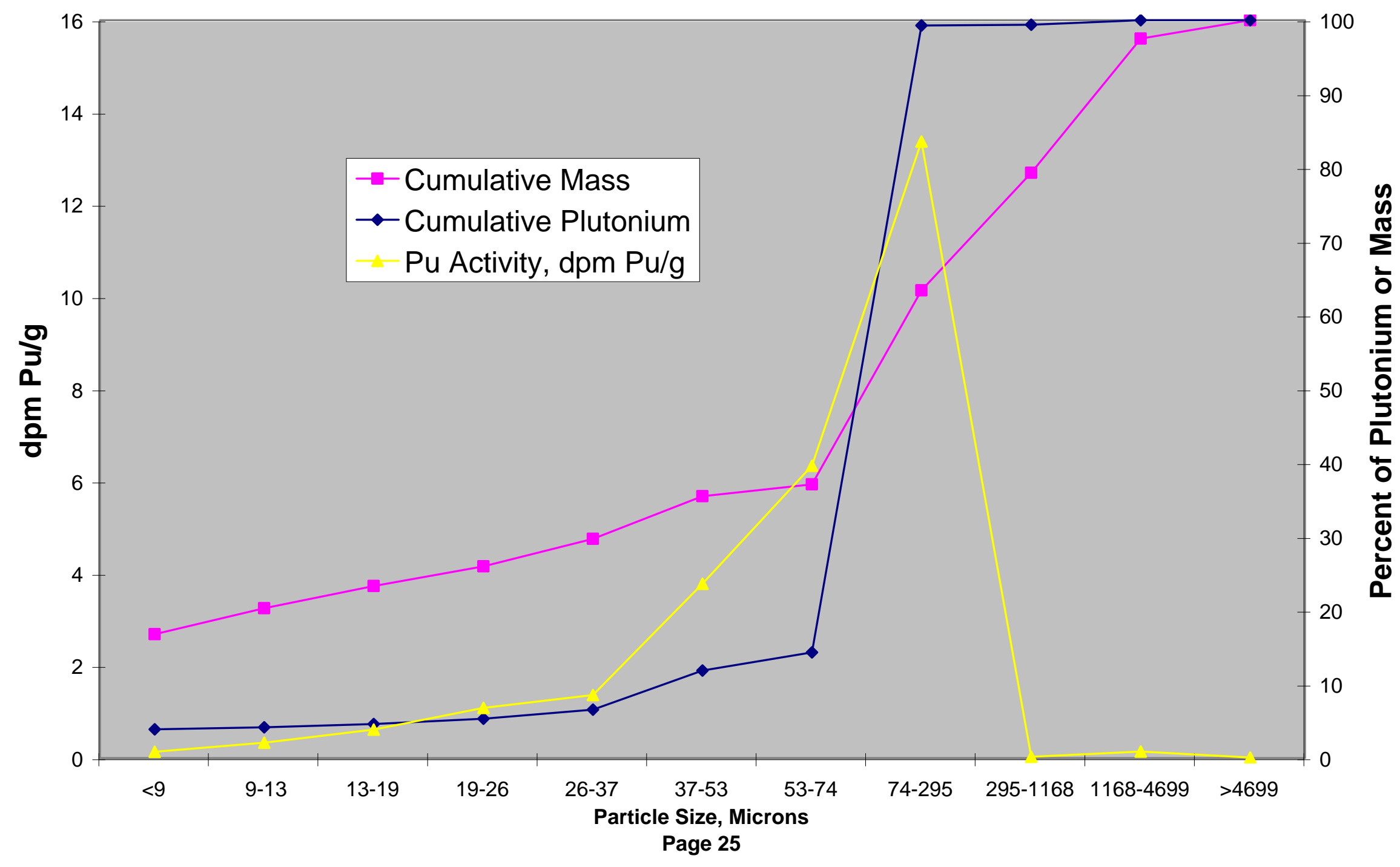


Figure 15. Plutonium and Mass Distribution in Clean Slate III Soil - PCMR2-C1

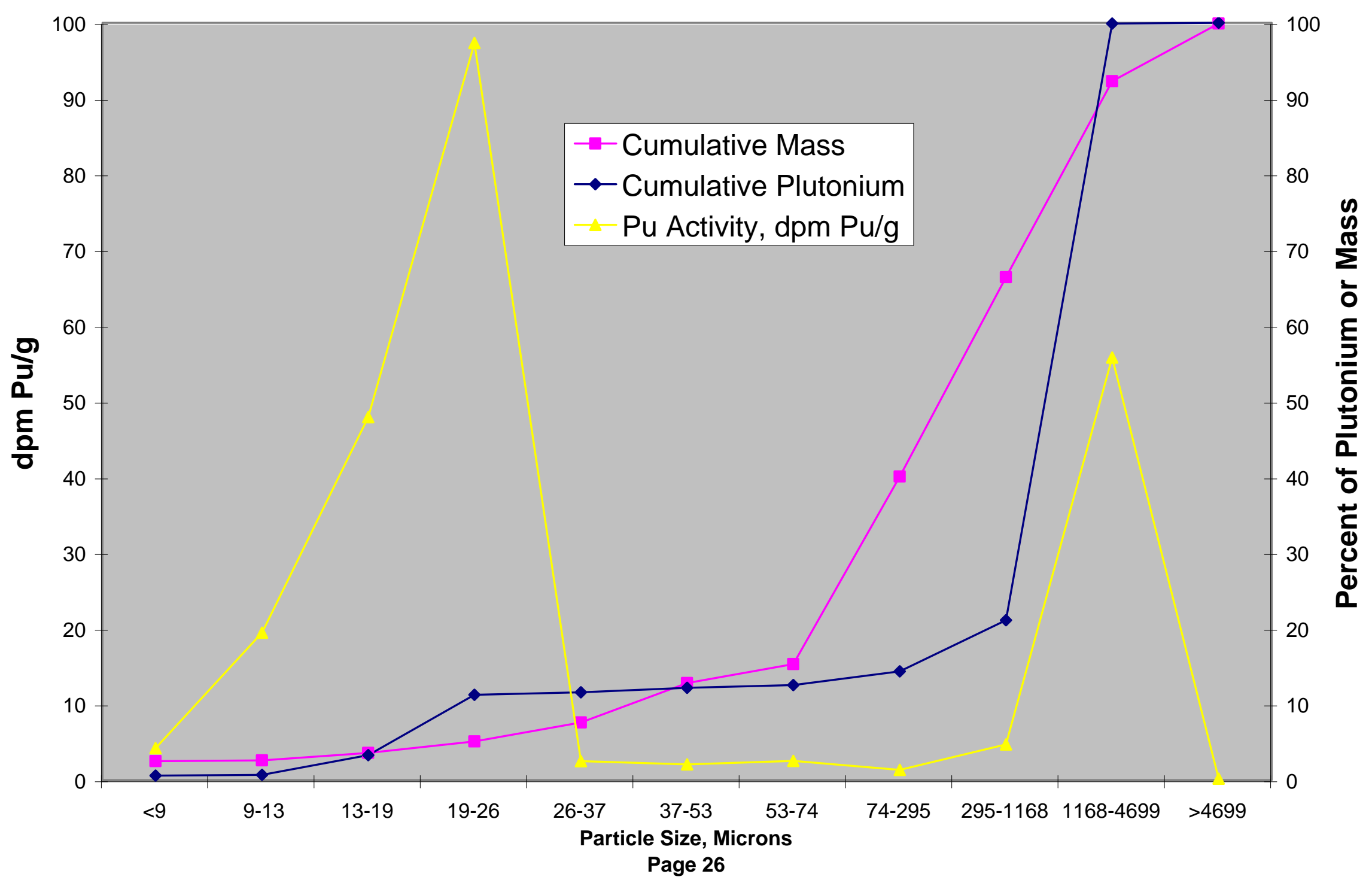


${ }^{1}$ Origins of the Nevada Test Site, United State Department of Energy, DOE/MA-0518, December 2000.

${ }^{2}$ United States Nuclear Tests, July 1945 through September 1992, DOE/NV-209 (Rev.14). US DOE Nevada Operations Office, December 1994.

3 Cho, Eung $\mathrm{Ha}$, et. Al., Soil Volume Reduction Technologies, Evaluation of Current Technologies, DOE Cooperative Agreement DE-FC26-98FT40396, Deployment Leading to Implementation, Final Report, submitted by West Virginia University to US DOE National Energy Technology Laboratory, July 2000.

${ }^{4}$ Final Environmental Impact Statement for the Nevada Test Site and Off-Site Location in the State of Nevada, United States Department of Energy, EIS Report, DOE/EIS -0243. Available on-line at: http://nepa.eh.doe.gov/eis/eis0243/eis0243 toc.html

${ }^{5} 1996$ Baseline Environmental Management Report, Nevada Test Site and Tonopah Test Range, US DOE Office of Environmental Management, 1996. Available on-line at: http://www.em.doe.gov/bemr96/nvts.html

${ }^{6}$ Cost/Risk/Benefit Analysis of Alternative Cleanup Requirements for Plutonium-Contaminated Soils On and Near the Nevada Test Site, DOE/NV-399, US DOE Nevada Operations Office, May 1995.

${ }^{7}$ Murarik, T.M., "Characterization, Liberation and Separation of Plutonium at the Nevada Test Site: Safety Shot Residues", Proceedings of the Soil Decon '93: Technology Targeting Radionuclides and Heavy Metals, June 16 and 17, 1993, Gatlinburg, TN, ORNL-6769, Oak Ridge National Laboratory, Oak Ridge, TN, September 1993.

${ }^{8}$ Heavy Metals Contaminated Soil Project Technical Summary, DOE/EM-0129P, National

Technology Transfer Center, Wheeling, WV, 1994. Available on-line at: www.nttc.edu/env/Heavy Metals/heavy metals/chap1.html

9 Misra, M., et. al., "Characterization and Physical Separation of Radionuclides from Contaminated Soils," Proceedings of the Soil Decon '93: Technology Targeting Radionuclides and Heavy Metals, June 16 and 17, 1993, Gatlinburg, TN, ORNL-6769, Oak Ridge National Laboratory, Oak Ridge, TN, September 1993.

${ }^{10}$ Papelis, et. al., Evaluation of Technologies for Volume Reduction of Plutonium-Contaminated Soils from the Nevada Test Site, DOE/NV/10845-57, US DOE Nevada Operations Office, June, 1996. Available on-line at: http://208.200.37.252/pdf/z01017a.pdf or at: http://plutonium-erl.actx.edu/pusoil.html

${ }_{11}$ Murari, T.M., et.al., "Characterization Studies And Indicated Remediation Methods for Plutonium Contaminated Soils at the Nevada Test Site", Spectrum '92, Boise, Idaho, August 2327, 1992.

${ }_{12}$ Misra, et.al., A Cost Effective Approach for Volume Reduction of Plutonium-Contaminated Soils," University of Nevada-Reno.

${ }^{13}$ Data provided by Sean Crawford (USDOE Nevada Operations Office) to Steve Hoeffner (Clemson University) on January 23, 2001. Data is from studies performed by University of Nevada-Reno and by IT Corporation around 1996. The IT data was included as an attachment to a memorandum from J.R. McKinley to L. Wille on August 26, 1996, Subject: Volume Reduction Study.

${ }^{14}$ Joe Messana, JVI Environmental, Personal Communication, March 2001.

${ }^{15}$ Misra, M. and R.K. Mehta, Physical Separation of Radionuclides from Contaminated Soil. University of Nevada-Reno.

${ }^{16}$ ThermoNUtech's Segmented Gate System at Tonapah Test Range, Clean Slate 2, Tonapah, Nevada, Federal Remediation Technologies Roundtable, 1999. Available on-line at http://bigisland.ttclients.com/frtr/00000180.html.

${ }_{17}$ Carl Fliermans, Westinghouse Savannah River Company, personal communication, January 2001.

Volume I Literature Review 
${ }^{18}$ Schake, A. R., et. al., "Magnetic Separation for Environmental Remediation." Report No. LAUR-94-3373, CONF-940301-44, Los Alamos National Laboratory, Los Alamos, NM. 1994.

${ }^{19}$ Spalding, B.P., Fixation of Radionuclides in Soil and Minerals by Heating, presented at the DOE Subsurface Contaminants Midyear Review, March 20-22, 2001, Omni Hotel, Atlanta, Georgia.

${ }^{20}$ Source: www.em.doe.gov/closure/final/nvfig24.html 


\title{
Evaluation of Remediation Technologies for Plutonium Contaminated Soils at the Nevada Test Site (NTS)
}

\author{
Cooperative Agreement \#DE-FC26-00NT40841
}

\author{
Volume II
}

Characterization of Clean Slate II Soil

Date Issued October 13, 2003 


\section{TABLE OF CONTENTS}

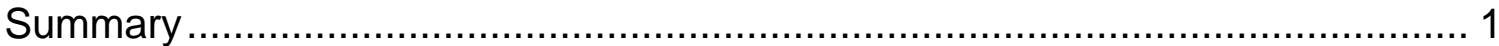

Collection of Clean Slate II Soils ................................................................... 3

Clemson Soil Project Summary ……........................................................ 3

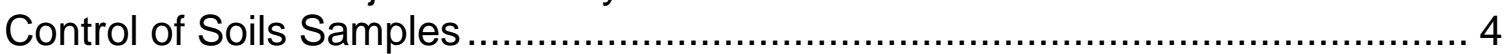

Characterization of NTS Clean Slate II Soil.................................................... 5

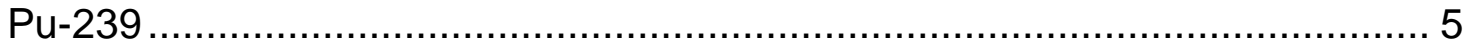

Pu-239 Variability as Function of Sample Size .......................................... 6

Gamma Spec Comparison .................................................................... 7

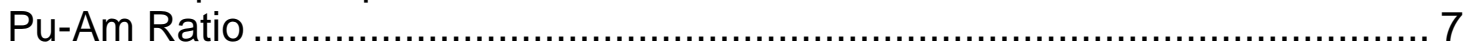

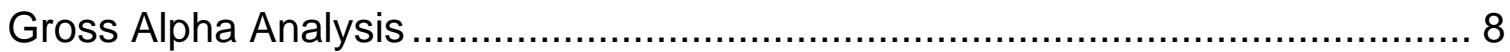

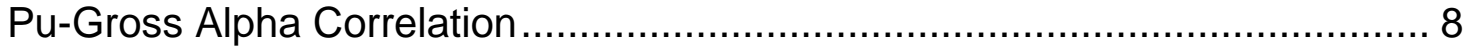

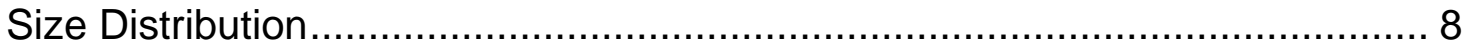

Plutonium Activity as a Function of Particle Size ........................................ 8

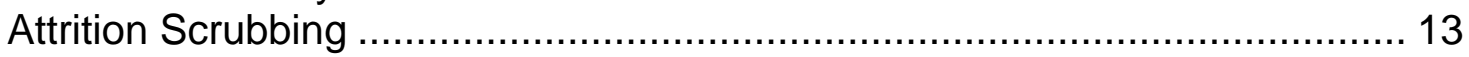

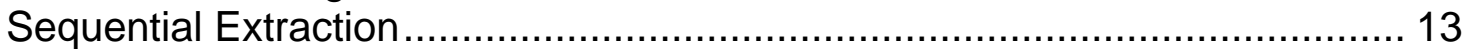

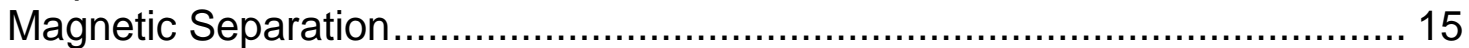

Procedure for Disposal of Clemson Soil, Developed by Bechtel Nevada........... 17

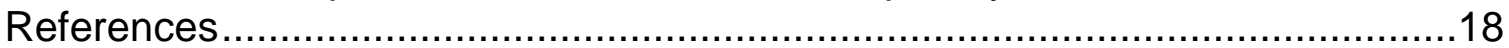




\section{LIST OF TABLES}

Table 1. Amount of Pu-239 Present in Clean Slate II Soil................................6

Table 2. Comparison of Am-241Measured Using Gamma Spectroscopy, $\mathrm{pCi} / \mathrm{g}$

Table 3. Pu-239/Am-241 Ratio for Untreated Clean Slate II Soil

Table 4. Particle Size Distribution of Clean Slate II Soil, \% Mass

in Each Fraction. Shown for 4 Replicates

Table 5. Plutonium Distribution in Clean Slate II Soil as a Function of Particle Size, $\mathrm{pCi} / \mathrm{g}$. Shown for 4 Replicates

Table 6. Plutonium Distribution in Clean Slate II Soil as a Function of Particle Size, \% Total Pu. Shown for 4 Replicates

Table 7. Effect of Attrition Scrubbing on Particle Size Distribution, $\%$ Mass in Each Fraction. Results are the average of 3 samples

Table 8. Effect of Attrition Scrubbing on Plutonium Distribution, \% Total Pu in Each Fraction.

Table 9. Summary of Extractants Used for Sequential Extraction

Table 10. Sequential Extraction of Clean Slate II Soil, Soil Not Heated in Muffle Furnace Prior to Extractions

Table 11. Sequential Extraction of Clean Slate II Soil, Soil Heated in Muffle Furnace Prior to Extractions

Table 12. Effect of Magnetic Separation on Removal of Alpha Activity From the Clean Slate II Soils. 


\section{LIST OF FIGURES}

Figure 1. Location of Safety Shot Sites (2) ...............................................

Figure 2. Correlation Between Pu-239/240 and Gross Alpha.........................10

Figure 3. Size Distribution of Clean Slate II Soil, Drum \#1 .............................11

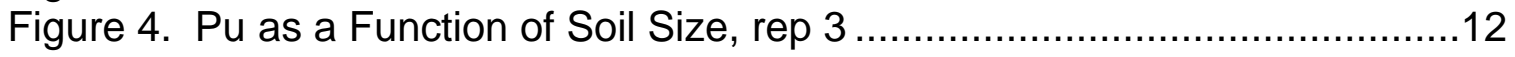




\section{Summary}

This report is a summary of studies that have been performed on the Clean Slate II soils obtained from the Nevada Test Site. Also included is information about the collection of the soils and the control and handling of the soil and the associated contact waste and residuals.

The soil was characterized to assist vendors in the design and optimization of their treatment processes and to indicate other possible treatment approaches.

The second phase of this study is to have select vendors apply their technologies to NTS plutonium contaminated soils. To support these vendor studies, six halffilled drums of soil from the Clean Slate II site [located on the Tonopah Test Range (TTR), see Figure 1(2)] were delivered to the Clemson Environmental Technologies Laboratory (CETL). These particular soils from the NTS are contaminated primarily with plutonium-239 and Am-241. The soil was characterized to assist vendors in the design and optimization of their treatment processes and to indicate other possible treatment approaches.

The average amount of Pu-239 in the untreated soil from Drum \#1 of the Clean Slate II Site was determined to be $1100 \mathrm{pCi} / \mathrm{g}$. Wet sieving indicated that $35-40 \%$ of the soil is larger than $300 \mathrm{um}$ and that there is very little plutonium activity $(<100 \mathrm{pCi} / \mathrm{g})$ in the $>300$ um fraction. Since $35-40 \%$ of the soil is greater than 300 um, the data indicate that size separation may be useful as part of a treatment process. Attrition scrubbing had no significant effect on particle size distribution. There does, however, appear to be a shift in activity from the 150-300 um fraction to the 38-75 um fraction. But the concentration of plutonium in the 150$300 \mathrm{um}$ fraction remains well above the $200 \mathrm{pCi} / \mathrm{g}$ target level.

Sequential extraction studies indicated that significant amounts of plutonium are soluble in the "organic" (HNO3/peroxide) and resistant (8 M HNO3) extracts. The solubility of plutonium in the $\mathrm{HNO} /$ peroxide is somewhat surprising because historical data indicated that the plutonium was present as plutonium dioxide and as fused plutonium silicate. These would usually be soluble in the resistant phase and any remaining residual phase.

The ratio of plutonium to americium, as determined by analyses at CETL, varies from 11.5 to 17.3, with an average of 14.7. There is a significant fluctuation in this ratio. As such, use of the Am-241 value as determined by gamma spectroscopy to determine the approximate amount of plutonium-239 would at best provided a crude estimate. Because of the poor correlation, CETL will use Am-241 analyses only to provide a rough indication of the amount of Pu-239. Good correlation is obtained between Pu-239 and gross alpha. Gross Alpha will be more routinely used to provide process feedback, and Pu-239 analysis will be used to provide definitive data. 


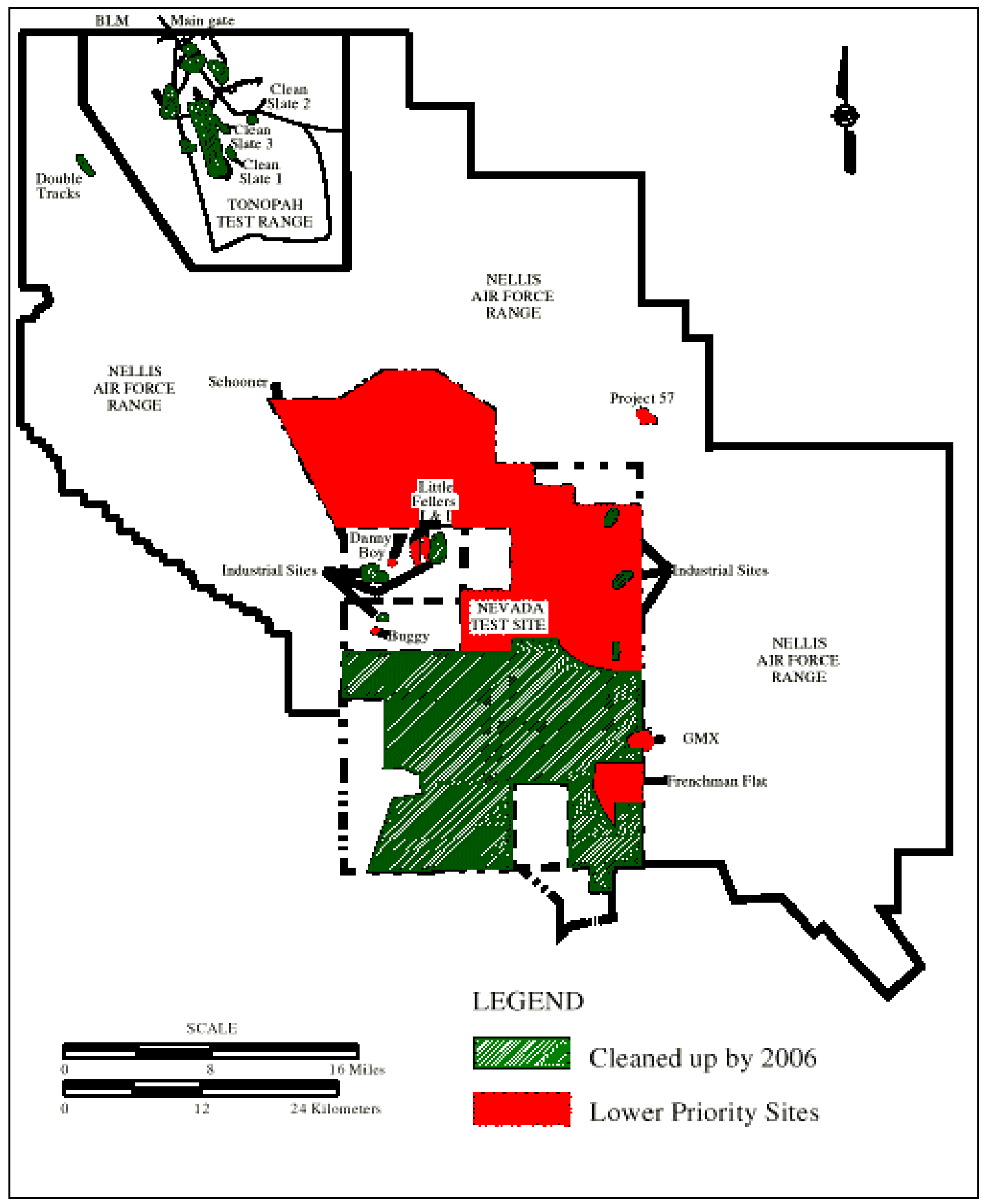

\begin{tabular}{|l|l|l|}
\hline \multirow{4}{*}{ NTS } & GMX & Area 5 \\
\cline { 2 - 3 } & Plutonium Valley & Area 11 \\
\cline { 2 - 3 } & Project 57 & Area 13 \\
\hline \multirow{2}{*}{ TTR } & Clean Slates II & Area 52 \\
\cline { 2 - 2 } & Clean Slates III & \\
\hline
\end{tabular}

Figure 1. Location of Safety Shot Sites (2). 
Magnetic separation was used in this research to determine the amount of paramagnetic plutonium particles in the soil and/or the amount of plutonium associated with the ferromagnetic soil particles. The data indicate the following:

- The magnetic separation was able to reduce the amount of activity in the soil from 1200 down to $600 \mathrm{pCi} / \mathrm{g}$ (for wet separation) and $750 \mathrm{pCi} / \mathrm{g}$ (for dry separation). However, both of these remain well above the $200 \mathrm{pCi} / \mathrm{g}$ target level.

- Both processes removed a similar portion of the activity (19\% of the total activity), but the wet process was more efficient $(6.1 \%$ of the soil contained $19 \%$ of the total activity) than the dry process $(15.1 \%$ of the soil contained $19 \%$ of the total activity).

\section{Collection of Clean Slate II Soils}

Bechtel Nevada collected soils from the Clean Slate II site off the Tonapah Test Range. There description of the collection of these soils follows:

\section{Clemson Soil Project Summary}

The Clemson Soil Project consists of containerizing radiologically impacted and clean soil and transporting the soil, to Clemson University, South Carolina, for analysis and remediation experimentation.

Soil from Clean Slates II, Tonopah Test Range (TTR), was containerized into twelve (12) 55-gallons drums was transported to Clemson University the week of November 26, 2001. The soil was shipped from the NTS, by an exclusive use, enclosed truck, via commercial carrier. The twelve (12) drums were transported to the Nevada Test Site (NTS), prior to transport to Clemson University for analysis and remediation experimentation.

A Real Estate Operations Permit (REOP), Job Hazard Analysis (JHA), Nevada Environmental Protection Assessment (NEPA) Checklist, Radiological Work Permit (RWP), and Work Package were prepared for the implementation of this project.

Six (6) 55-gallon drums were filled, to approximately $50-60 \%$ of capacity, with radiologically impacted soil, from previously processed soil piles. The estimated total transuranic soil activity is less than 1100 picoCuries/gram. This is well below the Department of Transportation (DOT) threshold of 2000 picoCuries/gram for a radioactive shipment. The exterior of the drums were surveyed and have no removable contamination above background. DOE regulations allow up to 20 $\mathrm{dpm} / 100 \mathrm{~cm}^{2}$ of removable alpha activity before the exterior is considered contaminated. Six (6) 55-gallon drums were filled, to approximately $50-60 \%$ capacity, with 'clean' (non-radiologically-impacted) soil.

The drums were analyzed with ISOCS and the radiological data was provided to Steve Hoeffner on December 31, 2001. 


\section{Control of Soils Samples}

Six half-filled 55-gallon drums of clean soil and six half-filled 55-gallon drums of plutonium-contaminated soils were collected by Bechtel Nevada from the Clean Slate II Site on the Tonopah Test Range on October 5, 2001. The drums were shipped to the Clemson Environmental Technologies Laboratory and received on November 26, 2001.

As received the drum lids were labeled with a marker as follows:

For the clean soils:

Clean Slates 2

Clean Soil

10-5-01

\#1 (through \#6)

For the plutonium-contaminated soils:

Impacted

Clean Slates 2

10-5-01

\#1 (through \#6)

CETL placed labels on the lids and the drums for each of the containers.

For the clean soils the labels read:

Nevada Test Site

Non-impacted Soil

Received 11/26/01

Drum \#1 (through \#6)

For the plutonium-contaminated the labels read:

Nevada Test Site

Radioactively Impacted Soil

Received 11/26/01

Drum \#1 (through \#6)

In addition, custody tags were placed on the drums. A tag is broken when a sample is taken. A new tag is then placed on the drum. The date the sample was taken, the amount of sample, and the purpose of the sample are recorded in a bound logbook.

Drums of the plutonium-contaminated soil are stored in the Radioactive Materials Storage Room, CETL Room \#028. Drums of the clean soil are stored in CETL Room \#029. Handling of the soils for treatment occurs in CETL Room \#029. Sample prep for analysis occurs in CETL Room \# 156. Analysis of the gross alpha, gamma spec or alpha spec occurs in CETL Room \# 142. 
In general terms the levels of security and control are:

1) The building is kept unlocked only during normal business hours (7:30 am $-5: 00 \mathrm{pm})$. Access to the building during off hours requires a key or a card key.

2) Access to any radioactive laboratory within the CETL requires a key or a card key at all times.

3) The Radioactive Materials Storage Room and Laboratory Room are kept locked when unoccupied. Only the RSO and his designees have keys with access to these rooms.

4) Custody seals are kept on the drums at all times except for when a small sample is taken for characterization and/or vendor studies.

5) Sampling of the drum is performed by the RSO.

6) Treatment and/or analysis of the soil are documented in the laboratory notebooks and can be tracked by date and by sample identification.

7) Analysis, characterization and treatment of the soil and management of the resulting residuals are restricted to CETL staff that are trained to work with radioactive materials and who have been assigned to this project. Participants are Tim Pruett, Rob Carlino, Mina Torraro and Steve Hoeffner. Vendor studies are performed by the vendor under the direction and guidance of a trained CETL staff member. All activities are performed in accordance with pre-approved procedures and/or work plans.

8) Only designated rooms are used when working with these soils (Rm 028 Radioactive Materials Storage, Rm 029 Vendor Studies and Soils Characterization, Rm 156 Sample Prep, and Rm 142 Gamma Spec, Alpha Spec and Gross Alpha/Beta Analysis).

9) Residuals generated from treatment and analyses are managed as detailed in the attached spreadsheet (to be added in next draft).

\section{Characterization of NTS Clean Slate II Soil}

A summary of the CETL characterization of the Clean Slate II soil is provided below. The soil was characterized to assist vendors in the design and optimization of their treatment processes and to possibly indicate what other treatment approaches might prove useful. Characterization of the Clean Slates II soils included:

- $\quad$ Pu-239, Am-241 and gross alpha analysis

- $\quad$ Particle size distribution

- $\quad$ Pu-239 distribution as a function of particle size

- $\quad$ Attrition scrubbing

- $\quad$ Sequential extraction, and

- Magnetic separation.

Some additional information is provided for each of these below.

$\underline{\mathrm{Pu}-239}$

The amount of $\mathrm{Pu}-239$ in the soils was determined by alpha spectroscopy. Soils were digested using $\mathrm{HCL} / \mathrm{HNO}_{3} / \mathrm{HF}$. The rigorous digestion using $\mathrm{HF}$ was required to effect complete dissolution of the plutonium from the soil. The Pu-239

5

Volume II Characterization of Clean Slate II Soil 
is isolated using anion exchange and cerium fluoride co-precipitation. Prepared samples were counted on EG\&G Ortec Alpha Spectroscopy System and results were analyzed using Maestro for Windows software, Ver. 5.30.

Preliminary analyses were performed to determine the relative amounts of radioactivity present on each of the six drums that were half-filled with plutoniumcontaminated soils from the Clean Slate II Site. These data indicated only minor differences between the drums. Drum \#1 was selected and the soil in this drum was homogenized by placing the drum on a drum tumbler. The drum was tumbled overnight.

The amount of plutonium in this blended soil was measured in 2- and 20-gram aliquots. Different aliquot sizes were used to determine if the soil might be inhomogeneous on the smaller 2-gram scale. A total of 6 samples were taken for each aliquot size. These numerous analyses were performed to also determine if there appeared to be any hot spots in the soil. The average amount of Pu-239 in the untreated soil from Drum \#1 of the Clean Slate II Site was determined to be $1100 \mathrm{pCi} / \mathrm{g}$ (see Table 1). No significant difference in activity or in analytical variability as a function of sample size was observed. These data are in good agreement with Bechtel Nevada anticipated results, around $1200 \mathrm{pCi} / \mathrm{g}$, which was based on historical data.

Pu-239 Variability as Function of Sample Size

There does not appear to be any difference in variability of results for Pu-239 for initial aliquot or samples sizes of either 2 or 20 grams (see Table 1). This would imply that there is a similar level of homogeneity in 2 or 20 grams of the soil. The range for each of the sample sets is also shown. No significant hot spots were indicated in these analyses.

Table 1. Amount of Pu-239 Present in Clean Slate II Soil

\begin{tabular}{|l|c|c|}
\hline \multirow{2}{*}{ Replicate Number } & \multicolumn{2}{|c|}{ Pu-239, $\mathrm{pCi} / \mathrm{g}$} \\
\cline { 2 - 3 } & 2 gram sample size & 20 gram sample size \\
\hline 1 & 1250 & 1140 \\
\hline 2 & 979 & 915 \\
\hline 3 & 813 & 1261 \\
\hline 4 & 1043 & 1098 \\
\hline 5 & 1279 & 1371 \\
\hline 6 & 1154 & 888 \\
\hline Average +/- SD & $1086+/-177$ & $1112+/-189$ \\
\hline \%RSD & 16.3 & 17.0 \\
\hline Range & $813-1279$ & $888-1371$ \\
\hline Overall Average +/- SD & $1099+/-175(\mathrm{RSD}=16.0 \%)$ \\
\hline
\end{tabular}




\section{Gamma Spec Comparison}

The amount of Am-241 in the soils was determined by gamma spectroscopy. No sample preparation was required. Samples were counted on Genie 2000 Spectroscopy System using a low-energy germanium detector.

Table 2 compares the amount of Am-241 measured by NTS, CETL and a commercial laboratory, General Engineering Laboratories (GEL). NTS measurements were made on the complete half-filled 55-gallon drums. The CETL and GEL measurements were made on laboratory scale samples (750 grams or less). Overall agreement is very good, with the exception of one outlier from GEL.

Table 2. Comparison of Am-241

Measured Using Gamma Spectroscopy, pCi/g

\begin{tabular}{|l|l|l|l|}
\hline Impacted Soil & $\begin{array}{l}\text { NTS } \\
\text { (Measured in drum) }\end{array}$ & $\begin{array}{c}\text { CETL } \\
\text { (Measured in lab) }\end{array}$ & $\begin{array}{c}\text { GEL } \\
\text { (Measured in lab) }\end{array}$ \\
\hline Drum 1 & 108 & 70 & 62 \\
& & 70 & 249 \\
& & & 137 \\
& & & 120 \\
\hline Drum 2 & 77 & 72 & --- \\
\hline Drum 3 & 65 & 77 & --- \\
\hline Drum 4 & 72 & 72 & --- \\
\hline Drum 5 & 71 & 66 & --- \\
\hline Drum 6 & 79 & 68 & --- \\
\hline
\end{tabular}

Pu-Am Ratio

The ratio of plutonium to americium, as determined by analyses at CETL, is summarized in Table 3. The ratio varies from 11.5 to 17.3, with an average of 14.7. This average value is similar to the value of 12 that Nevada expected to see, based on historical data (8). Notice that there is a significant fluctuation in this ratio. As such, use of the Am-241 value (as determined by gamma spectroscopy) to estimate the amount of plutonium-239 would at best provide a crude approximation. Because of the poor correlation, CETL will use Am-241 analyses only to provide a rough indication of the amount of Pu-239. Gross Alpha will be more routinely used to provide process feedback (see next paragraph), and Pu-239 analysis will be used to provide definitive data. 
Table 3. Pu-239/Am-241 Ratio for Untreated Clean Slate II Soil

\begin{tabular}{|c|c|c|c|}
\hline & Pu-239, pCi/g & Am-241, pCi/g & Pu-239/Am-241 \\
\hline DW-6-17 & 1140.5 & 78.6 & 14.5 \\
\hline DW-6-18 & 914.8 & 73.6 & 12.4 \\
\hline DW-6-19 & 1261.0 & 72.9 & 17.3 \\
\hline DW-6-20 & 1098.4 & 71.3 & 15.4 \\
\hline DW-6-21 & 1371.4 & 79.7 & 17.2 \\
\hline DW-6-22 & 888.4 & 77.5 & 11.5 \\
\hline Average & 1112.4 & 75.6 & 14.7 \\
\hline
\end{tabular}

Gross Alpha Analysis

The amount of gross alpha in the samples was determined by taking a portion of the acid digestate from the Pu-239 analysis (prior to any radiochemical separation). The aliquot was placed on a planchette, dried and counted on Canberra Alpha Beta System HT-1000 using a gas flow proportional counter.

\section{Pu-Gross Alpha Correlation}

Good correlation is obtained between Pu-239 and gross alpha (see Figure 2). Typically the gross alpha numbers are slightly higher than the Pu-239. An average ratio of 1.2 is obtained for the Gross Alpha/Pu-239 data presented in the figure. This indicates that about $85 \%$ of the total alpha activity is Pu-239. It is reasonable that the gross alpha is higher, since Am-241 and other alpha emitters may be present. The good correlation indicates that gross alpha can be used to provide a reasonable indication of the amount of Pu-239.

\section{Size Distribution}

TTR soil (125 grams) was allowed to soak overnight in about $500 \mathrm{~mL}$ of a $40 \mathrm{~g} / \mathrm{L}$ solution of sodium hexametaphosphate (a dispersant). The soil was then placed on a stack of sieves $(300,150,75$ and 38 micrometers), the sieves were placed on a Fritsch Instrument sieve shaker, a 3-nozzle spray head was attached to the top sieve and the sample was wet sieved for 15 minutes using a nominal volume of 2 liters of DI water.

The particle size distribution of the Impacted Drum \#1 soil is shown in Figure 3. Three soils aliquots were wet sieved. The results for each are shown on the graph. The data indicate that $35-40 \%$ of the soil is larger than $300 \mathrm{um}$.

Plutonium Activity as a Function of Particle Size

The different size fractions from the wet sieving were dried and weighed. The samples were digested to determine the amount of Pu-239 present in each of the size fractions.

A total of four aliquots of blended soil from Drum \#1 of the plutonium contaminated soils from the Clean Slate II site were wet sieved. All separations were performed identically. Although there were some differences, a typical 
distribution of plutonium as a function of particle size is shown in Figure 4. Results of all four aliquots are summarized in Tables V, VI and VII.

The data indicate very little plutonium activity $(<100 \mathrm{pCi} / \mathrm{g})$ in the $>300 \mathrm{um}$ fraction. Since $35-40 \%$ of the soil is greater than $300 \mathrm{um}$, the data indicate that size separation may be useful as part of a treatment process. All other size fractions contained significant amounts of plutonium activity. The data in Tables 4, 5 and 6 also indicate that, although the soil has been blended, there is still some variation from sample to sample in plutonium distribution as a function of particle size.

Table 4. Particle Size Distribution of Clean Slate II Soil, \% Mass in Each Fraction. Shown for 4 Replicates.

\begin{tabular}{|c|c|c|c|c|}
\hline & \multicolumn{4}{|c|}{ Replicate } \\
\hline $\begin{array}{l}\text { Particle Size, } \\
\text { Microns }\end{array}$ & 1 & 2 & 3 & 4 \\
\hline$>300$ & 39.8 & 39.3 & 37.7 & 36.0 \\
\hline $150-300$ & 14.8 & 20.5 & 21.0 & 20.5 \\
\hline $75-150$ & 22.6 & 24.5 & 24.1 & 23.6 \\
\hline $38-75$ & 6.6 & 6.2 & 9.4 & 8.3 \\
\hline$<38$ & 8.6 & 6.8 & 6.7 & 9.4 \\
\hline
\end{tabular}

Table 5. Plutonium Distribution in Clean Slate II Soil as a Function of Particle Size, pCi/g. Shown for 4 Replicates.

\begin{tabular}{|c|r|r|r|r|}
\hline & \multicolumn{4}{|c|}{ Replicate } \\
\hline $\begin{array}{l}\text { Particle Size } \\
\text { Microns }\end{array}$ & 1 & 2 & 3 & 4 \\
\hline$>300$ & 25 & 23 & 28 & 25 \\
\hline $150-300$ & 1166 & 303 & 641 & 443 \\
\hline $75-150$ & 599 & 308 & 663 & 524 \\
\hline $38-75$ & 1548 & 1003 & 1166 & 1511 \\
\hline$<38$ & 1813 & 3299 & 2248 & 1436 \\
\hline
\end{tabular}

Table 6. Plutonium Distribution in Clean Slate II Soil as a Function of Particle Size, \% Total Pu. Shown for 4 Replicates.

\begin{tabular}{|l|r|r|r|r|}
\hline & \multicolumn{5}{|c|}{ Replicate } \\
\hline $\begin{array}{l}\text { Particle Size, } \\
\text { Microns }\end{array}$ & 1 & 2 & 3 & 4 \\
\hline$>300$ & 2 & 2 & 2 & 2 \\
\hline $150-300$ & 30 & 15 & 24 & 19 \\
\hline $75-150$ & 24 & 18 & 28 & 26 \\
\hline $38-75$ & 18 & 15 & 19 & 26 \\
\hline$<38$ & 27 & 51 & 27 & 28 \\
\hline
\end{tabular}




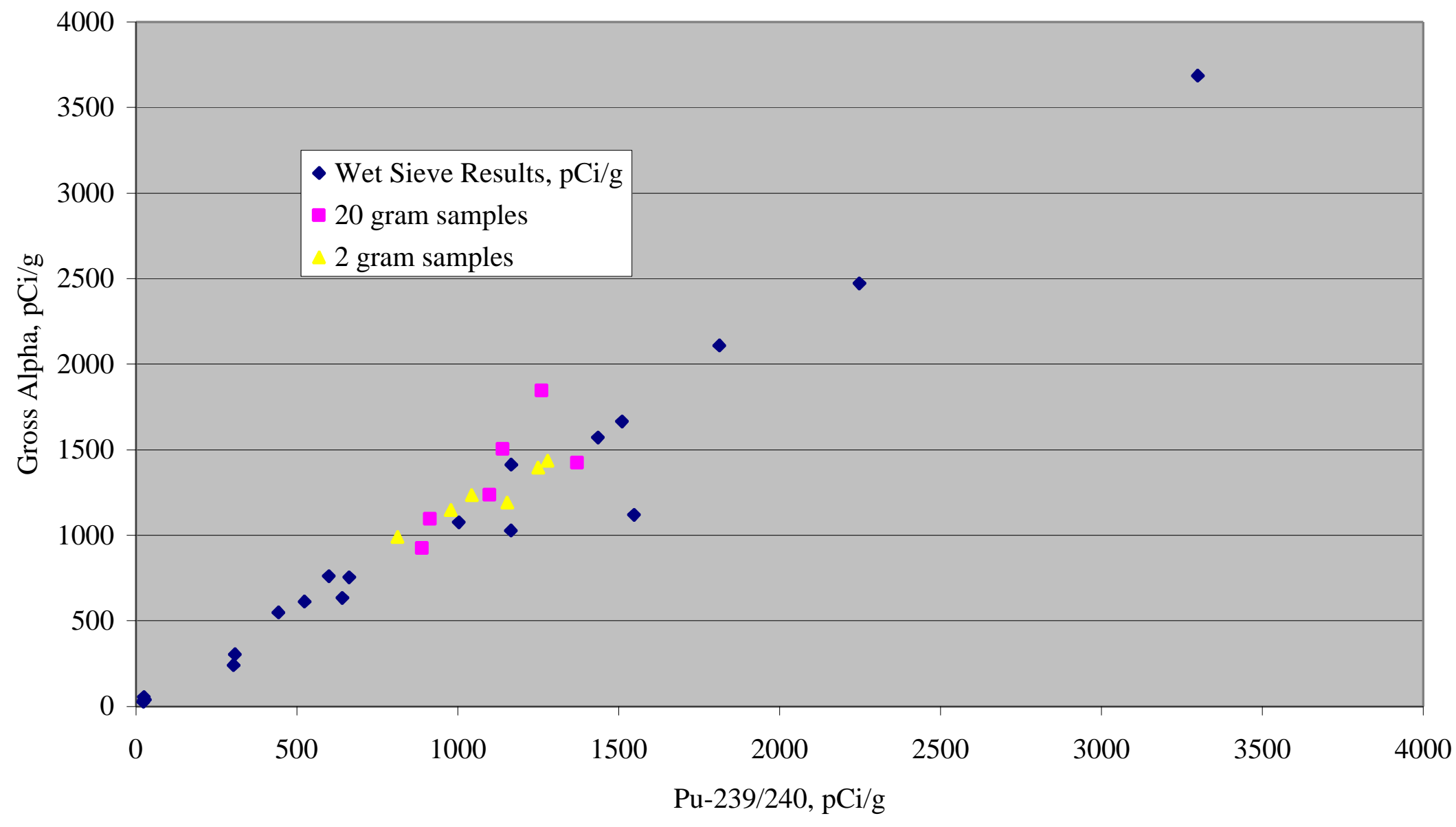

Figure 2. Correlation Between Pu-239/240 and Gross Alpha 


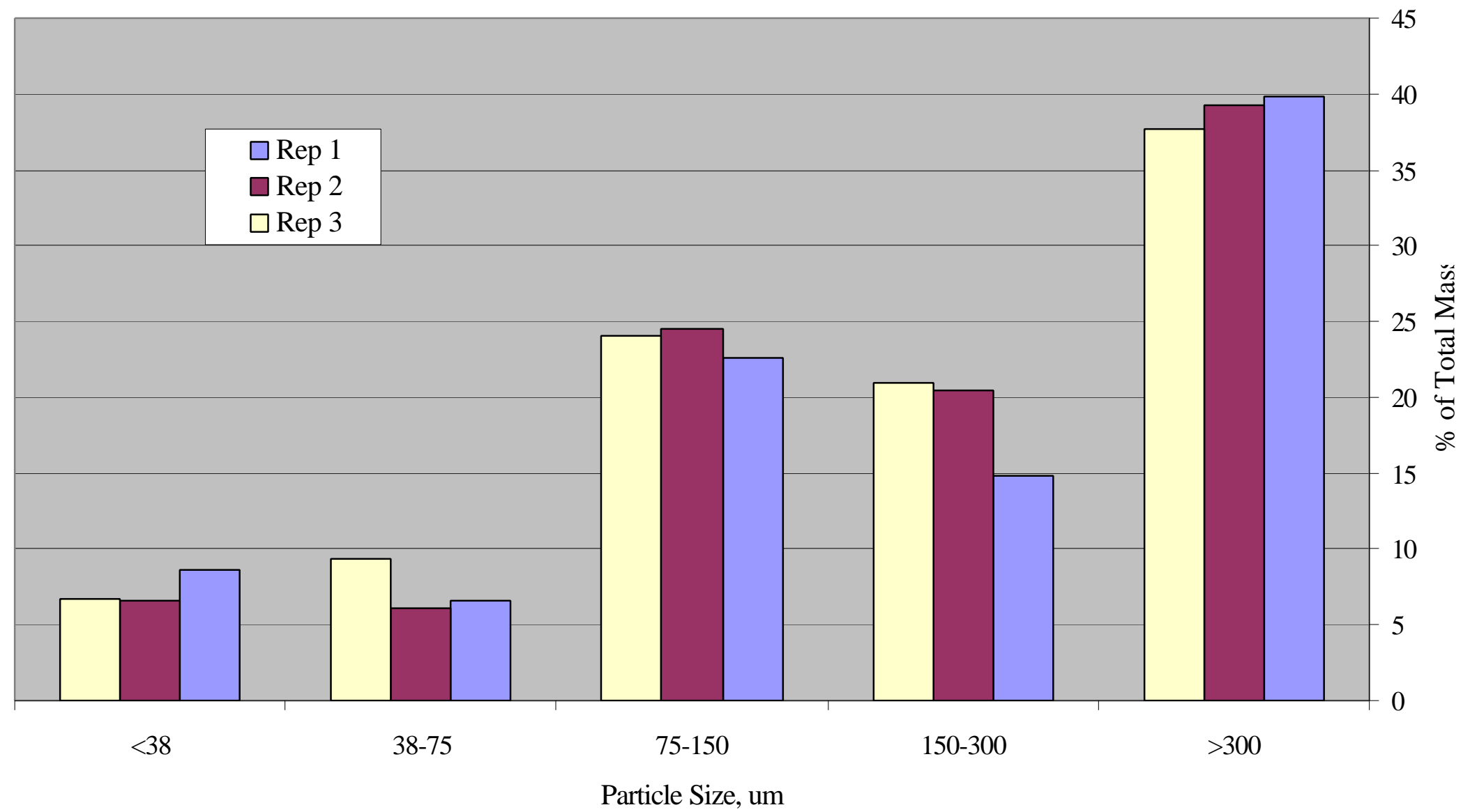

Figure 3. Size Distribution of Clean Slate II Soil, Drum \#1 


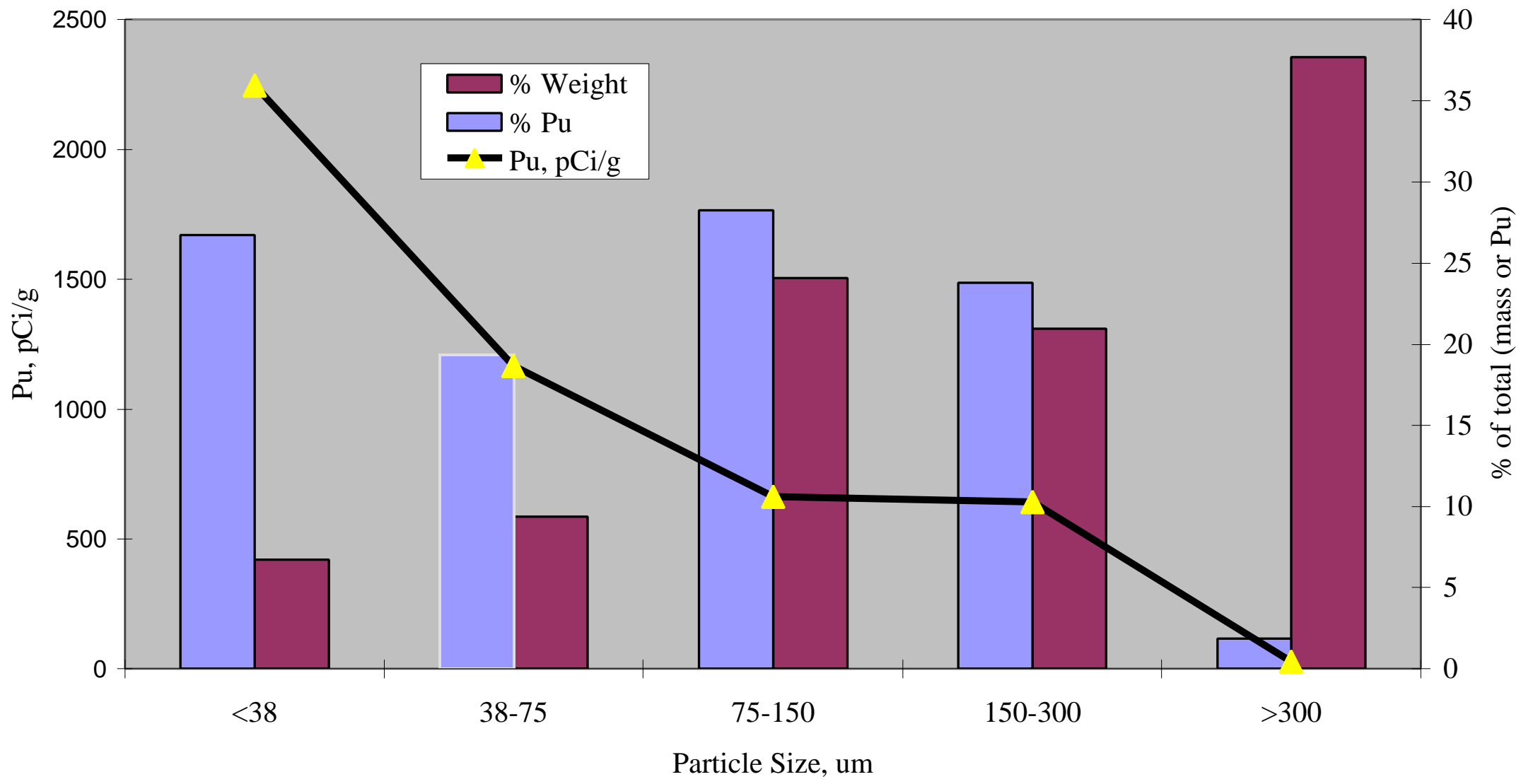

Figure 4. Pu as a function of soil size, Rep 3 


\section{Attrition Scrubbing}

50 grams of soil were slurried with $200 \mathrm{~mL}$ of $40-\mathrm{g} / \mathrm{L}$ sodium hexametaphosphate solution. The slurry was then subjected to attrition scrubbing using a Denver Instruments Model 061873400011. Particle size and plutonium distribution as a function of particle size was measured before and after attrition scrubbing.

The effect of attrition scrubbing on particle size distribution is shown in Table 7. The data indicate that effect of attrition scrubbing on particle size is minimal. At best there is a slight increase in the $<38$ um material. The effect of attrition scrubbing on distribution of plutonium activity is shown in Table 8. No additional plutonium activity in the $<38$ um material is produced by attrition scrubbing. There does, however, appear to be a shift in activity from the 150-300 um fraction to the 38-75 um fraction. But the concentration of plutonium in the 150-300 um fraction remains well above the $200-\mathrm{pCi} / \mathrm{g}$ target level. There is a possibility that attrition scrubbing may allow a slightly smaller cutoff size for the clean material from $>300$ um down to 250 or 200 um. This could add another $5-10 \%$ to the mass of the clean soil, bringing the total clean soil to $45-50 \%$. Additional testing would be needed to determine this. Since only attrition scrubbing and wet sieving would be needed to attain this, it would be good to investigate this further.

Table 7. Effect of Attrition Scrubbing on Particle Size Distribution, $\%$ Mass in Each Fraction.

Results are the average of 3 samples.

\begin{tabular}{|c|r|r|}
\hline Particle Size, Microns & Without Scrubbing & With Scrubbing \\
\hline$>300$ & 38.2 & 36.3 \\
\hline $150-300$ & 19.2 & 19.3 \\
\hline $75-150$ & 23.7 & 22.7 \\
\hline $38-75$ & 7.6 & 8.1 \\
\hline$<38$ & 7.8 & 10.0 \\
\hline
\end{tabular}

Table 8. Effect of Attrition Scrubbing on Plutonium Distribution, $\%$ Total Pu in Each Fraction.

\begin{tabular}{|c|r|r|}
\hline Particle Size, Microns & Without Scrubbing & With Scrubbing \\
\hline$>300$ & 2 & 2 \\
\hline $150-300$ & 24 & 16 \\
\hline $75-150$ & 26 & 27 \\
\hline $38-75$ & 21 & 27 \\
\hline$<38$ & 27 & 28 \\
\hline
\end{tabular}

Sequential Extraction

This technique uses a series of increasingly aggressive extractants similar to those recommended by NIST (7). Typically the elements that are soluble in the select extractants, shown in Table 9, are thought to be exchangeable, carbonates, reducible, organic or resistant. These descriptors provide a useful way to look at how tightly and in what fashion the contaminants are bound to the soil matrix. The sequential extraction process also may provide an indication of potential treatment technology approaches. 
Table 9. Summary of Extractants Used for Sequential Extraction

\begin{tabular}{|l|l|}
\hline \multicolumn{1}{|c|}{ Description } & \multicolumn{1}{c|}{ Extractant } \\
\hline Exchangeable & $0.4 \mathrm{M} \mathrm{Mg} \mathrm{Cl} 2$ \\
\hline Carbonates & $1 \mathrm{M} \mathrm{NH} 4 \mathrm{Ac}$ \\
\hline Reducible & $0.04 \mathrm{M} \mathrm{NH} 2 \mathrm{OH}^{\star} \mathrm{HCl}$ in $25 \% \mathrm{HAc}$ \\
\hline & 5 parts $30 \% \mathrm{H} 2 \mathrm{O} 2$ and 3 parts $0.02 \mathrm{M}$ \\
Organic Matter & $\mathrm{HNO3}$ \\
\hline Resistant & $8 \mathrm{M} \mathrm{HNO3}$ \\
\hline
\end{tabular}

Note: All extractions were performed at $50 \mathrm{C}$, for 4 hours.

TTR soil (12 grams) was soaked in $15 \mathrm{~mL}$ of DI water overnight. Next, $180 \mathrm{~mL}$ of the extractant of interest was added to the sample. The sample was placed in a water shaker bath and allowed to react for 4 hours. After each extraction step the sample was centrifuged at $3000 \mathrm{rpm}$ for 25 minutes. The supernatant was transferred into a beaker and the residual soil was rinsed twice, centrifuging each time. The rinses were combined with the supernatant, which was then analyzed for plutonium. The residual soil was carried to the next step of the sequential extraction process.

The results of the sequential extraction process applied to the untreated soil are shown in Table 10. The data indicate that significant amounts of plutonium are soluble in the "organic" (HNO3/peroxide) and resistant (8 M HNO3) extracts. The solubility of plutonium in the $\mathrm{HNO} /$ peroxide is somewhat surprising because historical data indicated that the plutonium was present as plutonium dioxide and as fused plutonium silicate. These would usually be soluble in the resistant phase and any remaining residual phase. 
Table 10. Sequential Extraction of Clean Slate II Soil, Soil Not Heated in Muffle Furnace Prior to Extractions

\begin{tabular}{|c|c|c|c|}
\hline & \multicolumn{4}{|l|}{ Percent of Total Pu-239 Activity } \\
\hline Sample I.D. & Rep 1 & Rep 2 & Rep 3 \\
\hline Exchangeable & 0.56 & 1.14 & 1.68 \\
\hline Carbonates & 0.92 & 1.17 & 0.56 \\
\hline Reducible & 1.70 & 6.36 & 4.97 \\
\hline Organic Matter & 69.12 & 17.15 & 48.59 \\
\hline Resistant & 27.70 & 74.18 & 44.20 \\
\hline
\end{tabular}

To determine if the plutonium was truly associated with an organic phase, a portion of the soil was also placed in a muffle furnace prior to extraction. Heating to $550 \mathrm{C}$ destroys organic material that is present in the soil. The results are shown in Table 11. The total amount of activity leached by this process remained about the same, with or without the use of the muffle furnace. However, the distribution of activity did change. After pretreatment with the muffle furnace about $20 \%$ of the activity is soluble in the "reducible" extractant.

The implications of this are uncertain, although perhaps the muffle furnace destroyed the organic matrix, oxidized some of the plutonium and made more of the plutonium available in the reducible phase.

Table 11. Sequential Extraction of Clean Slate II Soil, Soil Heated in Muffle Furnace Prior to Extractions

\begin{tabular}{|c|c|c|c|}
\hline & \multicolumn{3}{|c|}{ Percent of Total Pu-239 Activity } \\
\hline Sample I.D. & Rep 1 & Rep 2 & Rep 3 \\
\hline Exchangeable & 0.74 & 2.25 & 2.98 \\
\hline Carbonates & 1.20 & 1.42 & 1.27 \\
\hline Reducible & 24.03 & 15.25 & 24.23 \\
\hline Organic Matter & 38.26 & 13.20 & 40.59 \\
\hline Resistant & 35.77 & 67.88 & 30.94 \\
\hline
\end{tabular}

\section{Magnetic Separation}

Magnetic separation was used in this research to determine the amount of paramagnetic plutonium particles in the soil and/or the amount of plutonium associated with the ferromagnetic soil particles. Fifty gram samples of Clean Slate II were placed in polyethylene bottles $(125 \mathrm{~mL})$ with two 0.5 tesla magnets attached to the outside of the bottles. Then $50 \mathrm{~mL}$ of distilled water was added. The soil mixture was shaken softly to allow the soil to pass through the magnet field, and eventually the soil paramagnetic particles became attached to walls of the bottle at the location of the magnetic force. The samples were rinsed seven times with distilled water to remove the non-paramagnetic particles, thereby improving the magnetic separation efficiency. The magnetic and non-magnetic fractions were dried and weighed and then analyzed for gross alpha. The results are show in Table 12. Magnetic separation was also performed on dry soil

15

Volume II Characterization of Clean Slate II Soil 
without the use of water. The data indicate the following:

- The magnetic separation was able to reduce the amount of activity in the soil from 1200 down to $600 \mathrm{pCi} / \mathrm{g}$ (for wet separation) and $750 \mathrm{pCi} / \mathrm{g}$ (for dry separation). However, both of these remain well above the $200 \mathrm{pCi} / \mathrm{g}$ target level.

- Both processes removed a similar portion of the activity (19\% of the total activity), but the wet process was more efficient $(6.1 \%$ of the soil contained $19 \%$ of the total activity) than the dry process $(15.1 \%$ of the soil contained $19 \%$ of the total activity).

Table 12. Effect of Magnetic Separation on Removal of Alpha Activity From the Clean Slate II Soils

\begin{tabular}{|c|c|c|c|c|c|}
\hline \multirow{2}{*}{$\begin{array}{l}\text { Replicate } \\
\text { Number }\end{array}$} & \multicolumn{4}{|c|}{ Magnetic Fraction } & \multirow{2}{*}{$\begin{array}{c}\text { Non- } \\
\text { Magnetic } \\
\text { Fraction } \\
\text { Average } \\
\text { Gross } \\
\text { Alpha, } \\
\text { pCi/g }\end{array}$} \\
\hline & Grams & $\begin{array}{c}\text { Gross } \\
\text { Alpha, } \\
\text { pCi/g }\end{array}$ & $\begin{array}{c}\% \text { Alpha } \\
\text { Activity } \\
\text { Removed }\end{array}$ & $\begin{array}{l}\% \text { of Total } \\
\text { Soil Mass }\end{array}$ & \\
\hline \multicolumn{6}{|c|}{ Wet Separation } \\
\hline Rep 1 & 4.2 & 2779 & 17.7 & 8.3 & \multirow{10}{*}{606} \\
\hline Rep 2 & 2.1 & 4286 & 14.2 & 4.3 & \\
\hline Rep 3 & 3.4 & 8445 & 42.2 & 6.5 & \\
\hline $\operatorname{Rep} 4$ & 3.7 & 2452 & 14.2 & 7.6 & \\
\hline Rep 5 & 4.1 & 4900 & 30.4 & 8.1 & \\
\hline Rep 6 & 3.8 & 2701 & 15.6 & 7.5 & \\
\hline Rep 7 & 2.9 & 1709 & 7.6 & 5.8 & \\
\hline Rep 8 & 2.3 & 5264 & 18.5 & 4.6 & \\
\hline Rep 9 & 2.0 & 1926 & 5.7 & 3.9 & \\
\hline Rep 10 & 2.4 & 5571 & 19.7 & \multirow[t]{4}{*}{4.6} & \\
\hline Average & \multirow[t]{3}{*}{3.1} & & 18.6 & & \\
\hline SD & & & 10.7 & & \\
\hline$\%$ RSD & & & 57.6 & & \\
\hline \multicolumn{6}{|c|}{ Dry Separation } \\
\hline Rep 1 & 8.0 & 1546 & 19.0 & 15.4 & \multirow{5}{*}{748} \\
\hline Rep 2 & 7.7 & 1742 & 20.5 & 14.7 & \\
\hline Rep 3 & 7.4 & 1292 & 14.4 & 13.7 & \\
\hline Rep 4 & 7.0 & 2326 & 25.1 & 16.6 & \\
\hline Rep 5 & 8.3 & 1444 & 18.4 & 15.3 & \\
\hline Average & 7.7 & & 19.4 & & \\
\hline SD & & & 3.9 & & \\
\hline$\%$ RSD & & & 19.9 & & \\
\hline
\end{tabular}

16 


\section{Procedure for Disposal of Clemson Soil, Developed by Bechtel Nevada}

1. The "Clemson Soil" will originate at the TTR Clean Slate 2 site, be used by Clemson University for soil volume reduction technology testing, and, upon satisfying the requirements listed below, be disposed-of under the $\mathrm{BN}$ generator program.

2. All waste to be disposed-of as low level waste at the NTS must meet the requirements of the NTS Waste Acceptance Criteria (NTS WAC). Any waste that does not meet the NTS WAC will be the responsibility of Clemson for appropriate disposal.

3. Clemson University will prepare a BN Material Evaluation Form and submit it to BN Waste Control. Clemson must include as attachments to the form MSDS sheets for all chemicals added, descriptions of the tests performed, soil analyses (also see item 6), and other documentation that the returned "waste" meets the NTS WAC .

4. BN Waste Control personnel will review and approve the Form, then the waste must be accepted for disposal by the BN Waste Certification Official.

5. As the drums are filled at Clean Slate 2, BN Waste Control personnel will take one soil sample from each drum using an approved Sampling and Analysis Plan to characterize the drums of soil sent to Clemson University. It is expected that Clemson will perform additional soil analyses to support their test program (also see item 6).

6. BN Waste Control personnel will apply security seals to the drums prior to shipment to Clemson. Each seal must remain intact unless the drum is used in the testing at Clemson. For any drums that have been opened, Clemson will be responsible for maintaining security of the drums and characterizing the contents for disposal at the NTS.

7. Clemson will have to document all changes to soil used in their tests. This includes taking soil samples for processed waste streams for analysis at an approved Bechtel Nevada laboratory.

8. NTS cannot accept mixed waste or transuranic waste for disposal. It is Clemson's responsibility to provide process knowledge, analytical data and MSDS's for chemicals used to document that the material for disposal is lowlevel waste.

(rev. 7/23/01) 


\section{References}

1. Cho, Eung Ha, et. Al., Soil Volume Reduction Technologies, Evaluation of Current Technologies, DOE Cooperative Agreement DE-FC2698FT40396, Deployment Leading to Implementation, Final Report, submitted by West Virginia University to US DOE National Energy Technology Laboratory, July 2000.

2. Source: www.em.doe.gov/closure/final/nvfig24.html

3. Murarik, T.M., "Characterization, Liberation and Separation of Plutonium at the Nevada Test Site: Safety Shot Residues", Proceedings of the Soil Decon '93: Technology Targeting Radionuclides and Heavy Metals, June 16 and 17, 1993, Gatlinburg, TN, ORNL-6769, Oak Ridge National Laboratory, Oak Ridge, TN, September 1993.

4. 1996 Baseline Environmental Management Report, Nevada Test Site and Tonopah Test Range, US DOE Office of Environmental Management, 1996. Available on-line at: http://www.em.doe.gov/bemr96/nvts.html

5. Heavy Metals Contaminated Soil Project Technical Summary, DOE/EM0129P, National Technology Transfer Center, Wheeling, WV, 1994. Available on-line at: www.nttc.edu/env/Heavy Metals/heavy metals/chap1.html

6. Misra, M., et. al., "Characterization and Physical Separation of Radionuclides from Contaminated Soils," Proceedings of the Soil Decon '93: Technology Targeting Radionuclides and Heavy Metals, June 16 and 17, 1993, Gatlinburg, TN, ORNL-6769, Oak Ridge National Laboratory, Oak Ridge, TN, September 1993.

7. Schultz M., Inn K., Burnett W., Smith G., Biegalski S., and Filliben J., "Identification of Radionuclide Partitioning in Soils and Sediments: Determination of Optimum Conditions for the Exchangeable Fraction of the NIST Standard Sequential Extraction Protocol." Journal of Applied Radiation and Isoptopes, $\underline{49}$, 1289-1293 (1998).

8. Craig Lyons, NVO, Personal communications, 2002. 


\title{
Evaluation of Remediation Technologies for Plutonium Contaminated Soils at the Nevada Test Site (NTS)
}

\section{Cooperative Agreement \#DE-FC26-00NT40841}

\author{
Volume III
}

Remediation of Radioactive Surface Soils Workshop

Date Issued October 13, 2003 
Early on in the project, NETL requested that other sites (similar soil contamination, treatment approaches) be included in the literature search (e.g., Idaho, Rocky Flats, Paducah). NETL would like, if possible, for the results of this project to be useful/applicable to other sites. A review of site needs indicated several other sites that could benefit from these studies. In addition to the Nevada Test Site (NV04-0002-05S) these included the Mound Environmental Management Project (OH-M904), Rocky Flats (RF-ER09), and the Richland Laboratory (RL-SS12). Information about each of these is provided in Appendix A.

In an effort to further make these studies as useful as possible to NTS and other sites, a soils workshop was held at the Nevada Operations Office in Las Vegas, Nevada on August 14 and 15, 2001. The U.S. Department of Energy (DOE), National Security Administration Nevada Operations Office (NNSA/NV) and the Subsurface Contaminants Focus Area hosted the Remediation of Radioactive Surface Soils Workshop. The Waste Policy Institute (WPI), Clemson Environmental Technologies Laboratory, Bechtel Nevada, and the Desert Research Institute (DRI) provided support for the workshop.

The workshop was held, in part, to inform vendors, encourage vendor interaction, collaboration and/or teaming, and to respond to questions on the pending solicitation. The workshop brought together vendors; DOE site representatives and end users. The workshop provided an opportunity for DOE Operations Offices to exchange information with DOE sites on related radiological surface soil problems and to determine the availability of technologies for the removal, treatment, and disposal of the contaminants. Representatives from CETL, NETL and the NTS were present. Representatives from other DOE sites with similar concerns were also present. Vendors with potentially applicable technologies also attended. The total number of participants included:

- $\quad$ About 70 personnel from the government, private sector, and public participated

- $\quad$ DOE Operation Offices plus DOE focus areas \& other programs.

- 12 commercial technology vendors,

- 8 national laboratories

- University researchers, and state and federal regulators

Brief vendor presentations and poster sessions were made. Nevada Operations and WPI have summarized the workshop on the SCFA web site at:

http://www.envnet.org/scfa/nvconf/. As a result of the workshop, needs from 10 sites assimilated into tables and the capabilities of 12 vendors were summarized into tables. 


\section{APPENDIX A}

Volume III Remediation of Radioactive Surface Soils Workshop Cooperative Agreement \#DE-FC26-00NT40841

October 13, 2003 


\section{NV04}

\section{Soil Volume Reduction (former NV04-0002-05S}

Project been deferred to $2008 ; \mathrm{b} / \mathrm{c}$ cleanup level agreement not reached; no other project work until then; move back up in schedule if other project change or get efficiencies; Have method (suck/muck) for removing top 1"

The objective is to remove Pu-contamination from the upper inch or so of soil over several areas totaling about 115 acres at an estimated cost of a million dollars per acre. The Pu oxide is disseminated as dust-size particles. DOE-NV has tried a number of existing technologies, but none has proven effective.

These include magnetic methods, soil washing, and the segmented gate system. Action on this project has been delayed until 2008 , which should allow time to identify any available technology, or prove the technical infeasibility of the cleanup. Although the area will be part of Nellis AFB until at least 2015, regulators want $\mathrm{DOE}$ to clean up to resident rancher standards at $25 \mathrm{mrem}$ exposure, which may mean under $100 \mathrm{pCi} / \mathrm{g}$ concentration in the soil. SCFA, through a NETL solicitation, has recently conducted a market survey, and plans to issue a solicitation in the next year or two to address this need. SCFA offers technical support through ITRD, TechCon, the Lead Lab, and also has access to the U.S. Army Corps of Engineers. Clemson University has been awarded a contract through NETL to evaluate soil cleanup technologies for NV.

A technology to reduce volume of contaminated soil at soil sites. This may involve segregation of soils contaminated above a TBD corrective action levels or the treatment of soils to remove or separate contaminants there by reducing the volume of waste to be transported and disposed.

\section{OH-M904}

\section{Extraction of Plutonium and Thorium from Soils}

looked at segmented gate, physical size separation, soil washing - nothing has been cost effective for volume reductions; Working with chemical extraction;looking at particle separation based on binding of Thorium and Plutonium to diff particle sizes; producing probability maps for $\mathrm{Th}$ and $\mathrm{Pu}$, to minimize the excavation area; break-even point on extraction point $\sim 10 \mathrm{~K}$ yards; schedule - excavation 2002 , total vol $\sim 300 \mathrm{~K}$ cu yards; ITRD is helping with probability mapping; site can ; Probability mapping contact at /Sandia - Chris Rautman/Gary Brown.

Mound has tested the segmented gate system but it was only effective on thorium not plutonium. Mound also looked at several physical and chemical separation processes but successful technologies were not cost effective. Mound stated that a technology must be less than approximately $\$ 500 /$ ton to be 
cost effective compared with off-site burial. Clemson University is currently funded to work on the issue of soil volume reduction under TTP FT06IP01 (the point of contact for this TTP is Karen Cohen, 412-386-6667).

Soil contaminated with plutonium and/or thorium is currently excavated and shipped offsite for disposal. This represents the single largest cost element in the soils cleanup program. If a cost effective method could be identified to extract the contaminant from the soil and thus ship and dispose of a smaller volume, a significant cost savings could be realized.

\section{RF-ER09}

Treatment Alternative for Surface Soil Contaminated with Plutonium and other Radionulcides

Heavy Hitter for the site. Similar to the ER-17 (new need). NV tried parametic separaction without success. Segmented gate will not work because the contamination is homogeneous. Sieving. Dwn Kaback suggest a hepa drilling technology- Dwn could look into this. A screen on the front of the vacuumm may increase controlability.

This need is specifically called out in a current solicitation (PRDA No. DE-RA2601NT40891). RF has evaluated a number of potential approaches to the plutonium dispersed in soil problem. Similar problems exist at RL and NV. NV, with support of Desert Research Institute, has also investigated a number of technologies. A vacuuming technology may remove only the finest-grained soil material, and thus remove the contarnination, as the plutonium is associated with the finer fraction soil. Such equipment may be available at INEEL as excess from an earlier EM-50 project. SCFA will assist RF in identifying /recommending the appropriate technology (information on a commercially available technology has been furnished to the site- Dawn Kaback, 303-297-0180 $\times 111$ is contact) to address this need. Further technical assistance may be available through the Lead Lab, ITRD (for particle size separation technology contact Yvonne McClellan 505-844-6979), TechCon (Dale Pflug 630-252-6682) or another mechanism at the sites request. SCFA will also investigate a dust catching filter system previously developed to catch contaminated drill cuttings.

The Site requires treatment technologies for the treatment (in-situ or ex-situ) of surface soil contaminated with plutonium and other radionulcides (primarily Americium). The Site is interested in technologies that effectively stabilize in place, or technologies that provide cost effective volume reduction by separating the radioacive constituents for disposal. 


\section{RL-SS12 \\ Cost Effective, In Situ Remediation in the Vadose Zone of One or More of the Following Radionuclides: Uranium,}

Segmented gate is not insitu- thus not appropriate. RL is looking at a supersaturated grout that may solidify both metals and rads. The grout has the viscosity of water. (RL will share information from German scientist if interested). $\mathrm{RL}$ is both looking at this grouting technology as both a subsurface cap, to target small areas. The chemical component is gypsum with an inhibitor that acts to prevent gelling for a time. The injection spacing anticipated is 40 feet. Malcolm suggests phosphate ( and calcium citrate) grouts. The zone of grouting is between two wells where the chemicals mix. Phosphate is injected at one end well and Calcium citrate at the other. Grouting expertise is a potential application for technical assisstence. IP solicitation plans to target Hanford as a potential site for assistence in FY01. ORP may also be interested

NETL is in the process of developing a solitation for FY01 for remediation of rads in the vadose zone in deep and/or difficult settings. Karen Cohen is the point of contact and can be reached at 412-386-6667. RL is looking at super-saturated grout as subsurface barrier to target small areas. Delivery of grouting at deeper depths was identified for the technical assistance areas.

Numerous contaminated soil sites exist at the Hanford site as a result of liquid effluent discharge to the soil column. Cost effective in situ remediation technologies are required to deal with radioactive contamination. In situ technologies that are more cost effective than the baseline excavation/disposal costs ( $\$ 60 /$ ton) are needed (200 Area) to treat the top 15 feet of soil. In situ treatment technologies may also be required $(100,200$, and 300 Areas) if soil contamination extends beyond the 15 feet to depths where excavation costs become prohibitive. Primary radionuclides of concern include uranium, plutonium, cesium, cobalt, strontium-90, and technetium-99. 


\section{SITE NEED STATEMENT}

\section{General Reference Information}

Need Title:

Need Code:

Need Summary:

Origination Date:

Need Type:

Operations Office:

Geographic Site Name:

Project:

National Priority:

Operations Office Priority:

Problem Description information

Operations Office Program

Description:

Need/Problem Description:

\section{Functional Performance Requirements:}

\section{Definition of Solution:}

Targeted Focus Area: Potential Benefits:

\author{
Potential Cost Savings: \\ Potential Cost Savings \\ Narrative:
}

Technical Basis:

DOE/NV

Medium

5 of 12

\section{Soll Volume Reduction}

NV04-0101-05S

A technology is needed to reduce the volume of contaminated soil at soil sites. This may involve segregation of soils contaminated above a to be determined corrective action level or the treatment of solls to remove or separate contaminants thereby reducing the volume of waste to be transported and disposed.

January 1, 2001

Sclence and Technology Need

Nevada Test Site, Tonopah Test Range, Nellis Air Force Range

NV211/Soils

The DOE/NV Environmental Restoration Program encompasses activities that assess the degree of contamination resulting from the testing program at the Nevada Test Site, the Nellis Air Force Range, the Tonopah Test Range, and eight offsite locations, and performs actions required by federal and state regulations. The objects of the Program are to: (1) identify the nature and extent of the contamination, (2) determine its potential risk to the public and the environment, and (3) perform the necessary corrective actions in compliance with applicable regulatory guidelines and requirements.

A technology is needed to reduce the volume of contaminated soll at soil sites. This may involve segregation of soils contaminated above a to be determined corrective action level or the treatment of soils to remove or separate contaminants thereby reducing the volume of waste to be transported and disposed.

- Clean soll plutonium concentration less than $1000 \mathrm{pCi} / \mathrm{g}$

- Technology capable of treating wide variety of soils varying in composition and other characteristics

- Soll processing throughput maximized to minimize costly time in the field

- Significant soil volume reduction, at least $70 \%$

- Portable technology that operates effectively and with low maintenance in remote, arid environments

- Water consumption minimized by recycling or other means. Water consumption for dust control minimized by equipment design or operation

- Secondary waste generation, and dust and airborne contaminants production minimized; mixed waste or transuranic waste production is unacceptable. Soll sites remediated to meet regulatory requirements at a life-cycle cost that is significantly less than the known baseline cost, with no significant adverse environmental, safety or health impacts from deploying the innovative technology. Subsurface Contaminants Substantial cost savings because of reduce volumes of contaminated soil being transported and disposed at the NTS. Potential reduced risk to workers because of lower contaminated soll volumes being handled and to the environment because of fewer truck shipments of contaminated soll.

implementing the technology will result in an estimated cost savings of $\$ 33$ miltion The baseline project cost was reviewed to identify cost elements that would be impacted by a generic soll volume technology. These elements were then adjusted for an assumed 70 percent reduction in contaminated soil being managed. The cast of deploying the generic technology was estimated based on past experience. The total adjusted cost was then calculated. The difference between the baseline and the adjusted cost is the cost savings.

The existing technology results in large volumes of waste that require disposal. 
Basis:

Environment, Safety, and

Health Basis:

Regulatory Drivers:

Milestones:

Material Streams:

TSD System:

Major Contaminants:

Contaminated Media:

Volume/Size of

Contaminated Media:

Earliest Date Required:

Latest Date Required:

\section{Baseline Technology Information}

Easeline Technology

Process:

Life-Cycle Cost Using

Baseline:

Uncertainty on Baseline

Life-Cycle Cost:

Completion Date Using

Baseline:

Points of Contact (POC)
Contractor End User

POCs:
DOE End User POCs: reduction in waste volumes will decrease the number of waste shipments to the NTS. A reduction in the volume of waste generated during cleanup would reduce the physical risks to the public during transportation of waste to the disposal site, minimize the volume of waste (pollution prevention), and reduce the occupational and exposure risk to site workers.

Corrective action levels are currently being negotiated with the Nevada Division of Environmental Protection and the U.S. Air Force. Soil volumes will depend upon the corrective action level set through negotiations and techniques/technology used in reducing the volume of waste generated during cleanup to the corrective action level. Not applicable

LLW contaminated soils (1026). Technical risk score 3. Not on critical path to closure Volume reduction (1639)

Plutonium, depleted uranium, tritium, and other radionuclides

Surface and subsurface soil

111,000 cubic meters

FY 2007

FY 2007

Currently, soils are excavated using construction earth moving equipment to approximate depths.

Approximately $\$ 115,000$ million

The ER baseline planning assumption for soils is to characterize the area to be remediated, scrape and excavate the area as needed to remove surface soll exceeding the corrective action level, characterize the removed soil, load the soll into trucks lined with plastic wraps, and transport the soil to the NTS for disposal as LLW. The life-cycle cost estimates are parametric estimates based on past experience on similar projects.

FY 2014
Wayne Johnson, Bechtel Nevada - Office: 702-295-0573; Fax: 702-295-7761;

E-mail: iohnsowf@nv.doe.gov

Monica Sanchez, Environmental Restoration Division -Office: 702-295-0160;

Fax: 702-295-1113; E-mail sanchezminv doe.gov 


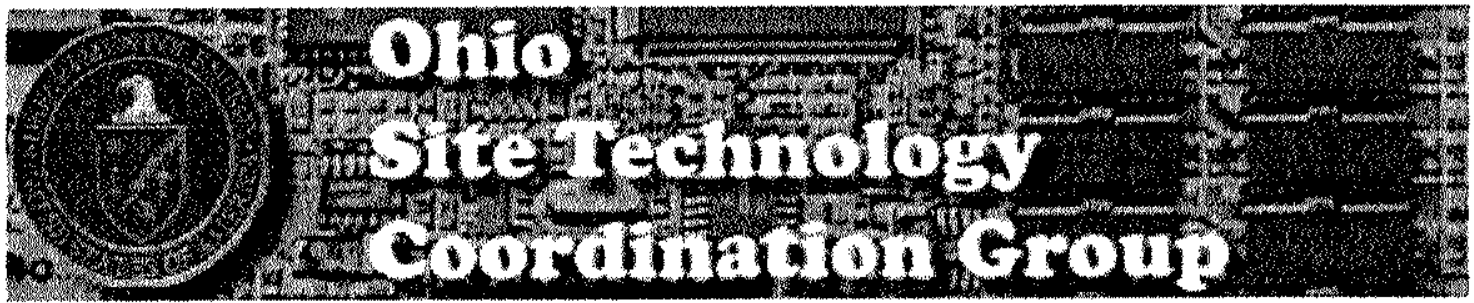

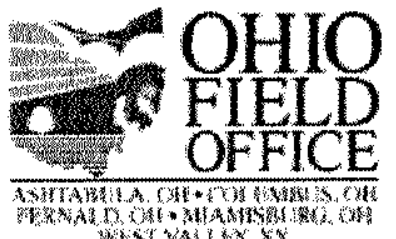

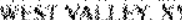

OH-M904

MOUND

TECHNOLOGY OPPORTUNITY STATEMENT

Ohio STCG

Technology Needs

Contacts

Other STCG Offices

Fernald, Ohio STCG

National STCG

Albuquerque, NM

Chicago, IL

Hanford. WA

ldaho

Nevada

Oakland, CA

Oak Ridge, $\mathrm{TN}$

Rocky Flats

Savannah River

Ohio Field Office and Area Offices

Ohio Field Office

Ashtabula Ohio

Columbus, Ohio

Miamisburg, Ohio

West Valley, New York

\section{GENERAL REFERENCE INFORMATION}

Opportunity Title: Extraction of Plutonium and Thorium from Soils

Identification Number: $\mathrm{OH}-\mathrm{M} \bigcirc \mathrm{O}$

Date of Latest Revision: 12/1/1998

Opportunity Description: Soil contaminated with plutonium and/or thorium is currently excavated and shipped offsite for disposal. This represents the single largest cost element in the soils cleanup program. If a cost effective method could be identified to extract the contaminant from the soil and thus ship and dispose of a smaller volume, a significant cost savings could be realized.

Category: Technology Opportunity

Ops Office: $\mathrm{OH}$

Site: Mound Environmental Management Project (MEMP)

End-User Program: Soil and Water Program

Priority Rankings:

End User Program Ranking: TBD

ACPC Plan Priority: 2 (Substantial benefit)

Sitewide Ranking: 4

Project Baseline Summary Number/Title: Soils, OH-MB-08, 0579

Waste Stream: LLW-2 
Critical Path and Activities: Will be provided by PTC and updated through PTC data call in April

Targeted Focus Area: SCFA

\section{PROBLEM DESCRIPTION}

Background: Past activities at Mound have resulted in contamination of the soil with radioactive material, primarily plutonium and thorium. With the exit of DOE from the site and the conversion of the site to an industrial complex, these contaminated areas are scheduled for cleanup.

Baseline Technology/Process: The current activities and the future schedules/budgets are based on excavation of the soil and offsite disposal.

\section{Issues related to Baseline:}

Technical: The current "box and bury" strategy is technical feasible, but very costly. It also transfers the risks from the Mound site to the disposal site and increases the risks during shipment.

Cost: Shipping and disposal costs represent the single largest cost element in the soils cleanup program. Significant savings can be realized if a cost effective alternative can be found to replace "box and bury".

Regulatory: Project schedules drive Mound's regulatory milestones and agreements. This technology would improve those schedules and also facilitate the conversion of Mound to a privately owned industrial complex.

Safety, Health \& Environment: Risks to the public health and the environment could be reduced due to shipping a much smaller volume of contaminated soil.

Stakeholder and Cultural: The local city government and the citizens group have expressed interest in reducing the volume of soil shipped offsite for disposal.

\section{Other:}

\section{OPPORTUNITY INFORMATION}

Opportunity Description: Soil contaminated with plutonium and/or thorium is currently excavated and shipped offsite for disposal. This 
represents the single largest cost element in the soils cleanup program. If a cost effective method could be identified to extract the contaminant from the soil and thus ship and dispose of a smaller volume, a significant cost savings could be realized.

Functional Performance Requirements: A method to extract plutonium and/or thorium from Mound soils must be able to achieve the site cleanup standards. This would allow the clean fraction to be placed back in the excavation. The method must also be cost effective compared to the baseline technology.

Schedule Requirements: The need is current. Soil cleanup activities are ongoing and are expected to be continuous throughout the remainder of Mound's cleanup program.

Consequences of Not Filling Need: Significant potential cost savings will not be realized

\section{END-USER POINTS-OF-CONTACT:}

DOE

James O. Johnson;

voice: $937-847-5234$

fax: $937-865-4219$;

e-mail james.o.johnson@em.doe.gov

Back to the Ohio Field Office Home Page 


\section{Ohio Heavy Metals}

The Ohio Heavy Metals Project is a joint project involving the DOE Fernald Site, the DOE Mound Plant, and the DOE Astabula/Reactive Metals site, to evaluate and demonstrate innovative technologies to remediate uranium, plutonium, and thorium in soils. Technologies being evaluated and demonstrated under the ITRD Program include a Segmented Gate soil separation system, a pilot scale demonstration of the Selentec chemical treatment process, Smart Sampling ${ }^{\mathrm{TM}}$ to enhance excavation decision-making, and an Alternative Remedial Technologies (ART) soil processing system.

- Project Summary

- Project Status

- Project Agreement/Charter

- List of Participating Organizations

- Information for Team Participants (Password Protected -- Please call Mike Hightower at (505) 8445499 if you need access to this information.)

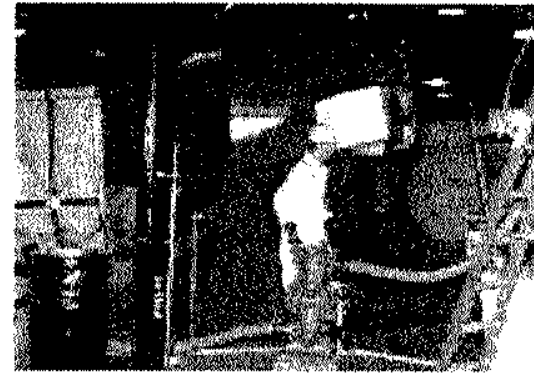

Chemical extraction for uranitucontaminated soils at Ashtabula, OH, January 1997.

More Project Photos (click on photos below for larger view)
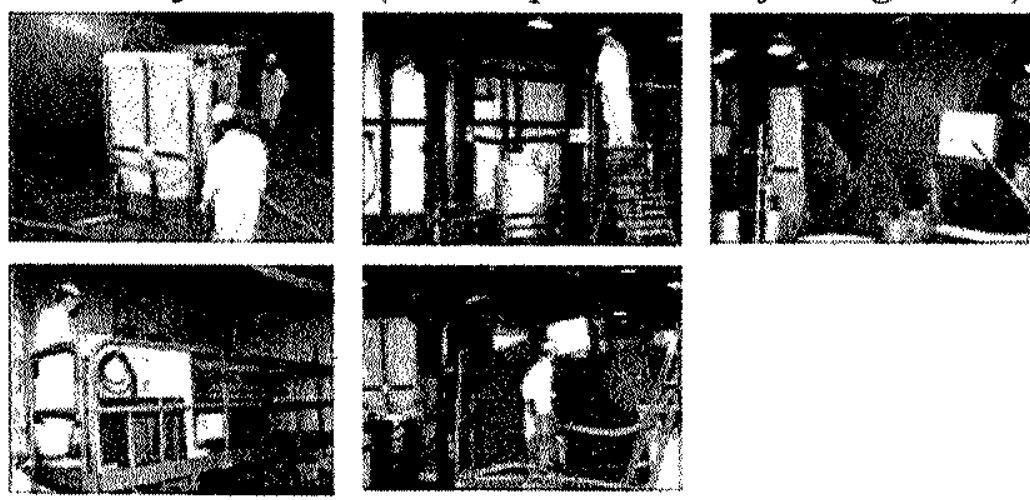
EM HOME | DOE HOME | SEARCH | WEBSITE OUTLINE
FEEDBACK | WTERACTIVE MAP | WHAT'S NEW PRIVACY AND SECURITY NOTICE

About This Document

Last Updated 09/16/1997 (mhp) 


\subsection{MOUnd PRS-66 Thorium and Piutonium CONTaminated SOIL.}

\subsubsection{ITRD MOUND PRS-66 BACKGROUND}

Located at the DOE Mound Plant in Miamisburg, Ohio, Potential Release Site 66, PRS-66, is an approximately 96,250 square foot historical disposal site located under the parking lot southeast of Buildings 29 and 98 and south of Building 51 (Figure 10). Currently, most of the area is an asphalt parking lot constructed in 1984. PRS-66 was once a steep ravine, used for the disposal of construction soils and debris, including 10,000 to 15,000 empty drums that once contained ${ }^{232} \mathrm{Th},{ }^{238} \mathrm{Pu}$, a washing machine contaminated ${ }^{210} \mathrm{Po}$ (date unknown), and a flat bed truck contaminated with ${ }^{232} \mathrm{Th}$. Other materials contaminated with ${ }^{210} \mathrm{Po}$, such as exhaust system ducts from T-Building, may have also been disposed of in the area.

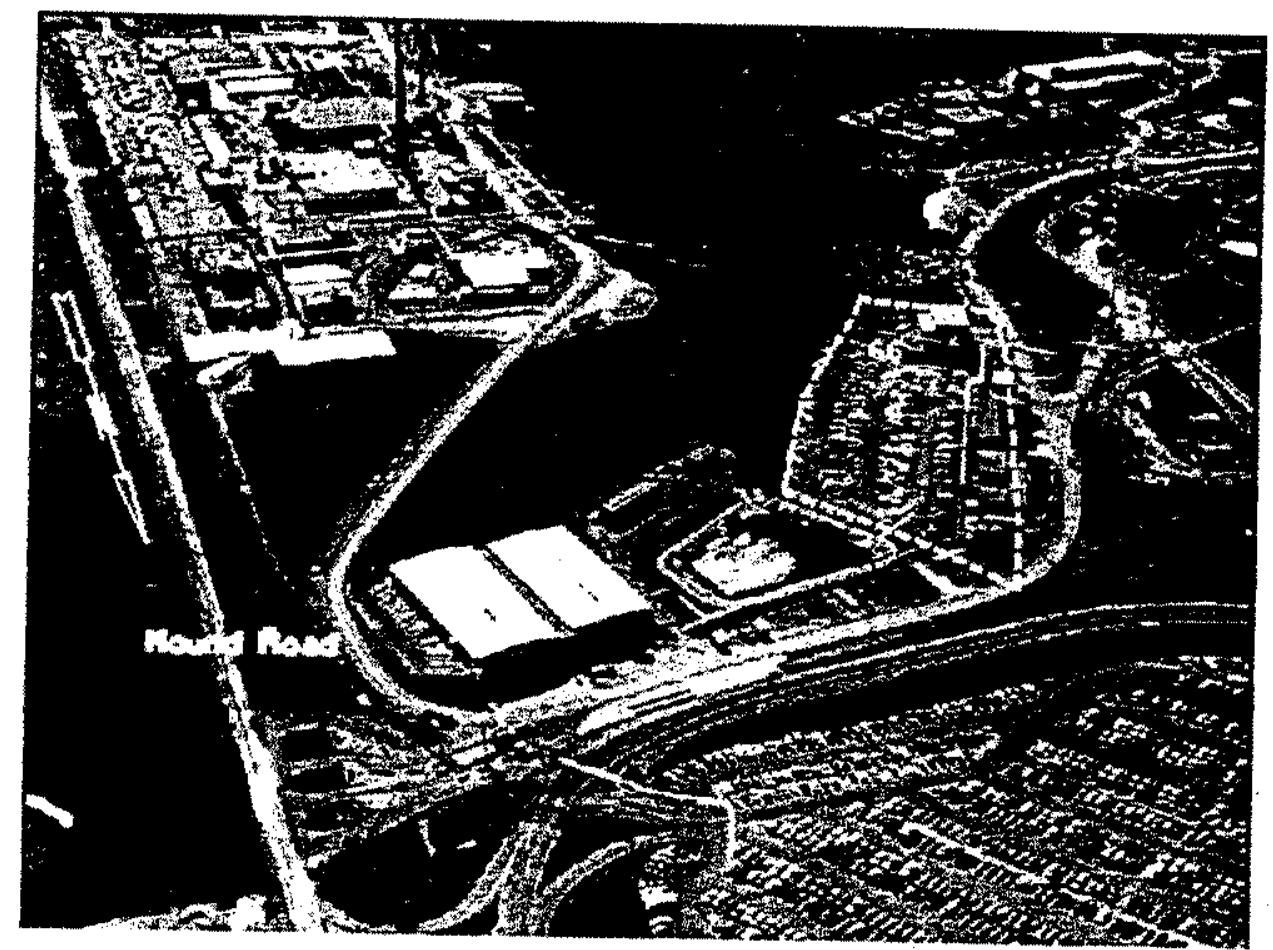

Figure 10. Mound Potential Release Site 66

The areal extent of fill in this area of the Mound site is depicted in Figure 11, which was obtained by subtraction of the terrain models for 1946 (pre-site construction) from those of 1994. A cross-section shown in Figure 12 demonstrates the vertical extent of the fill within PRS-66. 


\section{Ashtabula Environmental Management Project}

\section{CHEMICAL EXTRACTION SOIL WASHING}

\section{PROBLEMINEED}

The traditional approach of excavation, packaging, certification, transportation and burial at the

Ashtabula Environmental Management Project (AEMP) was a major expense. Remediation of contaminated soil had been estimated at over $\$ 45$ million of a total project cost of $\$ 150$ million.

\section{TECHNOLOGY DESCRIPTION}

The RMIDP soil washing plant uses $0.2 \mathrm{M}$ carbonate solution which is heated to approximately $115^{\circ} \mathrm{F}$ and contacts the soil for approximately 90 minutes to leach the uranium from the soil. The process results in contaminant removal efficiencies of approximately 85 percent and volume reductions in excess of 98 percent. The chemical extraction technology provides a remediation approach for the 40,000 tons of uranium contaminated soll at the AEMP in Ashtabula, Ohio. Soll washing provides projected savings of approximately $\$ 300$ per ton when compared to total life cycle ship and bury costs. The process is applicable to other radionuclides and contaminants present in the DOE complex.

Clean soil product from soil washing operations is analyzed using $X$-ray Fluorescence to ensure that free release standards have been met. Following verification analysis using Alpha Spectroscopy, the clean soil product is used as clean backfill on the RMI Extrusion Site.

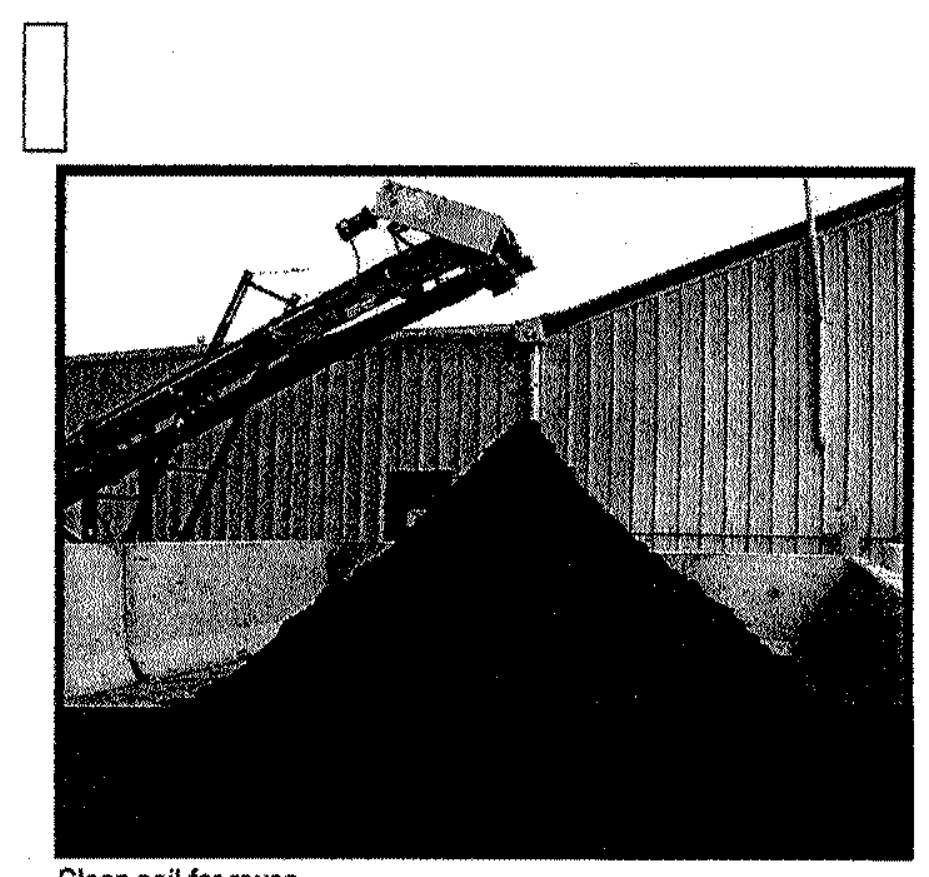

Clean soil for reuse

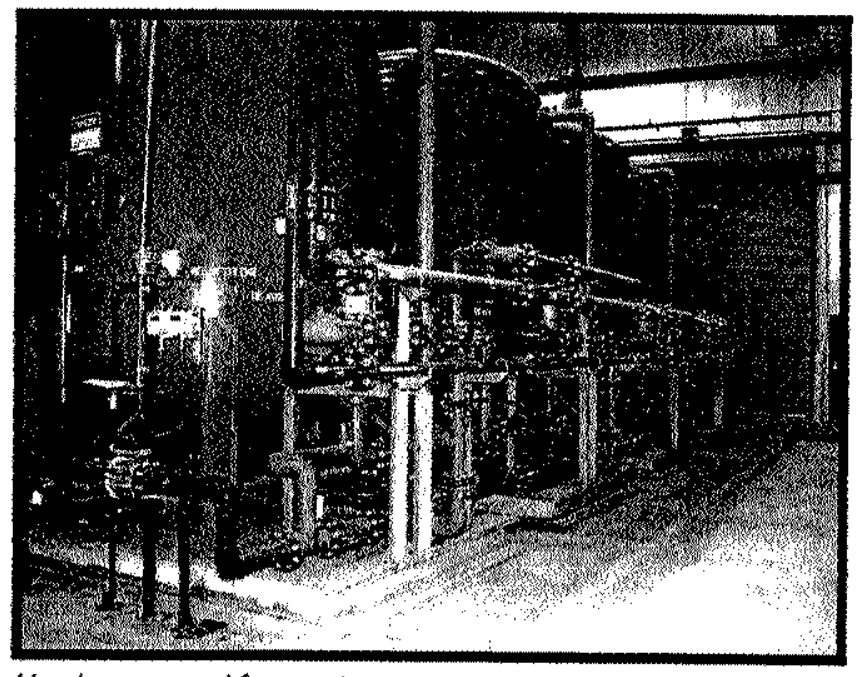

Uranium removal from water

\section{BENEFITS}

The AEMP soil washing process has successfully cleaned approximately 11,000 tons of soil to date resulting in cost savings of over $\$ 2.2$ million for the Ashtabula Environmental Management Project (AEMP). The plant has provided a clean soil product which meets all regulatory requirements for reuse as clean backfill soil. Over 98 percent of the contaminated soil entering the plant is recycled as clean material. The volume of contaminated. by-product material requiring disposal at an approved burial site is 2 percent.

\section{CONTACTS}

Mr. Geoffrey Gorsuch, Acting Director Ashtabula Environmental Management Project Phone: (440) 993-1944

\section{Mr. Jeff Kulpa, Director, Technical Projects} RMI Environmental Services

Phone: (440) 993-2804 


\section{GENERAL REFERENCE INFORMATION}

Need/Opportunity Title:

Need/Opportunity ID No:

Last Revision Date:

Need/Opportunity Summary:

Need/Opportunity Category:

Operations/Field Office:

Site:

End User Program:

Paths to Closure Priority Ranking: 2 (Substantial Benefit)

PBS Number/Title:

Waste Stream:
Treatment Alternative for Surface Soil

Contaminated with Plutonium and Other Radionuclides.

\section{RF-ER09}

November 17,1999

RFETS is currently planning the environmental remediation of the $903 \mathrm{Pad}$ and surrounding areas. The Site contractor is interested in receiving information on proven technologies, equipment and methodologies that are applicable to the remediation of plutonium contaminated soil.

Technology Opportunity

Rocky Flats Field Office (RFFO)

Rocky Flats Environmental Technology Site

Environmental Restoration (ER)
01 (Buffer Zone Closure Project)

undetermined

\section{PROBLEM DESCRIPTION}

Background: The 903 Pad was an open-air drum storage area from 1958 to 1967. Drums stored at the storage site contained plutonium, americium and uranium contaminated liquids. As a result of the deterioration of approximately to 420 drums, plutonium was released into the surface soils. Contamination of the area surrounding the 903 pad is believed to have occurred as a result wind action. Preliminary data indicate that up to 7820 yards of the $903 \mathrm{Pad}$ area are impacted by radiological contamination. The impacted soils cover an area of approximately 9.7 acres and are up to 6 inches deep.

"Baseline" Technology/Process: The current baseline for the 903 Pad soils consists of conventional digging and disposal. 


\section{Issues Related to Baseline:}

Technical - There are no technical issues related to the baseline approach.

Cost - It is believed that innovative remedial alternatives may help to decrease costs associated with this project.

Regulatory - All Site closure activities must be performed in accordance with the Rocky Flats Clean-up Agreement (RFCA). The Colorado Department of Public Health and Environment and the Environmental Protection Agency must approve the final remedial option.

Safety, Health and the Environment - The Site is interested in remedial alternatives that significantly minimize the generation of dust during soil removal, handling, processing and containerization.

Stakeholder and Cultural - Stakeholders are concerned about the long-term safety of residual contamination.

\section{NEED/OPPORTUNITY INFORMATION}

Need/Opportunity Description: RFETS is currently planning the environmental remediation of the $903 \mathrm{Pad}$ and surrounding areas. The Site contractor is interested in receiving information on proven technologies, equipment and methodologies that are applicable to the remediation of plutonium contaminated soil.

Function Performance Requirements: Treatment must reduce contaminant levels to below RFCA action levels.

Schedule Requirements: Treatment technology(ies) could be implemented as early as fiscal year (FY)2001 and will likely only be considered for implementation until FY2004.

Consequences of Not Filling Need/Opportunity: Larger than necessary project costs and waste volumes may be generated if this need/opportunity is not filled.

\section{POINTS OF CONTACT}

Site Technology Coordination Group (STCG) Point(s) of Contact: Gary Huffman, Chair (DOE-RFFO) 303-966-7490; gary.huffman@irfets.gov

Tom Anderson (AIMSI/RFFO) 303-966-4724; tom.anderson@rfets.gov

Contractor End User Point(s) of Contact:

J. Lane Butler (Kaiser-Hill) 303-966-5245; lane.butler@rfets.gov

DOE End User Point(s) of Contact:

Norma Castaneda (DOE-RFFO) 303-966-4226; norma.castaneda@rfets.gov 


\title{
TECHNOLOGY NEEDS/OPPORTUNITIES STATEMENT
}

\section{COST EFFECTIVE, IN SITU REMEDIATION OF RADIONUCLIDES IN THE VADOSE ZONE}

\author{
Identification No.: RL-SS12
}

Date: November 2000

Program: Environmental Restoration

OPS Office/Site: Richland Operations Office/Hanford Site

Operable Unit(s): All soil sites

PBS No.: RL-ER01, RL-ER02, RL-ER03

Waste Stream: Disposition Map Designations: ER-04 [technical risk score 3], ER-14 [technical risk score 5], ER-03 [technical risk score 3]

TSD Title: N/A

Waste Management Unit (if applicable): N/A

Facility: N/A

\section{Priority Rating:}

This entry addresses the "Accelerated Cleanup: Paths to Closure (ACPC)" priority:

1. Critical to the success of the ACPC

2. Provides substantial benefit to ACPC projects (e.g., moderate to high lifecycle cost savings or risk reduction, increased likelihood of compliance, increased assurance to avoid schedule delays)

3. Provides opportunities for significant, but lower cost savings or risk reduction, and may reduce uncertainty in ACPC project success

Need Title: Cost Effective, In Situ Remediation of Radionuclides in the Vadose Zone

\section{Need/Opportunity Category: Technology Opportunity}

Need Description: Numerous contaminated soil sites exist at the Hanford site as a result of liquid effluent discharge to the soil column. Cost-effective in situ remediation technologies are required to deal with radioactive contamination. In situ technologies that are more cost-effective than the baseline excavation/disposal costs ( $\$ 60 /$ ton) are needed (200 Area) to treat the top 15 feet of soil. In situ treatment technologies may also be required (100,200, and 300 Areas) if soil contamination extends beyond the 15 feet to depths where excavation costs become prohibitive. Primary radionuclides of concern include uranium, plutonium, cesium, cobalt, strontium-90, and technetium-99. Additionally, of concern is remediation of long-lived mobile radionuclides to be protective of groundwater. In some instances, it may also be necessary to remediate TRU waste in situ prior to surface capping of waste sites in the 200 Area. (Also see Science needs RLSS33-S, RL-SS34-S, and RL-SS36-S) 


\section{Schedule Requirements:}

Earliest Date Required: $8 / 1 / 99$

Latest Date Required: 9/30/15

Soil Remediation is ongoing. Characterization and remediation of the 200 Area sites began in FY 1999 and will extend to 2018.

Problem Description: Fifty years of defense plutonium production at Hanford resulted in the creation of a large number of contaminated soil sites. The Hanford site is essentially divided into three areas: the 100 Area along the Columbia River where the plutonium production reactors were located, the 300 Area at the south end of the site where fuel fabrication facilities were located, and the 200 Area located near the center of the site where the reactor-fuel processing and waste management facilities were located. The approximate total volumes of soil requiring remediation at the Hanford Site (liquid waste disposal sites and burial grounds) are: 3.9 million cubic yards in the 100 Areas, approximately 10 million cubic yards in the 200 Areas, and 0.8 million cubic yards in the 300 Area. Remediation schedules and requirements for these sites differ due to several factors including the types of contaminants present, the location of the area relative to the river, and the potential future land use for each area.

The 300 Area has several soil sites that resulted from liquid disposal in ponds and trenches. These areas will be cleaned up to meet industrial land-use requirements. Uranium is used as an indicator contaminant and soils with concentrations greater than 350 picocuries/gram in the top 15 feet are removed to reduce the risk potential from the direct exposure pathway. The baseline strategy for soil sites is to excavate the top 15 feet of contaminated soil and ship to on site disposal facilities. If contamination extends beyond 15 feet, soil contaminant concentrations and/or mobility must be low enough to prevent future groundwater problems. If concentrations exceed these levels, additional remedial measures (removal, containment or treatment) may be required. In situ treatment technologies may be required if soil contamination extends beyond the 15 feet to depths where excavation costs become prohibitive.

The 100 Area has over 340 contaminated soil sites that are expected to require remediation. Soil waste disposal units including cribs, french drains, trenches, ponds, and retention basins received radiologically and chemically contaminated liquid effluent from reactor and support operations. These areas will be cleaned up to meet residential land-use requirements. The baseline strategy for soil sites is to excavate the top 15 feet of contaminated soil and ship to on site disposal facilities. If contamination extends beyond 15 feet, soil contaminant concentrations and/or mobility must be low enough to prevent future groundwater problems. The main radioactive contaminants of concern in the deep zone are strontium-90, cobalt-60, cesium-137, and nickel63. If concentrations exceed these levels, additional remedial measures (removal, containment or treatment) may be required. In situ treatment technologies may be required if soil contamination extends beyond the 15 feet to depths where excavation costs become prohibitive. 
The 200 Area contains approximately 1000 different soil and burial ground sites. Soil waste sites were predominantly the result of liquid discharge to cribs, ponds and ditches. This area is located furthest from the Columbia River and is scheduled for remediation after the 300 and 100 Areas. This area will probably have an industrial future land use designation. The 200 Area remediation includes a combination of removal and leave in-place with in situ treatment and/or surface barrier placement strategies. The target/indicator contaminants will be developed for the 200 Area as part of the characterization activities. Excavation strategies will generally be similar to the other areas but the depth and target/indicator contaminants have not been identified. However, plutonium, uranium, cesium, cobalt, strontium, and technetium are all likely to be the key indicator contaminants for many of the contaminated sites. In situ technologies that are more cost effective than the baseline excavation/disposal costs $(\$ 60 /$ ton $)$ are needed to treat surface soils. Other potential concerns in the 200 Area include contamination (primarily uranium and technetium) that has migrated deep into the vadose zone ( $>150 \mathrm{ft}$ ) at concentrations that can impact groundwater, and near surface hot spots that prevent the sole use of surface barriers due to inadvertent intruder scenarios. In situ treatment technologies that can treat contamination at depth or treat hot spots to reduce health risks associated with intruder scenarios are required. In situ stabilization of TRU may be required prior to capping some waste sites in the 200 area. In situ vitrification is the current technique under consideration for TRU stabilization.

Potential Life-Cycle Cost Savings of Need (in S000s) and Cost Savings Explanation: The estimated life-cycle cost savings associated with filling this need is $\$ 4 \mathrm{M}$. This estimate is based on an assumed savings of $0.1 \%$ of the total 200 Area cost of $\$ 2.8 \mathrm{~B}$ plus $0.1 \%$ of the total 100 Area cost of $\$ 900 \mathrm{M}$.

Benefit to the Project Baseline of Filling Need: Use of in situ technologies may enable remediation approaches that could save cost and schedule for the project baseline.

Functional Performance Requirements: Reduce concentrations or mobility of radioactive contaminants to the point that remediation goals are met. The following remediation goals for contamination deeper than $15 \mathrm{ft}$ can be found in the Remedial Design Report/Remedial Action Work Plan for the 100 Area (DOE/RL-96-17 rev. 2): U-233/234, $1.1 \mathrm{pCi} / \mathrm{g}$; U-235, $1.0 \mathrm{pCi} / \mathrm{g}$; U238, $1.1 \mathrm{pCi} / \mathrm{g} ; \mathrm{Pu}-238,1,123 \mathrm{pCi} / \mathrm{g} ; \mathrm{Pu}-239 / 240,718,600 \mathrm{pCi} / \mathrm{g} ; \mathrm{Sr}-90,4.5 \mathrm{pCi} / \mathrm{g}$ and Tc-99, 15 $\mathrm{pCi} / \mathrm{g}$. The 200 Area sites do not currently have specific remediation goals, but contaminants of concern include isotopes of uranium, plutonium, cesium, cobalt, strontium, and technetium. Some remediation goals in the 200 Area will likely be linked to a concentration that is protective of groundwater. Treatment requirements for TRU prior to surface capping have not yet been established.

Work Breakdown

Structure (WBS) No:: 1.4.10.1.1.01.01 TIP No.: N/A

1.4 .10 .1 .1 .02 .05

1.4.10.1.1.02.07

Relevant PBS Milestone: PBS-MC-026, PBS-MC-027, M-16-00 


\section{Justification For Need:}

Technical: In situ technologies increase treatment flexibility and have the potential to help shorten remediation time periods and reduce costs.

Regulatory: Soil concentrations currently exceed preliminary remediation goals as defined in various RODs.

Environmental Safety \& Health: The contaminants pose a potential risk to human health and the environment. Remediation by conventional methods such as excavation may result in exposure to workers. There is also the potential for offsite releases during soil handling operations.

Cultural/Stakeholder Concerns: High exposures to remediation workers and potential for off-site releases are a concern. Stakeholders are'sensitive to introduction of chemicals into the vadose zone to accomplish in situ remediation.

Other: None.

Current Baseline Technology: Excavate and dispose.

Cost: Estimated cost to excavate and dispose is $\$ 60 /$ ton.

Waste: Excavated soil would be disposed in on site disposal facilities.

How Long It Will Take: Soil remediation activities in the 100 and 300 Areas are planned for the next ten years. Soil activities in the 200 Area are scheduled to continue until 2018.

End-User: Richland Environmental Restoration Project

Site Technical Points-of-Contact: Scott W. Petersen, BHI, (509) 372-9126; John April, BHI, (509) 372-9632; Curt Wittreich, (509) 372-9586; Ashur R. Michael, BHI, (509) 372-9074; Michael J. Truex, PNNL, (509) 375-2636

Contractor Facility/Project Manager: V. R. (Vern) Dronen (100 and 300 Areas), BHI, (509) 372-9075; Michael J. Graham (200 Area), BHI (509) 372-9179

DOE End-User/Representative Points-of-Contact: Arlene C. Tortoso DOE, (509) 373-9631; Bryan L. Foley, DOE, (509) 376-7087; Robert G. Mcleod, DOE, (509) 372-0096; Glenn I. Goldberg, DOE, (509) 376-9552; Owen Robertson, DOE, (509) 373-6295 


\title{
Evaluation of Remediation Technologies for Plutonium Contaminated Soils at the Nevada Test Site (NTS)
}

\author{
Cooperative Agreement \#DE-FC26-00NT40841
}

\author{
Volume IV
}

\section{Survey of Vendor Capabilities and Vendor Selection Process}




\section{Survey of Vendor Capabilities and Vendor Selection Process}

Potential vendors were identified through 1) review of vendors involved in previous studies, 2) input from other project participants, 3) library and internet search, 4) CETL previous experience with vendors, 5) CETL prior technology evaluations, 6) attendance of WM'01 Symposium, 7) poster presentation at SCFA midyear review, 8) attendance of ER Tech '01 and other miscellaneous avenues. A summary of the potential vendors is provided in the Appendix A. Many of the vendors that were involved in earlier studies were no longer in business, or had merged with other companies. The survey indicated that the pool of qualified vendors is fairly dynamic and routinely changes.

A vendor Request for Qualifications (Appendix B) was issued September 11, 2001 and closed on September 24, 2001. The solicitation was advertised by:

Posting detailed information on CETL web site.

Direct Contact with vendors on the list developed by CETL

Sent e-mail to attendees list: WM01 and Incinerator Conference

Ran advertisement in the South Carolina State paper

As a result of the direct contacts:

- 35 vendors were identified and contacted

- 26 expressed an interest in the solicitation

- $\quad$ About a dozen attended the soils remediation workshop (see Volume 3)

- 9 vendors responded to the Request for Qualifications.

The responses were reviewed and, according to CETL's review, three of the submittals met the RFQ criteria. These are IT Corp (bioremediation), Earthline Technolgies (physical/chemical soil washing) and URS Corp. (flotation). A summary of the vendor responses to the RFQ questions and the basis for vendor selection/qualification was e-mailed to our group for their review and concurrence. All were in agreement with the recommended selections.

Awards were issued and bench scale studies were begun in early 2002 .

1 
Appendix A - Summary of Vendors and Their Capabilities 


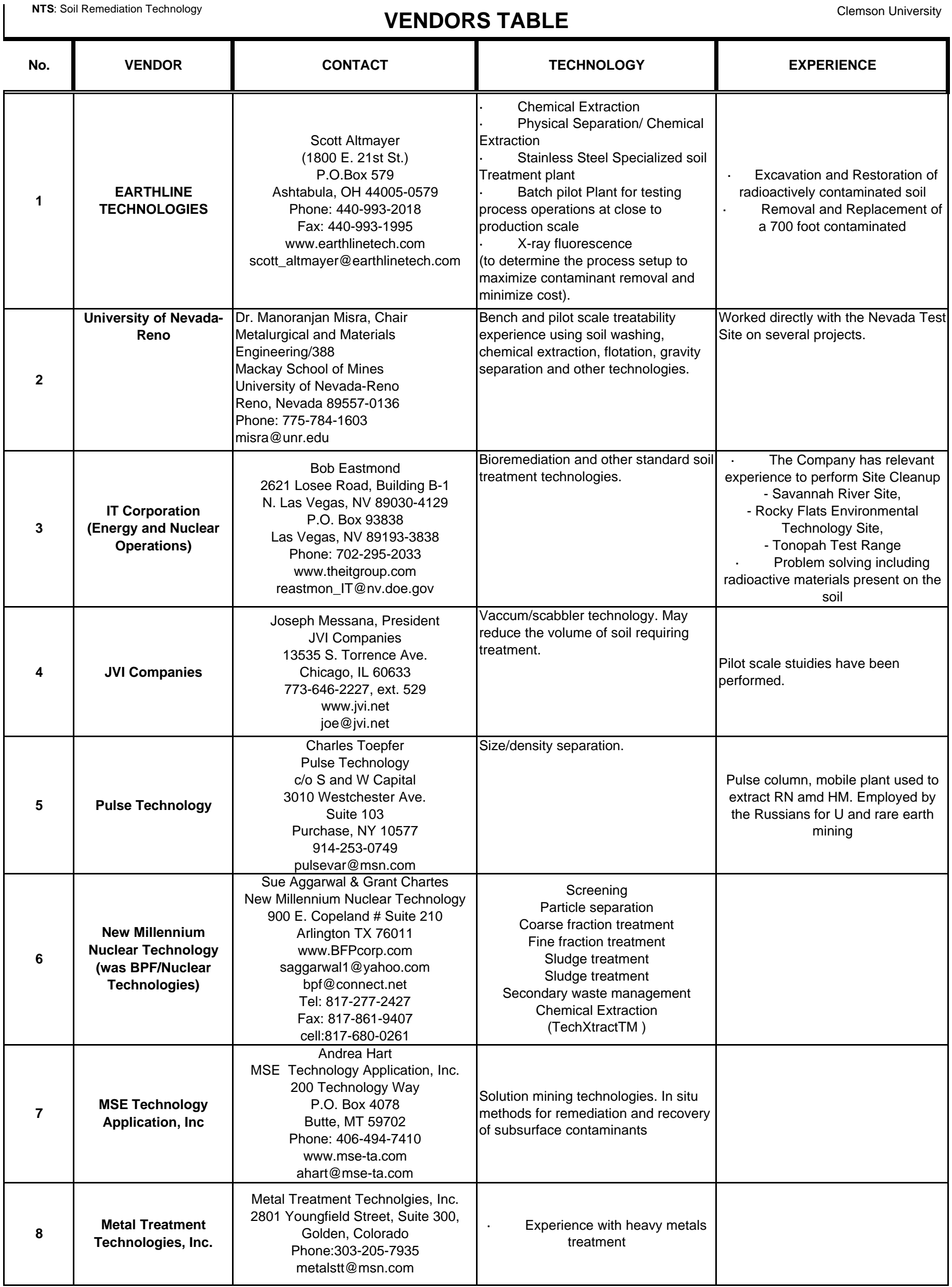




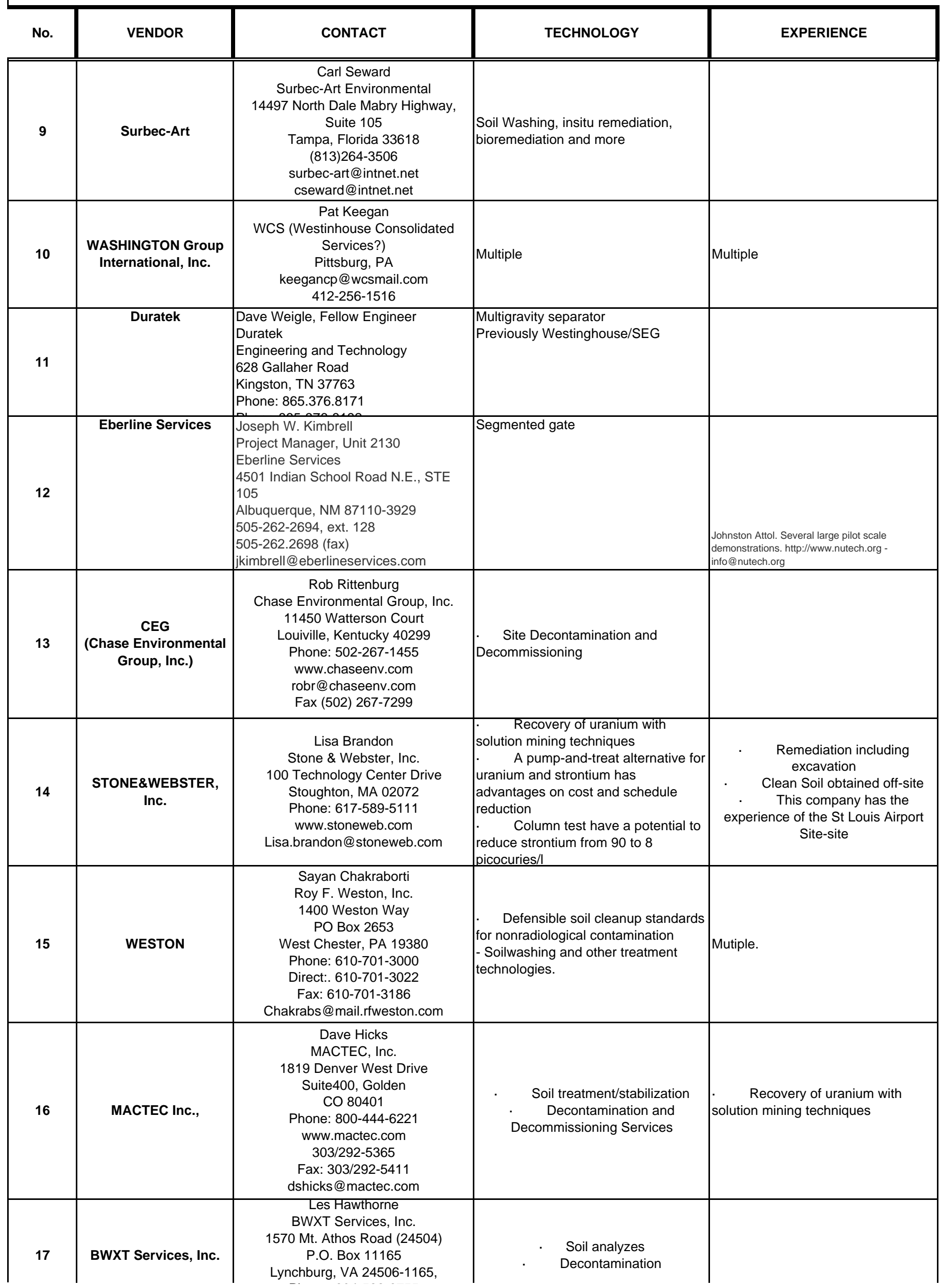




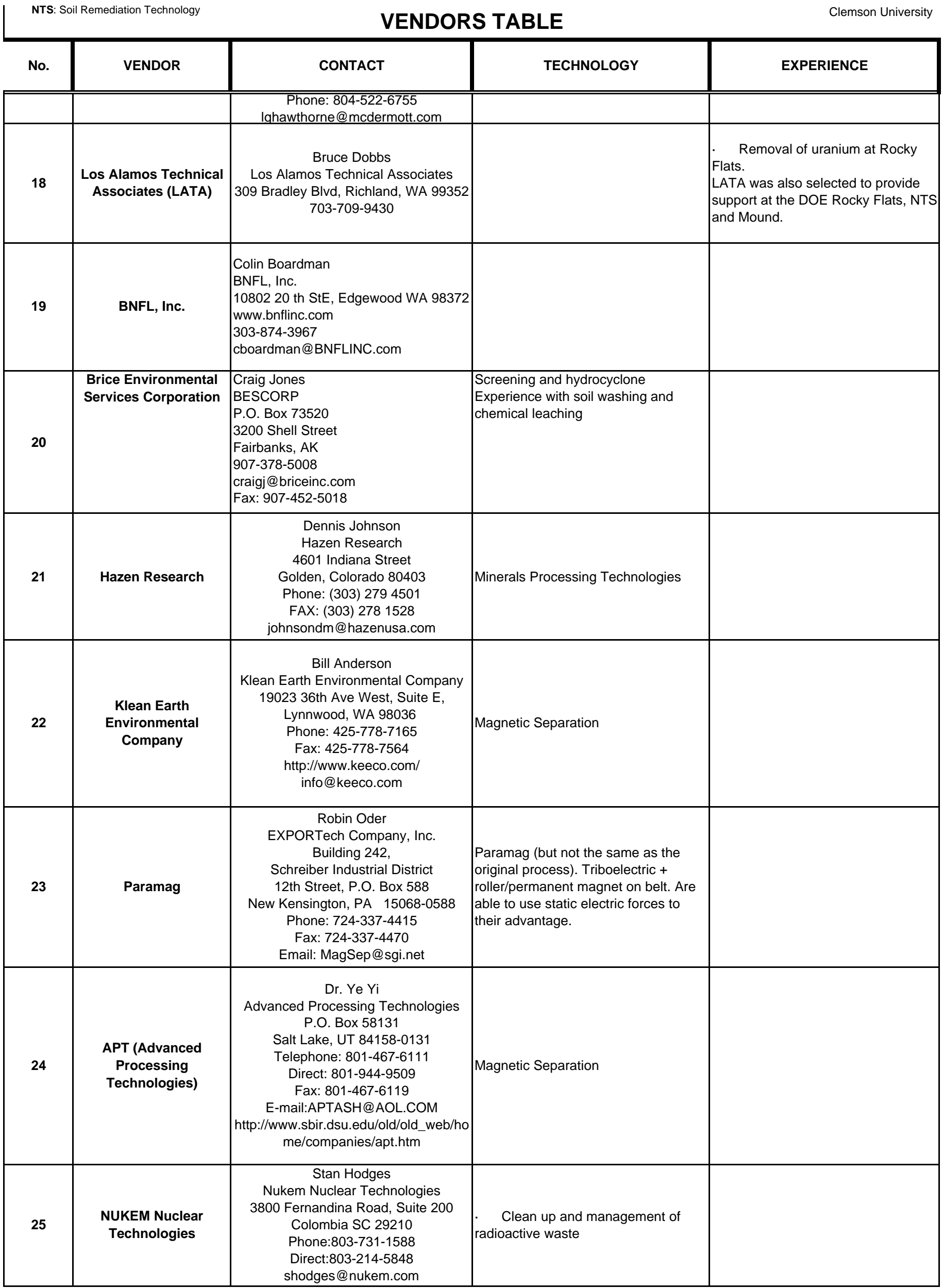




\begin{tabular}{|c|c|c|c|c|}
\hline No. & VENDOR & CONTACT & TECHNOLOGY & EXPERIENCE \\
\hline 26 & $\begin{array}{c}\text { Environmental } \\
\text { Chemical Corporation }\end{array}$ & $\begin{array}{l}\text { Bob MacDonald } \\
\text { Mitch Clark } \\
\text { Environmental Chemical Corporation } \\
\text { Corporate Headquarters } \\
1240 \text { Bayshore Highway } \\
\text { Burlingame, California } 94010 \\
\text { (650) 347-1555, ext. 315 } \\
\text { http://www.ecc.net/ } \\
\text { mclark@ecc.net } \\
\text { rmacdon@ecc.net }\end{array}$ & $\begin{array}{l}\text { Thermal Drying and Gas Cyclone } \\
\text { Very large company }\end{array}$ & \\
\hline 27 & COGNIS & $\begin{array}{c}\text { Bill Fristad } \\
\text { Parker Amchem } \\
\text { 32100 Stephenson Hwy } \\
\text { Madison Heights, Ml } 48071 \\
\text { 248-588-4719 } \\
\text { Fax: } 248-583-2976 \\
\end{array}$ & & \\
\hline 29 & $\begin{array}{l}\text { Jacobs Engineering } \\
\text { Group }\end{array}$ & $\begin{array}{l}1880 \text { Waycross Road } \\
\text { Cincinnati, OH } 45240 \\
\text { Phone: } 513-595-7745 \\
\text { Charles.rives@jacobs.com }\end{array}$ & $\begin{array}{c}\text { Environmental remediation } \\
\text { Environmental clean up }\end{array}$ & \\
\hline
\end{tabular}




\section{Appendix B - Request for Qualifications}




\section{Description: \\ Bench-Scale Demonstration of Treatment Technologies Volume Reduction of Plutonium-Contaminated Soil}

\section{REQUEST FOR QUALIFICATIONS}

This document is a Request for Qualification (RFQ) to prospective offerors interested in an opportunity to submit a proposal for the services described herein. This information is also posted under "Advertised Bids" on the Clemson University Procurement Office web site at www.clemson.edu/procurement.

Prospective offerors who are interested in the work may apply for consideration by responding to the information requested in Part V of this RFQ. A brief description of the services to be solicited by the resulting Request for Proposal (RFP) or Request for Sealed Bid and the general scope of work are contained herein.

Information must be received by:

The Clemson University Procurement Office

Administrative Services Building

Perimeter Road

Clemson, SC 29634.

No later than 4:00 pm local time, September 24, 2001. After that date and time further prospective offeror's information may not be accepted.

This RFQ does not commit Clemson University (CU) or the Clemson Environmental Technologies Laboratory (CETL) to issue a Request for Proposals, to pay any costs incurred in the preparation of the prospective offeror's responses, or to procure or contract for the services described herein. CU and CETL reserve the right to accept or reject any offeror's qualifications or the subsequent Request for Proposal or Sealed Bid if it is in the best interest of CU or CETL to do so. 


\section{PART I \\ GENERAL INFORMATION AND INSTRUCTIONS}

A. The Clemson Environmental Technologies Laboratory intends to solicit proposals or sealed bids from qualified prospective offerors to provide bench-scale demonstration of technologies to reduce the volume of soil contaminated with plutonium.

B. By submission of a response to this Request for Qualifications, prospective offerors are applying for consideration to receive a Request for Proposal or a Request for Sealed Bid for the services described herein.

C. Prospective offerors responding to the Request for Qualifications will be evaluated based on the information provided. All submittals will be considered in accordance with Section 11-35-1530(4), Request for Qualifications of the South Carolina Procurement Code. Depending on the number and type of offerors that qualify, the solicitation will be either a sealed bid or a Request for Proposal. Up to four (4) offerors will be selected for demonstration of their bench-scale technology. The failure of a prospective offeror to be selected to receive the Request for Proposal or Request for a Sealed Bid shall not be grounds for protest under section 11-35-4210.

D. Prospective offerors are to include all information as requested herein. All pages should be returned with your response and in the format specified. Prospective offerors must submit only that information which is specifically addressed in this Request for Qualifications.

E. Offeror's response should follow the listing of Requested Information in Part V. Offerors must supply the requested information listed and explain their responses with enough detail to allow for a thorough evaluation. All pages of the response should be numbered.

F. The Clemson University Procurement Office will receive RFQ's until 4:00 p.m., local time on the opening date shown. Responses after this date may or may not be accepted. Responses submitted via facsimile are not acceptable.

G. ONE ORIGINAL AND TWO (2) COPIES OF YOUR RESPONSE ARE REQUIRED.

\section{PART II}

\section{SCOPE OF QUALIFICATIONS}

The Clemson Environmental Technologies Laboratory will accept potential offeror's qualifications for provide bench-scale demonstration of technologies to reduce the volume of soil contaminated with plutonium. Potential offerors must provide all requested information in Part V. 


\section{PART III INTRODUCTION AND BACKGROUND}

Soils contaminated with radionuclides are an environmental concern at most Department of Energy (DOE) sites. Clean up efforts at many of these sites are ongoing using conventional remediation techniques. These remediation techniques are often expensive and may not achieve desired soil volume reduction. Several studies using alternative remediation techniques have been performed on plutonium-contaminated soils from the Nevada Test Site. Results to date exhibit less than encouraging results, but these processes were often not fully optimized, and other approaches are possible.

Clemson University and teaming partner Waste Policy Institute, through a cooperative agreement with the National Environmental Technologies Laboratory, are assisting the Nevada Test Site (NTS) in re-evaluating technologies that have the potential of reducing the volume of plutonium contaminated soil. This effort includes, in part, bench scale demonstration of applicable offeror technologies at the Clemson Environmental Technologies Laboratory. These studies performed at the CETL will provide an independent evaluation of offeror's technologies. It is anticipated the subsequent pilot-scale phase demonstration will require prior successful demonstration on NTS soils or similar.

\section{PART IV SCOPE OF WORK}

Clemson Environmental Technologies Laboratory (CETL) is seeking contractors that are interested in demonstrating their ability to treat plutonium-contaminated soil obtained from the Nevada Test Site (NTS). Offeror bench-scale demonstrations will be conducted at the CETL. A possible exception is technologies, which use improved soil removal techniques. CETL reserves the right to have these technologies, if selected, demonstrated at the Nevada Test Site on clean soils, if deemed appropriate. The purpose of these studies is to demonstrate the ability to reduce the volume of contaminated soil. In particular, offerors will be asked to demonstrate their ability to obtain a clean soil plutonium concentration of less than $200 \mathrm{pCi} / \mathrm{g}$ (lower is better since a clean up limit has not yet been established). At the NTS, the contaminant concentration ranges from approximately $200 \mathrm{pCi} / \mathrm{g}$ to $12,800 \mathrm{pCi} / \mathrm{g}$ (these are typical ranges, but values below 200 and above $12,800 \mathrm{pCi} / \mathrm{g}$ are possible). Preliminary estimates are that the soil to be treated in these bench scale studies will have an activity of around $1200 \mathrm{pCi} / \mathrm{g}$. Technologies must have the potential to be less costly than the baseline technology (see below). Reasonable Offeror travel, mobilization and shipping expenses will be paid by CETL (up to a maximum of $\$ 15,000$ ). CETL will provide radiation safety and utility support. Additional details can be found at www.cetl.org/nts. 


\section{Baseline Technology}

The baseline technology with which these technologies are competing consists of the following:

Perform characterization and assessment involving soil sampling and radiological surveys

Remove topsoil using grader

Pick up soil using scraper, and transport to processing area

Screen and assay soil using transportable belt detector system

Load soil into side-dump trailers lined with "burrito wraps"

Haul soil to the NTS, and dispose of at the Area 3 Radioactive Waste

Management Site

Ideally the DOE would like to be able to remediate soil sites to meet regulatory requirements at a cost that is significantly less than the known baseline cost (estimated to be $\$ 18 / \mathrm{ft}^{3}$ or less ${ }^{*}$ ), with no significant adverse environmental, safety or health impacts from deploying the innovative technology.

\section{ESTIMATED COSTS FOR BASELINE TECHNOLOGY, THOUSANDS OF DOLLARS}

Field Work Preparation (e.g.. field planning) $\$ 130$

Field Work (e.g. mobilization, site prep, infrastructure, logistics, demob) Waste Characterization (e.g. belt detector system, data collection) Excavation (e.g. road grader forming windrows, picking up with paddlewheel scraper)

Packaging for Disposal (e.g. material handling, burrito wraps, loading into trucks)

Transportation (e.g. hauling to NTS for disposal)

Disposal (e.g. disposal fee)

TOTAL OF ABOVE

\section{PART V}

\section{REQUESTED INFORMATION}

Prospective offerors will be evaluated and ranked based solely on the information submitted in their response to this Request for Qualifications. Prospective offerors must only submit information on their qualifications, experience, and ability to perform the requirements of this prospective contract. Any additional information WILL NOT be considered.

\footnotetext{
* ESTIMATED field costs for remediating the Clean Slate 3 site. The costs were taken from the Environmental Restoration Baseline document dated May 2000. These are just the field costs, and exclude planning, document preparation, engineering, etc. The estimated soil volume at this site is $1,200,000$ cubic feet. All costs are in $\$ 1000$.
} 
For the bench scale studies to be of interest to the Nevada Test Site, the corresponding full-scale process should meet the Desired Performance Criteria (posted at www.cetl.org/nts). The Desired Performance Criteria were used to develop the following pre-qualification criteria. To ensure that all qualifications are evaluated on the same basis, please address the following items. Provide as much detail as necessary to support your response:

1. Does your technology have the potential to treat plutonium-contaminated soils at less than the baseline cost?

2. Does your technology produce any hazardous, mixed or TRU waste?

3. Can your technology be demonstrated on a small scale using kilogram or less amounts of soil? (Improved soil removal techniques excluded, as detailed in the Desired Performance Criteria).

4. Can your demonstration be performed in a nominal 2 weeks?

5. Will your company perform this demonstration for compensation from CETL of $<=\$ 15,000$ ?

6. Does your technology have the potential to result in a $70 \%$ or greater volume reduction of contaminated soil (assume $1000 \mathrm{pCi} / \mathrm{g}$, target of 200 $\mathrm{pCi} / \mathrm{g}$ ?

7. Does your technology address the fact that a) the plutonium contamination distribution as a function of particle size varies from soil to soil, b) plutonium is present in at least two forms, and has been weathered: plutonium dioxide and fused plutonium silicate?

8. Do you or your teams have pilot and full-scale treatment capability?

9. If selected for full-scale treatment, do you or your teams have the capacity to meet the 2007 remediation deadline?

10. Does your technology minimize the generation of secondary waste? 


\title{
Evaluation of Remediation Technologies for Plutonium Contaminated Soils at the Nevada Test Site (NTS)
}

\section{Cooperative Agreement \#DE-FC26-00NT40841}

\author{
Volume V
}

Vendor Studies and Evaluation and Ranking 


\section{TABLE OF CONTENTS}

$\underline{\text { Section }}$

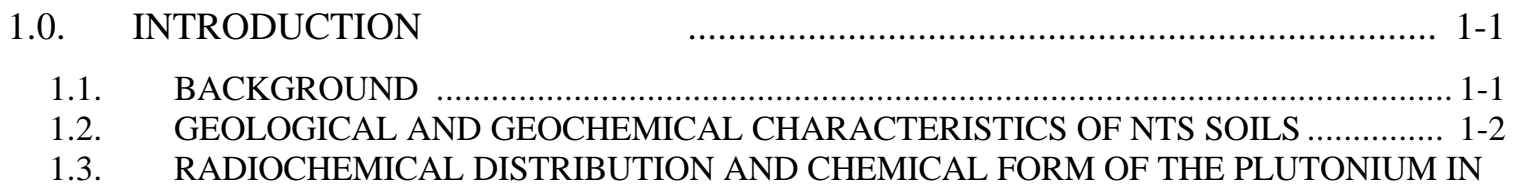

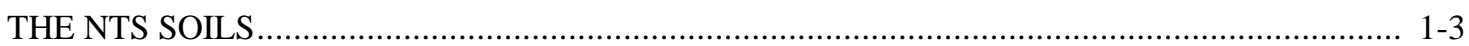

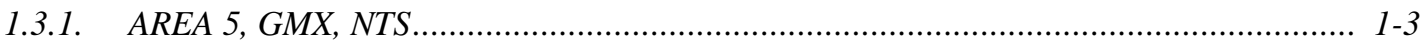

1.3.2. AREA 11, PLUTONIUM VALLEY, NTS .......................................................... 1 -3

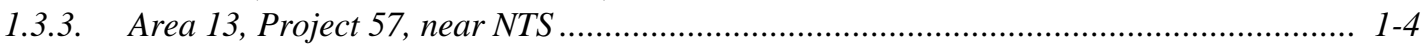

1.3.4. Area 52, Clean Slate I, II and III, Double Tracks.................................................. 1-4

1.4. STATEMENT OF PROBLEM AND GOALS …….................................................. 1-5

1.5. PREVIOUS WORK PERFORMED TO SUPPORT TECHNOLOGY SELECTION ............ 1-5

1.6. CURRENT WORK PERFORMED TO SUPPORT TECHNOLOGY SELECTION ............. 1-5

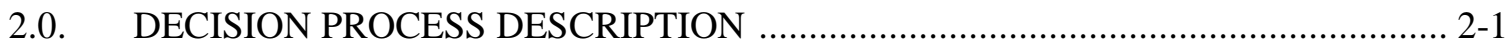

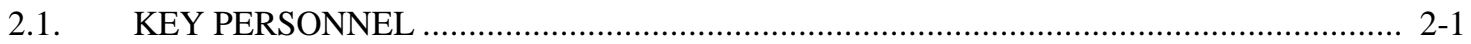

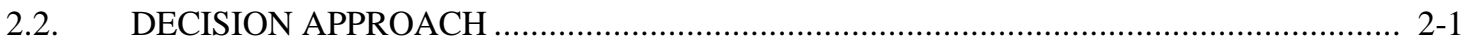

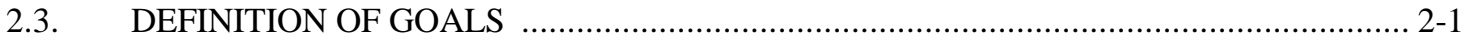

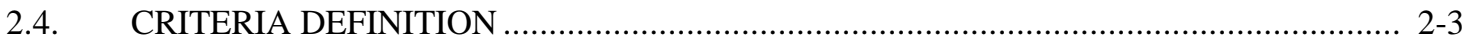

3.0. VENDOR TESTING - RESULTS AND INDEPENTENT EVALUATION .............. 3-1

3.1. BIOREMEDIATION TEST SUMMARY AND RESULTS …......................................... 3-1

3.2. SOIL WASHING TEST SUMMARY AND RESULTS ............................................. 3-2

3.3. HIGH CAPACITY FLOTATION TEST SUMMARY AND RESULTS ........................... 3-3

4.0. ANALYSIS

4.1. SCOPE OF THE DECISION ANALYSIS .................................................................. 4-1

4.2. GOALS OF THE PLUTONIUM IN SOILS VOLUME REDUCTION STUDY ................ 4-1

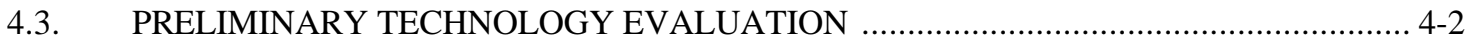

4.3.1. Goal 1: Minimize DOE Project Cost …................................................................... 4-3

4.3.2. Goal 2: Minimize DOE Custodial Responsibilities..................................................... 4-10

4.3.3. Goal 3: Minimize the Risks of Transportation Accidents........................................... 4-10

4.3.4. Goal 4: Minimize the Potential for Uptake Exposure of Workers ................................ 4-11

4.3.5. Goal 5: Maximize Implementation Confidence ……................................................ 4-12

4.3.6. Goal 6: Minimize Impact on Air Force Operations ..................................................... 4-13

5.0. COST BENEFIT ANALYSIS ................................................................................ $5-1$

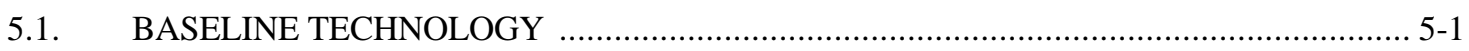

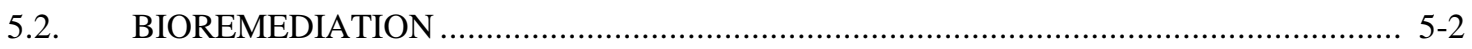

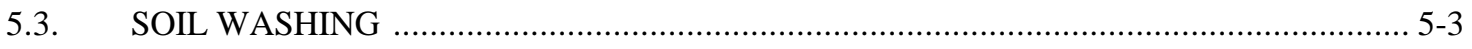

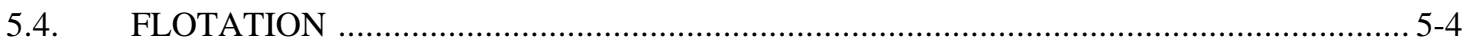

5-5 HIGH CAPACITY FLOTATION COST PROJECTION .................................................... 5-6

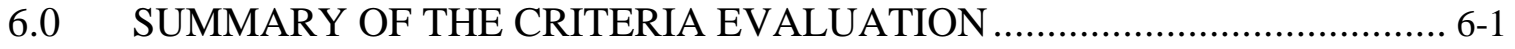

7.0. CONCLUSIONS AND RECOMMENDATIONS …........................................... 7-1

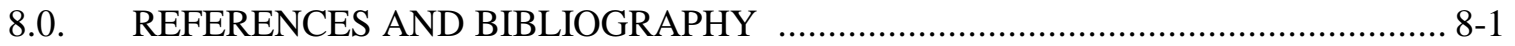

i

Volume V Vendor Studies Evaluation and Ranking

Cooperative Agreement \#DE-FC26-00NT40841

October 13, 2003 
Appendices

Appendix A. Vendor Technology Treatability Study Scoring

Appendix B. Cost Estimate Details

ii 


\subsection{INTRODUCTION}

Soils contaminated with radionuclides are an environmental concern at most U.S. Department of Energy sites. Remediation actions are on going at many sites, and plans for cleanup are underway at other sites, such as the Nevada Test Site (NTS). The NTS possesses widespread soil contamination caused by deposition of plutonium and other radionuclides from defense related nuclear test operations.

Clemson University and teaming partner Waste Policy Institute, through a cooperative agreement with the National Environmental Technologies Lab in Morgantown, West Virginia, are assisting the National Nuclear Security Administration Nevada Site Office (NNSA/NSO) in evaluating possible technologies that have the potential of reducing risks and clean-up cost.

\subsection{BACKGROUND}

In December of 1950 President Harry Truman established the NTS as the continental test site for research and development of nuclear weapons ${ }^{1}$. The site is located in the south central portion of Nevada and has been used by the Atomic Energy Commission and the Department of Energy (DOE) for 982 of the 1100 nuclear weapons tests conducted since World War $\mathrm{II}^{2}$. The site was chosen for nuclear testing because of the remoteness and climatology of the site ${ }^{1}$. From 1951 until the establishment of the Limited Test Ban Treaty in 1963, many atmospheric, tower, nuclear rocket, borehole, and underground tests were conducted at the $\mathrm{NTS}^{3}$.

The series of tests pertinent to this project are known as "Safety Shots" or "Safety Tests." Safety Tests were conducted between 1954 and 1963. The purpose of the tests was to investigate and evaluate the safety of nuclear weapon designs ${ }^{4}$. The sub-critical tests, which used depleted uranium $(\mathrm{U})$ and plutonium $(\mathrm{Pu})$ as tracer material, were conducted to investigate the physical and chemical reaction of plutonium materials when subjected to detonations of conventional chemical explosions in accidental or terrorist scenarios. An example of this kind of testing is the detonation of explosives on an open concrete pad or in an enclosed simulated storage facility. The Safety Tests were performed at several sites at the NTS as well as at the Nellis Air Force Range and the Tonopah Test Range (TTR) ${ }^{4}$.

The Department of Energy conducted safety shots at several locations on the Nellis Air Force Range, TTR (Double Tracks; Clean Slates 1, 2, and 3; and Area 13); at Plutonium Valley in Area 11 of the NTS; and the GMX site in Area 5 of the NTS. The safety tests did not result in significant nuclear yield, but did disperse contaminants in excess of 40 picocuries per gram in surficial soils over more than 1,200 hectares $(3,000 \text { acres })^{\mathbf{5}}$. Detailed information on the extent of contamination is provided in a recent Cost/Risk/Benefit analysis ${ }^{6}$.

$1-1$

Volume V Vendor Studies Evaluation and Ranking 
For the purpose of this study, the following sites have been targeted for remediation:

- Project 57 (Area 13, slightly outside the Northeast corner of the NTS)

- Clean Slates II (Area 52, TTR)

- Clean Slates III (Area 52, TTR)

- Small Boy

\subsection{GEOLOGICAL AND GEOCHEMICAL CHARACTERISTICS OF NTS SOILS}

Soils for the region are classified as sands, loamy sands or sandy clay loams ${ }^{7}$. Plutonium and its daughter isotopes, primarily americium, were dispersed from the source of detonations in a widening plume dependent on prevailing environmental conditions at the time of the test shots. Fine plutonium particles became airborne and were either transported off-site by the wind currents or were deposited downwind of the point of detonation as a result of fusing with silica particles. Over the years, the plutonium became integrated with the gravel, sand and silt particles at the site and with varying degrees of cementation caused by environmental weathering, the plutonium became incorporated into the surface hardpan typical of such arid areas. The bulk of the activity typically resides within the top few centimeters of the soil. The plutonium particles have become relatively immobile over the past 30 years and will remain so until disturbed ${ }^{3}$. Contaminant concentrations range from 200 to 12,800 picocuries per gram (pCi/g) over the 3,000 acres of land ${ }^{3}$.

The surface chemistry and physical properties of radionuclides are significantly different from that of the host soil. For example, the density, magnetic susceptibility, surface wetability and electrical charge of certain transuranic elements are markedly different from that of quartz, clay and other minor constituents ${ }^{8}$.

Area 11 Soils - Scanning Electron Microscope/Energy Dispersive X-ray Spectroscopy (SEM/EDX) indicates that fine clay and silt attach to relatively large particles and agglomeration of fine clays is also observed. This information, along with the wet screening results, suggests that the soil pretreatment steps are necessary to disintegrate the lumped particles for effective separation. SEM and petrographic analyses have shown that the major mineralogical constituents of the soil are clay, quartz, magnetite, titanomagnetite and limestone. The mineralogical analysis of the coarse size NTS soil indicates the presence of magnetite, sanidine, titanomagnetite and biotite. The fine fraction contains clay, quartz and feldspar.

$1-2$

Volume V Vendor Studies Evaluation and Ranking 


\subsection{RADIOCHEMICAL DISTRIBUTION AND CHEMICAL FORM OF THE PLUTONIUM IN THE NTS SOILS}

\subsubsection{AREA 5, GMX, NTS}

No information is available on this area. The assumption is that the soil would be similar to other nearby areas.

\subsubsection{AREA 11, PLUTONIUM VALLEY, NTS}

A study was performed by Misra on an Area 11 soil from the NTS ${ }^{8}$. More than $75 \%$ of the total radionuclides are dispersed in the minus 40-micron size soil fractions ${ }^{9}$. Thirtyone percent (weight) of soil is minus 20 microns, $95 \%$ is minus 125 microns. The radionuclides are present as particles and/or are partially attached to clay particles. In some instances radionuclides are bonded to magnetite (which is magnetic) and clay particles $^{8}$.

In a study performed by Lockheed Environmental Systems and Technologies (LESAT), only about $45 \%$ of the total curie activity was contained in the soil smaller than 20 microns (soil was wet sieved) ${ }^{7}$. This increases to just under $60 \%$ for soil that is smaller than 75 microns. In comparing these results to those in the previous paragraph, some variability in plutonium distribution as a function of particle size is indicated for Area 11 soils. Photo-optical microscopy and scanning electron microscope analyses indicated the presence of discrete, agglomerated, fused and mixed matrix soil particles.

Work by Murarik ${ }^{10}$ has shown that the activity of plutonium increased in the wet size fractions as compared to the dry size fraction. This may indicate that the transuranics are finely dispersed and loosely bound to clay particles. In such instances it should be easy to separate much of the plutonium from the soil using pretreatment techniques.

In another study by Misra ${ }^{11}$, particle size and activity distributions were determined for an Area 11 soil and for a Clean Slate I soil. This Area 11 soil appears to be significantly different from the first Area 11 soil mentioned above. In general the data indicate a courser soil. As might be expected, the percent of fine material increases when the soil is wet sieved. Only about $10 \%$ of the soil is minus 150 microns. The minus 150 -micron fraction contains less than $20 \%$ of the total plutonium when dry sieved and nearly $70 \%$ when wet sieved. Similar to the above soil, the highest concentrations of plutonium occur in the smaller sized fractions.

The limited data indicate that the size distribution and plutonium distribution may vary significantly for Area 11 soils. Available data for the Area 11 soils show increasing plutonium activity with decreasing particle size. This may or may not be the case for other Area 11 soils, as the following data for some other Area soils indicates significant variability within a given Area.

$1-3$

Volume V Vendor Studies Evaluation and Ranking 


\subsubsection{Area 13, Project 57, near NTS}

A limited amount of data is available for the Area 13 soils $^{9}$. Most of the plutonium contamination was associated with smaller particles $(<40 \mathrm{~mm})$. These data suggest that even in soils with very low average plutonium activity, such as the soil of Area 13, specific activities in smaller size fractions may be orders of magnitude higher ${ }^{9}$.

\subsubsection{Area 52, Clean Slate I, II and III, Double Tracks}

In contrast to Area 11 and 13 soils, almost all the plutonium activity was found in medium size fractions ( $83 \%$ of the soil mass was between 75 and 250 microns) for an Area 52 soil (see Misra ${ }^{9}$, source of the soil was not more specifically identified). It is possible that the mineralogy of the area in combination with the specific history of the plutonium test and nuclear devices used in area 52 resulted in association of the plutonium with a coarser size fraction (larger than $125 \mathrm{um}$ ). The shot in Area 52 was exploded in a bunker, whereas the shots in areas 11 and 13 were above ground detonations. This may explain why plutonium in area 52 was deposited as a fused plutonium-silicate, whereas in areas 11 and 13 it was deposited as a plutonium oxide ${ }^{9}$.

In another study by Misra ${ }^{11}$, particle size and activity distributions were determined for a Clean Slate I soil. The percent of fine material increases slightly when the soil is wet sieved. The highest concentrations of plutonium occur in the mid-sized fraction (300-850 microns).

An extensive amount of soil characterization work was done by University of NevadaReno and by the IT Corporation in support of pilot-scale demonstrations for soils from Double Tracks, Clean Slate I, Clean Slate II and Clean Slate III ${ }^{12}$.

Clean Slate II - The amount of soil passing a particular sieve size varies up to around $20 \%$. This indicates very large differences in the plutonium distribution. As a result, the amount of plutonium that can be removed by size separation is going to vary significantly for Clean Slate II soils. The soil size fraction containing the highest concentration of plutonium varies significantly from soil to soil, ranging from 74-295 microns to 9-13 microns. The data clearly show the variability in soil mass distribution, plutonium mass distribution and plutonium specific activity as a function of particle size.

Clean Slate III - The amount of soil passing a particular sieve size varies around $25-30 \%$. This indicates very large differences in the plutonium distribution. As a result, the amount of plutonium that can be removed by size separation is going to vary significantly for Clean Slate III soils. The soil size fraction containing the highest concentration of plutonium varies significantly from soil to soil, ranging from $>4700$ microns to $9-13$ microns. The data clearly show the variability in soil mass distribution, plutonium mass distribution and plutonium specific activity as a function of particle size.

$1-4$

Volume V Vendor Studies Evaluation and Ranking 


\subsection{STATEMENT OF PROBLEM AND GOALS}

Several areas of the Nevada Test Site (NTS) contain fine particles of plutonium in the surface soils. Safety tests, performed to demonstrate that detonations of conventional explosives would not initiate a chain reaction in a stockpile of nuclear weapons (thus the name, 'Safety Shots') dispersed the plutonium. This dispersed plutonium: (1) Constitutes some (minimal) risk to human health and the environment, (2) exceeds proposed regulation-based limits, and (3) ties DOE to long-term custodial responsibilities at these sites. Some of the safety shot sites (the "Double Track" and "Clean Slate" Sites) is under joint custody of DOE and the Air Force under an agreement with the original custodian, the Bureau of Land Management. This agreement establishes custodial responsibilities for DOE at these sites. DOE would like to clean-close these sites and eliminate this custodial responsibility.

DOE's baseline technology uses a standard road grader/scraper to skim the soils, a belt detector to characterize the soil, and a conveyor to load it into a truck. The truck bed is lined with a "burrito wrap" that encloses the soil to keep the truck bed clean and prevent air dispersal. The soil is then transported to a disposal facility at a distant location on the NTS. The baseline requires removal and transportation of a large amount of soil and will incur great cost.

\subsection{PREVIOUS WORK PERFORMED TO SUPPORT TECHNOLOGY SELECTION}

The desire to minimize the volume of soil that has to be transported and disposed has prompted assessment of technologies to reduce the overall volume of Pu-contaminated soils. The following sections summarize the work that has been performed to date.

The removal of Pu from NTS has been assessed using a wide variety of techniques and combinations of techniques including size segregation, attrition scrubbing, gravity-based separation, flotation, air flotation, segmented gate, bioremediation, magnetic separation, and vitrification. In addition, the volume of $\mathrm{Pu}$-contaminated soil that would be produced by remediation is related to the method of removal and processing. As an alternate to the baseline technology of removal with a conventional grader and loader, tools such as scabbler-type equipment (used in other cases to remove asbestos and radiological contamination) have been considered. Table 1-1 summarizes the methods considered and the status of their application to the NTS Pu-contaminated soils problem.

\subsection{CURRENT WORK PERFORMED TO SUPPORT TECHNOLOGY SELECTION}

Based on the results of this technology performance assessment, DOE, through the National Environmental Technology Laboratory and its supporting contractor, Clemson University, issued a call (in September 2001) for technologies to undergo additional laboratory testing. Potential vendors were identified through 1) review of vendors

$1-5$

Volume V Vendor Studies Evaluation and Ranking 
involved in previous studies, 2) input from other project participants, 3) library and internet search, 4) CETL previous experience with vendors, 5) CETL prior technology evaluations, 6) attendance of WM'01 Symposium, 7) poster presentation at SCFA midyear review, 8) attendance of ER Tech ' 01 and other miscellaneous avenues. The solicitation was advertised by posting detailed information on CETL web site, directly contacting vendors on the list developed by CETL, sending an e-mail to the attendees list of the WM01 and Incinerator Conference, and running an advertisement in the South Carolina State paper.

As a result of the direct contacts, 35 vendors were identified and contacted, 26 expressed an interest in the solicitation, and about a dozen attended the soils remediation workshop (see Volume 3). Because the funding for this testing was limited, offerors were requested to provide a proposal for testing for less than $\$ 15,000$.

Nine vendors responded to the Request for Qualifications. Table 1-2 summarizes the proposals received and the screening evaluation for implementation by the NETL team. The responses were reviewed and, according to CETL's review, three of the submittals met the RFQ criteria (see Volume 4). These are Earthline Technologies, Shaw (IT Corp), and URS Corp. Awards were issued and bench scale studies were begun in early 2002.

Sections 2.0 and 3.0 describe the test procedures and results for the Soil Washing, Bioremediation, and Floatation technologies proposed by Earthline, Shaw, and URS, respectively. 
Table 1-1. Summary of Treatment Methods and Technology Status.

\begin{tabular}{|c|c|}
\hline Technology Assessed & Status prior to CETL Studies \\
\hline $\begin{array}{l}\text { Attrition Scrubbing - scrubbing to break up } \\
\text { agglomerated materials or to remove coatings } \\
\text { from larger soil particles }\end{array}$ & $\begin{array}{l}\text { Potentially viable - attrition scrubbing shifts } \mathrm{Pu} \\
\text { activity toward the smaller sized particles, } \\
\text { allowing more of the large particles to be } \\
\text { removed as clean. But would have to be } \\
\text { coupled with another treatment method to meet } \\
\text { treatment goals }\end{array}$ \\
\hline $\begin{array}{l}\text { Size Separation - Separation of different size } \\
\text { soil particles by sieving or other conventional } \\
\text { size separation }\end{array}$ & $\begin{array}{l}\text { Not viable if deployed alone - Pu distribution at } \\
\text { NTS preferentially into soils less than } 120 \\
\text { microns would be favorable except that } 40-50 \\
\% \text { of the affected soils are in this size range, so } \\
\text { the volume reduction would not be sufficient. } \\
\text { Low Pu content }(<0.001 \%) \text { too low to apply } \\
\text { traditional mineral separation technology }\end{array}$ \\
\hline $\begin{array}{l}\text { Gravity Separation - Separation based on the } \\
\text { principle of Stokes Law that heavier particles } \\
\text { settle faster than light particles }\end{array}$ & $\begin{array}{l}\text { Not likely viable - very fine grain size of the } \\
\text { Pu-rich particles, agglomeration, and multiple } \\
\text { factors in soil particle density make success of } \\
\text { process unlikely }\end{array}$ \\
\hline $\begin{array}{l}\text { Chemical Extraction - Using chemical } \\
\text { reactions to change the nature of } \mathrm{Pu} \text { so that it } \\
\text { can be easily removed from the soil }\end{array}$ & $\begin{array}{l}\text { Viable and promising- laboratory tests } \\
\text { indicated that chemical extraction of } \mathrm{Pu} \text { from } \\
\text { soils is effective. Removal of } \mathrm{Pu} \text { from the } \\
\text { resulting leachate requires additional testing. }\end{array}$ \\
\hline $\begin{array}{l}\text { Flotation - Separation of the contaminant from } \\
\text { soil using a selective reagent. Aeration of the } \\
\text { mixture to float the Pu-bearing reagent }\end{array}$ & $\begin{array}{l}\text { Viable - Contrasts between soils and Pu oxide } \\
\text { in characteristics relevant to flotation (zeta } \\
\text { potential) is high. Separation of surrogates by } \\
\text { flotation was more than } 90 \% \text { effective. Use of } \\
\text { air alone for separation is ineffective and not } \\
\text { viable. }\end{array}$ \\
\hline $\begin{array}{l}\text { Segmented Gate - Coupled in line analyzer and } \\
\text { belt-conveyance system sorts soils with } \\
\text { different radiation levels into separate lots. }\end{array}$ & $\begin{array}{l}\text { Not viable alone - mixing of soil by baseline } \\
\text { excavation/ recovery technique, widely } \\
\text { dispersed distribution of } \mathrm{Pu} \text {, and low } \\
\text { concentration of } \mathrm{Pu} \text { oxide particles prevents the } \\
\text { technology from being effective. }\end{array}$ \\
\hline $\begin{array}{l}\text { Bioremediation - Leaching of Pu oxide with } \\
\text { sulfuric acid produced from elemental sulfur in } \\
\text { the presence of sulfur-oxidizing bacteria }\end{array}$ & $\begin{array}{l}\text { Viable and promising - laboratory results and } \\
\text { field testing were favorable. Technology has } \\
\text { established technical basis from other metal } \\
\text { leaching processes. }\end{array}$ \\
\hline $\begin{array}{l}\text { Magnetic Separation - Separation of the } \mathrm{Pu} \\
\text { oxide from the soils by differences in magnetic } \\
\text { susceptibility }\end{array}$ & $\begin{array}{l}\text { Potentially viable - magnetic susceptibility of } \\
\text { fine soil is low, although wet magnetic } \\
\text { separation showed some promise, the } \\
\text { technology is very sensitive to operational } \\
\text { variables and soils size distributions. }\end{array}$ \\
\hline $\begin{array}{l}\text { Vitrification and fixation - chemically binds } \\
\text { the Pu in a stable glass form }\end{array}$ & $\begin{array}{l}\text { Not viable - technology does not remove } \\
\text { contaminants or provide volume reduction. It } \\
\text { is also very expensive and has high electrical } \\
\text { power requirements that are unfavorable to } \\
\text { implementation at a remote site. }\end{array}$ \\
\hline
\end{tabular}

Table 1-2. Proposals Received For Evaluation.

$1-7$

Volume V Vendor Studies Evaluation and Ranking

Cooperative Agreement \#DE-FC26-00NT40841

October 13, 2003 


\begin{tabular}{|c|c|c|}
\hline Technology Name & Vendor & Test Action and Basis \\
\hline $\begin{array}{l}\text { Centrifugal Gravo- } \\
\text { Magnetic Separation }\end{array}$ & UNR & $\begin{array}{l}\text { Not selected for testing; test } \\
\text { cost too high; requires } \\
\text { significant water supply }\end{array}$ \\
\hline $\begin{array}{l}\text { Soil Washing (Physical } \\
\text { Separation \& Chemical } \\
\text { Extraction) }\end{array}$ & Earthline & Selected and Tested \\
\hline Bioremediation & IT Corporation (Shaw) & Selected and Tested \\
\hline $\begin{array}{l}\text { Soil Washing (Smart } \\
\text { Physical Separation Only) }\end{array}$ & Roy F. Weston & $\begin{array}{l}\text { Not selected for testing; } \\
\text { Insufficient documentation } \\
\text { of required volume } \\
\text { reduction }\end{array}$ \\
\hline Flotation & URS & Selected and Tested \\
\hline Electrokinetic Separation & Electropetroleum & $\begin{array}{l}\text { Not selected; Ability to } \\
\text { meet } 70 \% \text { volume reduction } \\
\text { assumes all Pu to be in soils } \\
<38 \text { um. Team for full- } \\
\text { scale treatment not } \\
\text { identified. }\end{array}$ \\
\hline $\begin{array}{l}\text { Soil Washing (Physical } \\
\text { /Chemical Separation) }\end{array}$ & ART & $\begin{array}{l}\text { Insufficient funding and } \\
\text { could not test }\end{array}$ \\
\hline Plasma Arc (Vitrification) & ReTech & $\begin{array}{l}\text { Did not provide volume } \\
\text { reduction for removal; } \\
\text { Deemed non responsive }\end{array}$ \\
\hline $\begin{array}{l}\text { Soil Washing (Physical } \\
\text { Chemical Separation) }\end{array}$ & New Millennium & $\begin{array}{l}\text { Proposal was a generic } \\
\text { statement of qualifications } \\
\text { and did not provide } \\
\text { sufficient information to } \\
\text { judge performance against } \\
\text { selection criteria }\end{array}$ \\
\hline
\end{tabular}

$1-8$ 


\subsection{DECISION PROCESS DESCRIPTION}

\subsection{KEY PERSONNEL}

This project is supported by NETL Cooperative Agreement \# DE-FC26-00NT40841. Key Project Team members include:

David Schwartz, DOE-NETL project manager, Ralph Smiecinski, DOE-Nevada,

Ed Hohman, Bechtel Nevada,

Sean Crawford, Bechtel Nevada (formerly DOE-Nevada),

Dale Pflug, TechCon,

Steve Hoeffner, Clemson Environmental Technologies Laboratory

James Navratil, Ph.D., Clemson Environmental Technologies Laboratory

Rich Smalley, Duratek, Inc.

\subsection{DECISION APPROACH}

Three technologies were demonstrated through laboratory bench scale testing. Test results provided preliminary data that is used in this report for qualitative and quantitative decision making for technology evaluation. The approach applied to each of the technology tests is defined in the Decision Analysis Flow Chart (Figure 2-1) developed for this project. First, the project team defined the problem requiring a remedy. Based on the problem statement, a set of goals were established that provide defined boundaries to a resolution of the problem. Preliminary remedial alternatives were identified for achieving the desired results for accomplishing the remedial goals. As a means to select the most appropriate technology for the remedy, criteria were developed for evaluating alternative technologies. Critical measures were defined for numerically scoring each criterion so that schedule, cost, technical deliverables and technical/site uncertainties could be managed comparatively between alternatives. Critical measures were included for qualitative and quantitative issues and scored from 1 to 5 with 1 being the least desirable and 5 being the most desirable for meeting the project goals. A weighted sensitivity value was applied to each of the goals and reflected as a multiplier when scoring the critical measures defining each criterion. Further details are provided in section 4 .

\subsection{DEFINITION OF GOALS}

Goals describe what the outcome will be if the technology would perform successfully. Due to their general nature, goals do not provide an explicit measure of their individual

$2-1$

Volume V Vendor Studies Evaluation and Ranking 
Figure 2-1. Decision Analysis Tool.

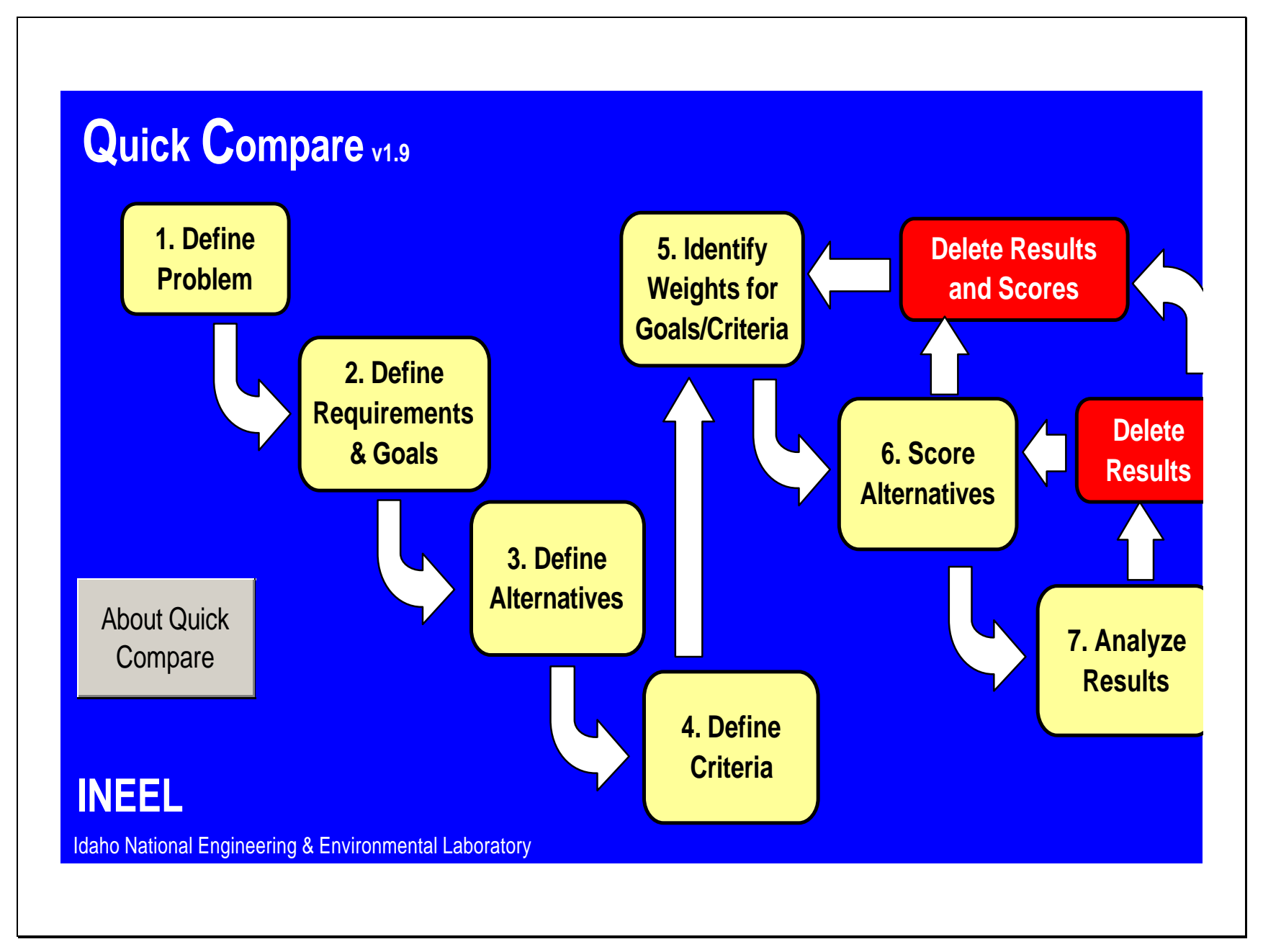

2-2 
merit nor do they indicate how well each technology would perform in meeting them.

The goals serve as the guiding light toward which all actions in the project should move. The goals also provide a conceptual framework within which tradeoffs between competing issues can be evaluated.

\subsection{CRITERIA DEFINITION}

Criteria define the data and information needed to perform the alternative evaluation and function as objective measures of the goals. Considerations that must be used when defining criteria include:

- Differentiate between alternatives;

- Relate to goals and values of DOE and other stakeholders;

- Be measurable or estimable;

- Be reasonably independent of each other; and,

- Be well understood by all decision makers. 


\subsection{VENDOR TESTING - RESULTS AND INDEPENDENT EVALUATION}

Key Technology vendor personnel include:

$\underline{\text { Bioremediation }}$

Shaw Environment \& Infrastructure, Inc.

Douglas Jerger, Ph.D., Manager, Environmental Biotechnology

Gregory Bennett, Senior Project Chemist

Soil Washing

Earthline Technologies, Inc.

John Hughes, Senior Project Engineer

Jeff Kulpa, Senior Project Engineer

High Capacity Flotation

URS Corporation

Ye Yi, Ph.D., Senior Consulting Engineer

\subsection{BIOREMEDIATION TEST SUMMARY AND RESULTS}

Shaw Environmental \& Infrastructure, Inc. (Shaw) completed a bench scale treatability study of a bioacidification/biosolubilization treatment process (bioremediation) at the CETL under CETL's observation. The treatment process was designed by Shaw. The tests were performed on NTS soils and results reported in the Shaw document entitled "Treatability Testing Report for the Removal of Plutonium From Nevada Test Site Area Y Soil Using Biological Treatment” dated May 7, 2003.

Bioremediation of $\mathrm{Pu}$-contaminated soil was accomplished using a two-step process that removes $\mathrm{Pu}$ from soil and then precipitates and concentrates the $\mathrm{Pu}$ as insoluble sulfide solids. The basis of the technology is the biologically-mediated solubilization of $\mathrm{Pu}$, as a sulfate salt, under aerobic conditions using sulfur-oxidizing bacteria (SOB) in a bioacidification reactor. The SOB generate sulfuric acid directly on the surface and within the pores of contaminated soil particles. The increased hydrogen ion concentration in soil pore water shifts the adsorption equilibrium at the soil surface, replacing radionuclide/metal ions with hydrogen ions. The solubilized radionuclide/metal ions are leached out of the soil matrix using water. The metal-laden solution (leachate) is further treated by sulfate-reducing bacteria (SRB) in a conventional, continuous-flow, suspended-growth anaerobic bioreactor. The production of sulfide from sulfate facilitates the precipitation of insoluble $\mathrm{Pu}$ sulfide. The process concentrates $\mathrm{Pu}$ from a large volume of soil into a small volume of $\mathrm{Pu}$ sulfide sludge. The sludge can then be processed for Pu recovery or stabilized for disposal.

3-1

Volume V Vendor Studies Evaluation and Ranking 
Results indicated that biological treatment could successfully treat NTS soil by removing $\mathrm{Pu}$ from the soil and recovering the radionuclide in a small mass of sludge. The bioacidification/biosolubilization process achieved 61 - 88\% removal of $\mathrm{Pu}$ from the soil, based on a comparison of the radioactivity in the soil to the radioactivity in the leachate. Final concentration of plutonium in the soil was around $200 \mathrm{pCi} / \mathrm{g}$. The Eberline results (the independent laboratory used by Shaw) for the SOB leachates were higher than either the CETL gross alpha and isotopic plutonium results or the Shaw gross alpha results. As a result, the calculation of the percentage of plutonium extracted/leached using the Eberline results (88\%) is higher than that obtained using CETL (67\% by gross alpha and $76 \%$ by isotopic plutonium) or Shaw data ( $61 \%$ by gross alpha). Plutonium activity balance (pCi) for all studies were good (106\% CETL gross alpha, 105\% isotopic plutonium and $116 \%$ Shaw gross alpha), with the Eberline activity balance being somewhat higher (123\%) The bioprecipitation process achieved greater than $99 \%$ removal of $\mathrm{Pu}$ based on $\mathrm{Pu}$ activity in the leachate and $\mathrm{Pu}$ activity in the sludge. The combined processes resulted in greater than a 97\% volume reduction in $\mathrm{Pu}$ containing solids based on the original volume of the soil and the final volume of the SRB reactor sludge.

The laboratory study demonstrates the viability of the bioremediation process for treatment of the plutonium-contaminated NTS soils. Prior studies by Shaw also confirm this. Field treatment will require the \% moisture of the soil be maintained around $15 \%$ and that the soil be aerated or that there be an oxygen source available. Treatment duration is determined by the growth rate of the SOB and there is some control over this by controlling nutrient and oxygen levels. In addition, the initial level of bacteria influences the treatment time. Laboratory studies indicate that three or more leaches of the soil may be required to remove sufficient plutonium from the soil. Treatment times of 6 months or more may be necessary. It may be possible to minimize on-site visits during this time, at least after initial shake down operations are complete. But, there remains the possibility that on-going on-site maintenance of the process may be required. This would make its application to the TTR difficult. It may be possible achieve similar results without the bacteria using dilute sulfuric acid. This should be investigated prior to field demonstration.

\subsection{SOIL WASHING TEST SUMMARY AND RESULTS}

A bench scale treatability study of the Earthline Technologies, Inc. (Earthline) soil washing process was completed at the Clemson Environmental Technologies Laboratory (CETL) on NTS soils contaminated with $\mathrm{Pu}$. The testing included multiple chemical leaching experiments and process water studies to determine contaminant removal efficiencies, volume reduction effectiveness, and approximate cost of implementation. The treatability study was performed from June $17-21,2002$ and reported in the Earthline document entitled "Nevada Test Site Soil Washing Treatability Study Final Report” dated January 2003.

$3-2$

Volume V Vendor Studies Evaluation and Ranking 
Soil washing using conventional mineral processing unit operations consists of physical screening, chemical extraction of the Pu using stirred tank reactors, followed by liquid/solid separation, and plutonium recovery from the leach solution using Ultrafiltration (UF) and Nanofiltration (NF) membrane systems.

Earthline reported that the results of the treatability study demonstrated that the entire fraction of the NTS soils could be effectively washed using sulfuric acid and potassium permanganate to achieve an anticipated $97-98 \%$ volume reduction and $90-95 \%$ contaminant removal efficiency at production scale (final concentration of plutonium in the soil was less than $50 \mathrm{pCi} / \mathrm{g}$ ). Independent analyses by CETL confirm these results. Based on the high efficiency estimate of Earthline, the soil washing process has the potential to concentrate the Pu to a level approaching that of TRU waste resulting in a complex disposition path. The system efficiency could be adjusted to avoid this condition.

The bench scale test also measured the recovery of the Pu from the leach solution using a laboratory scale NF membrane. The NF membrane selected for the bench scale test rejected $30-50 \%$ of the $\mathrm{Pu}$ from the acid leach solution. Earthline has designed the production scale system with a NF membrane that they believe will achieve a much higher rejection percentage of $\mathrm{Pu}$. That membrane was not available for the bench scale studies. Earthline is confident that the technical issues with recycling the leachate water will be solved with the production scale NF membrane, however, that has not been successfully demonstrated. Furthermore, another project Earthline has been involved with at the Ashtabula site was plagued with water recycle problems.

The laboratory study demonstrates the viability of the soil washing process for treatment of the plutonium-contaminated NTS soils. Soil washing is an established treatment technology. Soil washing systems are typically fairly robust and amenable to field conditions. Treatment can be stopped and started as needed to accommodate scheduling requirements. Personnel will need to be on-site throughout the treatment process. Although the technology has potential and could result in significant cost savings, successful bench scale leachate recycle and reuse must be demonstrated before proceeding further.

\subsection{HIGH CAPACITY FLOTATION TEST SUMMARY AND RESULTS}

CETL performed a treatability study of a High Capacity Flotation technology designed by URS Corporation. The test procedure and results are summarized in the URS report entitled "Plutonium Oxide Removal from Soil by High Capacity Flotation System Final Report” dated September 30, 2002.

Plutonium oxide, like any other metal oxide, can be concentrated and removed from soil by selective flotation. To achieve the concentration and removal objectives, two prerequisites exist: first, oxide particulates have to be fully liberated from other soil

$$
\text { 3-3 }
$$

Volume V Vendor Studies Evaluation and Ranking 
particles by means of slurrying. If fused and locked with soil particles, oxide particles have to be fully exposed at the surfaces. Second, appropriate flotation chemicals have to be identified and used. Under this scheme, soils contaminated by plutonium oxide particles can be slurried with water. Pre-identified chemicals are added into the slurry to selectively adsorb onto plutonium oxide surfaces. Air bubbles are then introduced into the system to let oxide particles that have chemicals adsorbed at the surfaces, attach onto air bubbles. These particle-loaded bubbles rise to the surface to form a froth phase. Plutonium oxide particles thus can be concentrated and separated from soil by removing and collecting the froth phase. The water used in the process is recovered and reused.

A total of nine tests were conducted at CETL. Six tests were parameter evaluations including flotation chemical screening. The last three tests were complete process design tests representing three different systems and processing designs. The data demonstrate that the high capacity flotation technology can consistently provide approximately 30$35 \%$ of $\mathrm{Pu}$ Oxide removal from the feed soil into a concentrated waste. The CETL data were independently confirmed by samples sent to General Engineering Laboratories. At this removal efficiency, the soil reduction is constant at approximately $86-87 \%(13-14 \%$ soils concentrated into the waste). These results were achieved with fatty acids as flotation chemicals. Test data also demonstrate that the entire process water is recyclable for continued use. Recycled processing water has no radioactivity.

The laboratory study of the flotation process, as demonstrated by URS Corporation, cannot, by itself, meet the treatment goals. Integration with other unit operations may or may not be cost effective and would have to be evaluated on a case-by-case basis. Similar to soil washing the flotation process is an established technology and is fairly robust and amenable to field conditions. Treatment can be stopped and started as needed to accommodate scheduling requirements. Personnel will need to be on-site throughout the treatment process. Because of the poor performance of the flotation process, no further studies are recommended.

3-4 


\subsection{ANALYSIS}

\subsection{SCOPE OF THE DECISION ANALYSIS}

The scope of the decision analysis consisted of the following:

- Accurate Problem Definition;

- Establish Goals for Problem Remedy;

- Identify Remedial Alternatives;

- Define Evaluation Criteria;

- Define Treatability Study Parameters for Testing Viable Technologies;

- Perform Treatability Studies;

- Set up a Model for Scoring Technologies; and,

- Report Results of Technology Evaluation.

\subsection{GOALS OF THE PLUTONIUM IN SOILS VOLUME REDUCTION STUDY}

The scope of this evaluation and decision analysis incorporates a standard management approach employed by DOE to simplify projects to elements of project schedule, project costs, and project deliverables. All of the project goals have a relationship to one or more of the three elements and in meeting one goal there may also be an impact to other goals. The project team has identified six goals that would determine success of the Plutonium in Soils Volume Reduction Study. The goals are:

1. Minimize DOE Project Cost;

2. Minimize DOE Custodial Responsibilities;

3. Minimize the Risks of Transportation Accidents;

4. Minimize the Potential Uptake Exposure of Workers;

5. Maximize Implementation Confidence; and,

6. Minimize the Impact on Air Force Operations.

These six goals allowed the identification of discriminating criteria and "critical measures" for scoring the criteria. Most significantly, the goals remained stable throughout the decision process. The stability of the goals demonstrated the understanding of the problem, and the adherence of the Team to the defined decision process. One significant challenge of this evaluation was that the goals and measures to score them required some extrapolation for implementation of the process beyond the laboratory performance data.

4-1 


\subsection{PRELIMINARY TECHNOLOGY EVALUATION}

The preliminary evaluation of the three remedial technologies reflects the capability of each technology to meet the established project goals. A total of 100 points were possible for each technology. The technologies were evaluated against the ability to meet the following 6 goals. The relative importance of each goal was weighted by dividing the 100 possible points as follows:

Goal 1: Minimize DOE Project Cost

Goal Weight

Goal 2: Minimize DOE Custodial Responsibilities 30

Goal 3: Minimize the Risks of Transportation Accidents 20

Goal 4: Minimize the Potential Uptake Exposure of Workers 15

Goal 5: Maximize Implementation Confidence 15

Goal 6: Minimize the Impact on Air Force Operations

To evaluate each technology the goals were divided into Criterion. These Criteria were further divided into Critical Measures. So the evaluation process flows in the following manner:

\section{Critical Measures $\rightarrow$ Criterion $\rightarrow$ Goal $\rightarrow$ Technology}

There are only two variables that affect the final value of each goal: the score of the Critical Measures, and the relative weight of the six goals, as detailed above. For goals that have more than Criterion, the weight or points are equally divided among the Criterion. For example, the first goal, Minimize DOE Project Cost, has three Criteria. Since this first goal was weighted at 30, the three criteria are each weighted at 10. For goals that have only one Criterion, the weighting is the same for each:

$\begin{array}{llcc} & \text { Goal Weight } & \text { Criterion Weight } \\ \text { Goal 1: } & \text { Criterion 1 } & 30 & 10 \\ & \text { Criterion 2 } & & 10 \\ & \text { Criterion 3 } & & 10 \\ \text { Goal 2: } & \text { Criterion 4 } & 20 & 20 \\ \text { Goal 3: } & \text { Criterion 5 } & 15 & 15 \\ \text { Goal 4: } & \text { Criterion 6 } & 15 & 15 \\ \text { Goal 5: } & \text { Criterion 7 } & 10 & 5 \\ & \text { Criterion 8 } & & 5 \\ \text { Goal 6: } & \text { Criterion 9 } & 10 & 10\end{array}$

4-2 
The Critical Measures were determined based on a numerical 1 through 5 score $(1$ being least desirable and 5 being most desirable) and are summarized in Appendix A.

A summary of the ranking of the technologies is presented in Table 4-1. The ranking of the technologies is determined as follows:

\section{Criterion Weighted Score}

1. Score Critical Measures on scale of 1 to 5 ;

2. Obtain the average of all the Critical Measure values for each Criterion. This is the Criterion Score;

3. Multiply the Criterion Score by the Relative Criterion Weight (RCW) factor. The $\mathrm{RCW}$ is the criterion weight divided by the maximum value possible for the criterion measure (which is 5)*.

4. The resulting value is the individual Criterion Score.

* This relative weight factor assures that the maximum overall score is 100 .

\section{Goal Weighted Score}

1. Add all Criterion Scores for each individual Goal;

2. Resulting score is the individual Goal Weighted Score.

\section{$\underline{\text { Technology Test Score }}$}

1. Add all Goal Weighted Scores;

2. Resulting Score is the final Technology Test Score based on 100 as a maximum.

As an example, in Appendix A, the first Criterion is Project Reduction Potential. For Bioremediation, the three critical measures were scored at 3,3, and 4. The average of these critical measures, the Criterion Score, is 3.3. The Relative Criterion Weight is The Criterion Weight (10 for this Criterion) divided by 5 , or 2 . The Criterion Weighted Score is then $3.3 * 2=6.7$. Rounded the nearest whole number this is 7 . The maximum score possible for this Criterion is 10 . This process is repeated for the other two Criteria for this goal. The goal score is then the sum of the three Criterion Weighted Scores $(7+8$ $+7=22$ ). The maximum score for this goal is 30 . The process is repeated for the other criterion and goals, then the Goal Scores are added to obtain the overall score for the technology, 72 for the bioremediation, out of a total of 100 possible.

\subsubsection{Goal 1: Minimize DOE Project Cost}

Implementation of an alternative remedial technology in place of the baseline technology will only occur if a significant cost savings for DOE can be demonstrated. The technology evaluation with regard to a potential for project cost savings is based on three criteria:

- Criterion 1 - Project Reduction Potential

○ Schedule risk with respect to baseline

4-3

Volume V Vendor Studies Evaluation and Ranking 
- Reduce volume of soil requiring packaging transportation and disposal

- Avoid (minimize) issues related to waste disposition requirements (No orphaned waste streams)

- Criterion 2 - Minimize Soil Volume that has to be Handled

○ Treated soils must be $\leq 1000 \mathrm{pCi} / \mathrm{gm} \mathrm{Pu}$

- Nominally, $70 \%$ is the minimum effective reduction

- Criterion 3 - Minimize DOE ER Cost for the Project

- Soil excavation and handling

- Soil treatment and leachate recovery

- Leachate drying

- Material assay and packaging

- Transportation

○ Disposal

The bioremediation and soil washing technologies can be implemented within the baseline parameters with moderate to minimal risk to project schedule or cost. Both technologies will also generate a greater than 70 percent reduction of the volume of soil that will require final disposition. Flotation is considered to be more of a challenge for meeting baseline schedule and cost parameters and was tested at an efficiency of less than 60 percent $\mathrm{Pu}$ removal. The percent reduction in the volume of soil requiring packaging, transportation and disposal for the flotation technology is below the limit determined to be economically viable as a stand-alone treatment system although it could be employed in trains or with enhancement that may achieve the required volume reduction. One advantage that the bioremediation system has compared to the soil washing system is that it will generate a limited volume of secondary waste. The soil washing system will require additional development to resolve the secondary waste issue regarding the uncertainty of recycling leachate water.

Averaged scores for the three measures evaluated for Criterion 1 (Project Reduction Potential) for the bioremediation treatment, soil washing, and flotation were 7, 7 and 4 respectively, out of a total of 10 possible.

Scoring of Criterion 2, Minimize Soil Volume that has to be Handled, was based on a preliminary remedial target for Pu concentration for treated soils in the field at $\leq 1000$ $\mathrm{pCi} / \mathrm{gm}$. In the laboratory, since the starting material was only $1100-1200 \mathrm{pCi} / \mathrm{g}$, the target was $200 \mathrm{pCi} / \mathrm{g}$. The laboratory target was to treat the contaminated soil so that $70 \%$ of the soil contained less than $200 \mathrm{pCi} / \mathrm{g}$ of plutonium. Excavation of Pu contaminated soils will require that each technology handle the same volume of pre-treated material as the baseline. Any soil with concentrations above the field target will require additional handling and disposition. Bioremediation and flotation technologies have some uncertainty associated with removal efficiencies and waste handling requirements. Soil washing can obtain target removal concentrations and significantly reduce the volume of

4-4

Volume V Vendor Studies Evaluation and Ranking 
soil that requires disposal. The averaged scoring for bioremediation, soil washing and flotation for this category are 8,9 and 2, respectively, out of a total of 10 possible.

Scoring of Criterion 3, Minimize DOE ER Costs for the Project, was based on six critical measures:

- Soil excavation and handling;

- Soil treatment and leachate recovery;

- Leachate drying;

- Material assay and packaging;

- Transportation; and,

- Disposal.

The baseline remediation costs have been estimated and will be used as a benchmark to compare costs of alternative technologies that can be implementation to reduce the volume of $\mathrm{Pu}$ soils.

Each technology will require excavation of impacted soils but may not require the same level of waste packaging as the baseline. This will result in less exposure potential of workers during the waste handling activities.

The treatment and leachate recovery will be a cost above the baseline remediation since soil treatment prior to packaging, transport and disposal is not designed into the baseline process. Each of the three technologies will require the necessary equipment, utilities, and operational personnel for design, construction and implementation of the treatment system. Uncertainties include locating utilities to remote areas and secondary waste issues.

Secondary waste will be generated in the form of process leachate and may yield waste streams that are problematic with regard to disposition path. Leachate drying may provide some technical risk and result in waste forms that will require an expensive disposition. Bioremediation and flotation will generate leachate that can be processed with minimal technical risk and an identifiable deposition path. Soil washing will generate a leachate that will require enhanced treatment or possibly a complex disposition path.

Regulatory and safety compliance of waste packaging will require an established QA program that will include a monitoring and confirmation data acquisition element to ensure proper waste packaging protocols are being used. All three technologies can use field analytical instruments to confirm compliance with simple packaging requirements. There may also be situations when special packaging for some waste forms require a greater level of analytical QC to meet waste acceptance criteria at disposal facilities.

4-5

Volume V Vendor Studies Evaluation and Ranking 
Table 4-1. Scoring Summary.

\begin{tabular}{|c|c|c|c|c|c|c|c|}
\hline Technology & $\begin{array}{l}\text { Goal Name } \\
\text { (Goal Weight) }\end{array}$ & Criterion Name & $\begin{array}{l}\text { Criterion } \\
\text { Score }^{1}\end{array}$ & $\begin{array}{c}\text { Relative } \\
\text { Criterion }^{-} \\
\text {Weight }^{2}\end{array}$ & $\begin{array}{c}\text { Criterion } \\
\text { Weighted } \\
\text { Score }^{3} \text { / Max. } \\
\text { Possible }\end{array}$ & $\begin{array}{c}\text { Goal } \\
\text { Score/ } \\
\text { Max. } \\
\text { Possible }\end{array}$ & $\begin{array}{c}\text { Overall Score/ } \\
\text { Maximum } \\
\text { Possible }\end{array}$ \\
\hline \multirow{9}{*}{ Bioremediation } & \multirow{3}{*}{$\begin{array}{l}\text { Minimize DOE } \\
\text { Project Cost (30) }\end{array}$} & Project Reduction Potential & 3.3 & $10 / 5=2$ & $7 / 10$ & \multirow{3}{*}{$22 / 30$} & \multirow{9}{*}{$69 / 100$} \\
\hline & & $\begin{array}{l}\text { Minimize soil volume that has to be } \\
\text { handled }\end{array}$ & 4.0 & $10 / 5=2$ & $8 / 10$ & & \\
\hline & & $\begin{array}{l}\text { Minimize DOE ER Costs for this } \\
\text { project }\end{array}$ & 3.5 & $10 / 5=2$ & $7 / 10$ & & \\
\hline & $\begin{array}{l}\text { Minimize DOE } \\
\text { Custodial } \\
\text { Responsibilities } \\
\text { (20) }\end{array}$ & $\begin{array}{l}\text { Minimize DOE Custodial } \\
\text { Responsibilities }\end{array}$ & 4.0 & $20 / 5=4$ & $16 / 20$ & $16 / 20$ & \\
\hline & $\begin{array}{l}\text { Minimize the } \\
\text { Risks of } \\
\text { Transportation } \\
\text { Accidents (15) }\end{array}$ & $\begin{array}{l}\text { Minimize the risks of transportation } \\
\text { accidents }\end{array}$ & 3.0 & $15 / 5=3$ & $9 / 15$ & $9 / 15$ & \\
\hline & $\begin{array}{l}\text { Minimize the } \\
\text { Potential Uptake } \\
\text { Exposure of } \\
\text { Workers (15) }\end{array}$ & $\begin{array}{l}\text { Minimize the potential uptake } \\
\text { exposure of workers }\end{array}$ & 4.0 & $15 / 5=3$ & $12 / 15$ & $12 / 15$ & \\
\hline & \multirow{2}{*}{$\begin{array}{c}\text { Maximize } \\
\text { Implementation } \\
\text { Confidence (10) }\end{array}$} & Maximize process simplicity & 3.0 & $5 / 5=1$ & $3 / 5$ & \multirow{2}{*}{$6 / 10$} & \\
\hline & & Optimize process system portability & 3.0 & $5 / 5=1$ & $3 / 5$ & & \\
\hline & $\begin{array}{l}\text { Minimize the Impact } \\
\text { on Air Force } \\
\text { Operations (10) }\end{array}$ & $\begin{array}{l}\text { Minimize Impact on Air Force } \\
\text { Operations }\end{array}$ & 2.0 & $10 / 5=2$ & $4 / 10$ & $4 / 10$ & \\
\hline
\end{tabular}




\begin{tabular}{|c|c|c|c|c|c|c|c|}
\hline Technology & $\begin{array}{l}\text { Goal Name } \\
\text { (Goal Weight) }\end{array}$ & Criterion Name & $\begin{array}{l}\text { Criterion } \\
\text { Score }^{1}\end{array}$ & $\begin{array}{c}\text { Relative } \\
\text { Criterion }^{\text {Weight }}{ }^{2}\end{array}$ & $\begin{array}{c}\text { Criterion } \\
\text { Weighted } \\
\text { Score }^{3} / \text { Max. } \\
\text { Possible }\end{array}$ & $\begin{array}{c}\text { Goal } \\
\text { Score/ } \\
\text { Max. } \\
\text { Possible }\end{array}$ & $\begin{array}{l}\text { Overall Score/ } \\
\text { Maximum } \\
\text { Possible }\end{array}$ \\
\hline \multirow{9}{*}{ Soil Washing } & \multirow{3}{*}{$\begin{array}{l}\text { Minimize DOE } \\
\text { Project Cost (30) }\end{array}$} & Project Reduction Potential & 3.3 & $10 / 5=2$ & $7 / 10$ & \multirow{3}{*}{$21 / 30$} & \multirow{9}{*}{$64 / 100$} \\
\hline & & $\begin{array}{l}\text { Minimize soil volume that has to be } \\
\text { handled }\end{array}$ & 4.5 & $10 / 5=2$ & $9 / 10$ & & \\
\hline & & $\begin{array}{l}\text { Minimize DOE ER Costs for this } \\
\text { project }\end{array}$ & 2.5 & $10 / 5=2$ & $5 / 10$ & & \\
\hline & $\begin{array}{l}\text { Minimize DOE } \\
\text { Custodial } \\
\text { Responsibilities } \\
\text { (20) }\end{array}$ & $\begin{array}{l}\text { Minimize DOE Custodial } \\
\text { Responsibilities }\end{array}$ & 3.0 & $20 / 5=4$ & $12 / 20$ & $12 / 20$ & \\
\hline & $\begin{array}{l}\text { Minimize the } \\
\text { Risks of } \\
\text { Transportation } \\
\text { Accidents (15) }\end{array}$ & $\begin{array}{l}\text { Minimize the risks of transportation } \\
\text { accidents }\end{array}$ & 3.5 & $15 / 5=3$ & $10 / 15$ & $10 / 15$ & \\
\hline & $\begin{array}{l}\text { Minimize the } \\
\text { Potential Uptake } \\
\text { Exposure of } \\
\text { Workers (15) }\end{array}$ & $\begin{array}{l}\text { Minimize the potential uptake } \\
\text { exposure of workers }\end{array}$ & 3.0 & $15 / 5=3$ & $9 / 15$ & $9 / 15$ & \\
\hline & \multirow{2}{*}{$\begin{array}{c}\text { Maximize } \\
\text { Implementation } \\
\text { Confidence (10) }\end{array}$} & Maximize process simplicity & 3.0 & $5 / 5=1$ & $3 / 5$ & \multirow[t]{2}{*}{$6 / 10$} & \\
\hline & & Optimize process system portability & 3.0 & $5 / 5=1$ & $3 / 5$ & & \\
\hline & $\begin{array}{l}\text { Minimize the Impact } \\
\text { on Air Force } \\
\text { Operations (10) }\end{array}$ & $\begin{array}{l}\text { Minimize Impact on Air Force } \\
\text { Operations }\end{array}$ & 3.0 & $10 / 5=2$ & $6 / 10$ & $6 / 10$ & \\
\hline
\end{tabular}




\begin{tabular}{|c|c|c|c|c|c|c|c|}
\hline Technology & $\begin{array}{c}\text { Goal Name } \\
\text { (Goal Weight) }\end{array}$ & Criterion Name & $\begin{array}{l}\text { Criterion } \\
\text { Score }^{1}\end{array}$ & $\begin{array}{l}\text { Relative } \\
\text { Criterion } \\
\text { Weight }^{2}\end{array}$ & $\begin{array}{c}\text { Criterion } \\
\text { Weighted } \\
\text { Score }^{3} / \text { Max. } \\
\text { Possible }\end{array}$ & $\begin{array}{c}\text { Goal } \\
\text { Score/ } \\
\text { Max. } \\
\text { Possible }\end{array}$ & $\begin{array}{l}\text { Overall Score/ } \\
\text { Maximum } \\
\text { Possible }\end{array}$ \\
\hline \multirow{9}{*}{ Flotation } & \multirow{3}{*}{$\begin{array}{l}\text { Minimize DOE } \\
\text { Project Cost }(30)\end{array}$} & Project Reduction Potential & 2.0 & $10 / 5=2$ & $4 / 10$ & \multirow{3}{*}{$10 / 30$} & \multirow{9}{*}{$42 / 100$} \\
\hline & & $\begin{array}{l}\text { Minimize soil volume that has to be } \\
\text { handled }\end{array}$ & 1.0 & $10 / 5=2$ & $2 / 10$ & & \\
\hline & & $\begin{array}{l}\text { Minimize DOE ER Costs for this } \\
\text { project }\end{array}$ & 2.2 & $10 / 5=2$ & $4 / 10$ & & \\
\hline & $\begin{array}{l}\text { Minimize DOE } \\
\text { Custodial } \\
\text { Responsibilities } \\
\text { (20) }\end{array}$ & $\begin{array}{l}\text { Minimize DOE Custodial } \\
\text { Responsibilities }\end{array}$ & 1.0 & $20 / 5=4$ & $4 / 20$ & $4 / 20$ & \\
\hline & $\begin{array}{l}\text { Minimize the } \\
\text { Risks of } \\
\text { Transportation } \\
\text { Accidents (15) }\end{array}$ & $\begin{array}{l}\text { Minimize the risks of transportation } \\
\text { accidents }\end{array}$ & 3.0 & $15 / 5=3$ & $9 / 15$ & $9 / 15$ & \\
\hline & $\begin{array}{l}\text { Minimize the } \\
\text { Potential Uptake } \\
\text { Exposure of } \\
\text { Workers (15) }\end{array}$ & $\begin{array}{l}\text { Minimize the potential uptake } \\
\text { exposure of workers }\end{array}$ & 3.0 & $15 / 5=3$ & $9 / 15$ & $9 / 15$ & \\
\hline & Maximize & Maximize process simplicity & 2.0 & $5 / 5=1$ & $2 / 5$ & \multirow{2}{*}{$4 / 10$} & \\
\hline & Confidence (10) & Optimize process system portability & 2.0 & $5 / 5=1$ & $2 / 5$ & & \\
\hline & $\begin{array}{c}\text { Minimize the Impact } \\
\text { on Air Force } \\
\text { Operations (10) }\end{array}$ & $\begin{array}{l}\text { Minimize Impact on Air Force } \\
\text { Operations }\end{array}$ & 3.0 & $10 / 5=2$ & $6 / 10$ & $6 / 10$ & \\
\hline
\end{tabular}




\section{Table 4-1. Scoring Summary - Notes}

Note 1 -- Criterion scores (CS) were the average of multiple critical measure scores. The maximum value is 5 . All critical measures and associated scores are listed in Appendix A.

Note 2 - The Relative Criterion Weight $(\mathrm{RCW})$ is the criterion weight for each criterion divided by the maximum possible value for the criterion measure (which is 5). This relative weight factor assures that the maximum overall score is 100 .

Note 3 -- Weighted criterion score is the CS*RCW. Value is rounded to the nearest whole number. 
Transportation costs will be impacted by the efficiency of the treatment technologies. Bioremediation and soil washing have similar efficiencies that significantly reduce the volume of $\mathrm{Pu}$ contaminated soil resulting in reduced transportation requirements. Soil washing will generate a more complex secondary waste that will require packaging and transport. The operational efficiency of flotation will leave a larger percentage of waste that will require packaging/transport/disposal.

Disposal requirements and volumes for the three technologies are similarly impacted, as are the transportation requirements. Factors that will affect costs include the complexity of the waste disposition requirements and the type of disposal facility (i.e. NTS disposal).

The six measures listed above provided the level of discrimination necessary to evaluate each technology with respect to project cost/schedule risk compared to the baseline remediation. Bioremediation, soil washing and flotation received scores of 7, 5, and 4, respectively, out of a total of 10 possible. Uncertainty related to waste disposition path and secondary waste streams had the most impact on scoring.

\subsubsection{Goal 2: Minimize DOE Custodial Responsibilities}

Implementation of an alternative remedial technology from the baseline technology will need to minimize custodial responsibilities for DOE. Evaluation of the potential for reduced custodial responsibilities is based on one criterion:

- Criterion 4 - Minimize DOE Custodial Responsibilities

- Decrease Pu level to below applicable limits

○ Avoid/Minimize "Long-term Monitoring/Legacy” Responsibilities

Bioremediation and soil washing treatment systems will remediate all of the $\mathrm{Pu}$-soils to levels below current interim regulatory limits, but the soil washing system will likely require more extensive monitoring after treatment is completed. The generation of a secondary waste will add complexities to custodial care requirements. In addition, one alternative presented by Earthline includes construction of a landfill to stage untreated soils prior to bulk treatment. This will also increase custodial monitoring. The bioremediation system was scored high as custodial monitoring will likely consist of event triggered monitoring based on future land use plans. The floatation system was not able to reduce the level of plutonium to applicable limits. The averaged scoring for bioremediation, soil washing and flotation for Goal 2 are 16, 12 and 4, respectively, out of a total of 20 possible.

\subsubsection{Goal 3: Minimize the Risks of Transportation Accidents}

Implementation of an alternative remedial technology from the baseline technology will need to minimize the risks of transportation accidents. Evaluation of the risk of transportation accidents is based on one criterion:

4-10

Volume V Vendor Studies Evaluation and Ranking 
- Criterion 5 - Minimize the Risks of Transportation Accidents

- Transportation of primary waste to disposal

- Primary waste volume

- Primary waste characteristics

- Disposition of secondary waste

- Secondary waste volume

- Secondary waste characteristics

Risks associated with transportation accidents involve two factors: the volume of soil being transported, and the concentration of $\mathrm{Pu}$ in the waste packages being shipped. Based on these factors, it is estimated that all three technologies will reduce the volume of soil that will have to be transported to disposal facilities. Compared to the baseline, waste packages will have moderately increased concentrations of $\mathrm{Pu}$ when transported from Safe Shots Sites to disposal facilities. Uncertainties concerning the disposition of secondary waste and availability/acceptance of waste for disposition at NTS disposal facilities will affect the risks of transportation accidents. The averaged scoring for bioremediation, soil washing and flotation for this category are 9, 10 and 9, respectively, out of a total of 15 possible.

\subsubsection{Goal 4: Minimize the Potential for Uptake Exposure of Workers}

Implementation of an alternative remedial technology from the baseline technology will need to minimize the potential for uptake exposure of workers. Evaluation of the potential for uptake exposure of workers is based on one criterion:

- Criterion 6 - Minimize the Potential for Uptake Exposure of Workers

- Exposure above baseline

- Increment due to processing exposure

- Increment due to modified waste form

○ Increment to modified waste composition

All remediation designs that incorporate soil excavation and ex-situ treatment equipment have some potential for uptake exposure of workers. At NTS, the arid environment and dry soils must be considered when designing a system that minimizes the exposure potential. All technologies evaluated, including the baseline, require excavation of surface soil and transport/handling to the treatment facility. Minimizing the potential for worker exposure is a factor of waste handling at the treatment facility, dust control, handling of secondary waste, and packaging of final waste volumes being transported for disposition. The bioremediation technology scored higher for minimizing the potential for uptake exposure of workers because the process does not require as much posttreatment waste handling as flotation and does not generate as much secondary waste as soil washing. The averaged scoring for bioremediation, soil washing and flotation for this category are 12,9 and 9, respectively, out of a total of 15 possible.

4-11 


\subsubsection{Goal 5: Maximize Implementation Confidence}

An alternative remedial technology other than the baseline technology will require a high level of confidence for the implementation. Evaluation of the potential to maximize the implementation confidence is based on two criteria:

- Criterion 7 - Maximize Process Simplicity

○ Simplicity of Operations

- Low Operations and Maintenance Requirements

○ Compatibility with isolated, arid environment

- Criterion 8 - Optimize Process System Portability

○ "Load and go" transportability between sites

○ Self supply with utilities

- Communication and controls directly transferable

○ Operations personnel transferable

The NTS sites are extreme areas for deploying treatment systems. The remoteness and physical setting make accessibility difficult. Utilities such as electricity and water are not readily available and extreme temperatures and dust problems are expected conditions. The treatment system hardware and equipment will need to be simple to operate and maintain/repair and demand limited outside support and utilities requirements. The bioremediation and soil washing systems scored equally for process simplicity. Both technologies operate with similar compatibility limitations such as water supply and utility requirements. In addition, both systems will require personnel on site for O\&M. The primary uncertainties include a continuous source of water for the bioremediation system and secondary waste treatment associated with the soil washing system. The flotation process received a lower score because it is not a stand-alone system and coupling with another technology will add to the process complexity. The averaged scoring for bioremediation, soil washing and flotation for this category are 3, 3, and 2, respectively, out of a total of 5 possible.

The NTS sites are geographically spread out over a large area and without fixed facilities. For this reason and the extreme conditions outlined for Criterion 7, portability of the treatment system is a major factor for a full-scale system. Optimally, the treatment system would be self-contained for power and water and constructed on a trailer(s) or modules for re-locating from site to site. The flotation system is potential the most portable of the technologies, however, it is not a stand-alone system and the secondary treatment system may not be as portable. That uncertainty resulted in a lower score than the bioremediation and soil washing systems. The bioremediation and soil washing processes can operate with some transfer of equipment, utilities and personnel. The averaged scoring for bioremediation, soil washing and flotation for this category are 3, 4 and 2 , respectively, out of a total of 5 possible.

4-12 


\subsubsection{Goal 6: Minimize Impact on Air Force Operations}

Implementation of an alternative remedial technology from the baseline technology will need to minimize impact on Air Force operations. Evaluation of the potential for minimized impact on Air Force operations is based on one criterion:

- Criterion 9 - Minimize Impact on Air Force Operations

o Minimum time (duration) to complete

- Minimum item for range clearance for personnel

- Flexibility in schedule (schedule restricted vs. schedule independent)

The United States Air Force continues to use the TTR for various operations and missions that may require significant security clearances that are not easily issued to personnel performing O\&M on the treatment system. Treatment activities should be planned to operate in short/non-restrictive time increments and a flexible mode of operation for starts and stops. Soil washing and flotation are both systems that can be interrupted with minimal inconvenience to operating parameters. The bioremediation system is more of a continuous treatment that can be adversely affected if required to shutdown. The averaged scoring for bioremediation, soil washing and flotation for this category are 4, 6 and 6, respectively, out of a total of 10 possible. 


\subsection{COST BENEFIT ANALYSIS}

\subsection{BASELINE TECHNOLOGY}

The baseline technology with which these technologies are competing consists of the following:

- Perform characterization and assessment involving soil sampling and radiological surveys

- Remove topsoil using grader

- Pick up soil using scraper, and transport to processing area

- Screen and assay soil using transportable belt detector system

- Load soil into side-dump trailers lined with "burrito wraps"

- Haul soil to the NTS, and dispose of at the Area 3 Radioactive Waste Management Site

Ideally the NNSA/NSO would like to be able to remediate soil sites to meet regulatory fvrequirements at a cost that is significantly less than the known baseline cost (estimated to be $\$ 21 / \mathrm{ft}^{3}$ or less), with no significant adverse environmental, safety or health impacts from deploying the innovative technology. These are ESTIMATED field costs for remediating the Project 57, Clean Slate 2, Clean Slate 3, and Small Boy sites. The costs were provided by Bechtel Nevada. These are just the field costs, and exclude planning, document preparation, engineering, etc. The estimated total soil volume at these sites is $2,682,000$ cubic feet.

Table 5-1. Baseline Cost Projection.

\begin{tabular}{|l|r|r|}
\hline \multicolumn{1}{|c|}{ Task } & \multicolumn{1}{|c|}{$\begin{array}{c}\text { Cost, } \\
\mathbf{1 0 0 0} \text { 's }\end{array}$} & \multicolumn{1}{|c|}{$\mathbf{1} \mathbf{f t}^{\mathbf{3}}$} \\
\hline Field Work Preparation (e.g.. field planning) & $\$ 3,199$ & $\$ 1.19$ \\
\hline $\begin{array}{l}\text { Field Work (e.g. mobilization, site prep, infrastructure, logistics, } \\
\text { demob) }\end{array}$ & $\$ 3,276$ & \\
\hline Waste Characterization (e.g. belt detector system, data collection) & $\$ 2,069$ & $\$ 0.77$ \\
\hline $\begin{array}{l}\text { Excavation (e.g. road grader forming windrows, picking up with } \\
\text { paddlewheel scraper) }\end{array}$ & $\$ 4,480$ & \\
\hline $\begin{array}{l}\text { Packaging for Disposal (e.g. material handling, burrito wraps, } \\
\text { loading into trucks) }\end{array}$ & $\$ 15,418$ & $\$ 1.67$ \\
\hline Transportation (e.g. hauling to NTS for disposal) & $\$ 9,125$ & $\$ 3.40$ \\
\hline Disposal (e.g. disposal fee) & $\$ 19,194$ & $\$ 7.16$ \\
\hline TOTAL OF ABOVE & $\$ 56,761$ & $\$ 21.16$ \\
\hline
\end{tabular}

The cost estimates for each of the following treatment technologies were originally based on a soil volume of $1,200,000 \mathrm{ft}^{3}$, the estimated volume of contaminated soil at the Clean Slate 3 site (except for the bioremediation cost estimate, which was based on treatment of

5-1 
25,000 cubic yards or $675,000 \mathrm{ft}^{3}$ ). This was used as a basis because that was the baseline information that was available to the vendors at the time of their studies. To allow comparison to the latest baseline data, these costs have all been adjusted for a soil treatment volume of 2,682,000 $\mathrm{ft}^{3}$. This was accomplished by multiplying the cost by the ratio $(2,682,000 / 1,200,000)$, except for the packaging, transportation and disposal costs for bioremediation and soil washing - these were set at $3 \%$ of the baseline cost. This approach was deemed adequate for these simple cost estimates.

To evaluation of the cost estimates the following factors were considered:

- Completeness of Project Scope (are line items reasonable? Are any tasks missing?)

- Reasonable Level of Effort

- Reasonable cost of equipment, supplies, reagents and utilities

- Reasonable labor rates

- Comparison of unit costs

- Contingencies and adjustments

\subsection{BIOREMEDIATION}

Estimated field costs for remediating the plutonium-contaminated Nevada Test Site soils are shown below. The costs were taken from a WM'03 paper $^{13}$. Complete details are provided in Appendix B. These are just the field costs, and exclude planning, document preparation, engineering, etc. The costs have been adjusted for a soil volume of 2,682,000 cubic feet.

\section{Table 5-2. Bioremediation Cost Projection.}

\begin{tabular}{|l|r|r|}
\hline \multicolumn{1}{|c|}{ Task } & \multicolumn{1}{|c|}{\begin{tabular}{c}
\multicolumn{1}{|c|}{ Cost, } \\
1000's
\end{tabular}} & \multicolumn{1}{|c|}{$\$ \mathbf{f t}^{\mathbf{3}}$} \\
\hline Premobilization & $\$ 1,035$ & $\$ 0.39$ \\
\hline $\begin{array}{l}\text { Site Preparation (Site survey and layout, office and support trailers, tools, } \\
\text { electrical service, site monitoring instruments, water trucks, personnel } \\
\text { transportation, labor) }\end{array}$ & $\$ 2,649$ & $\$ 0.99$ \\
\hline $\begin{array}{l}\text { Leach Bed Construction (Excavation and construction, aeration system, } \\
\text { blower installation) }\end{array}$ & $\$ 2,608$ & $\$ 0.97$ \\
\hline $\begin{array}{l}\text { Soil Management (Excavator, loader, dump truck, water truck, pug mill, } \\
\text { equipment mob/demob, labor) }\end{array}$ & $\$ 1,366$ & $\$ 0.51$ \\
\hline $\begin{array}{l}\text { Chemicals (sulfur, nitrogen, ethanol, polymer, lime, caustic, bacterial } \\
\text { inoculants (SOB and SRB) }\end{array}$ & $\$ 3,228$ & $\$ 1.20$ \\
\hline $\begin{array}{l}\text { Leachate Treatment Equipment (Tanks, lime silo, polymer/flocculation } \\
\text { skid, sulfide scrubber skid) }\end{array}$ & $\$ 207$ & $\$ 0.08$ \\
\hline $\begin{array}{l}\text { Leachate Treatment Skids (Tanks, pumps, bioreactor, filter press, pug mill, } \\
\text { lime feeder, piping, instrumentation, electrical, controls, } \\
\text { installation/fabrication, painting, engineering, designing, procurement } \\
\text { procedures and plans) }\end{array}$ & $\$ 869$ & $\$ 0.32$ \\
\hline $\begin{array}{l}\text { Leachate Treatment Installation (Secondary containment, skid } \\
\text { mob/demob, feed and leachate basins, leachate basin cover) }\end{array}$ & $\$ 579$ & $\$ 0.22$ \\
\hline \begin{tabular}{l} 
Operation (Maintenance, electrical, labor analytical) \\
\hline
\end{tabular} & $\$ 2,401$ & $\$ 0.90$ \\
\hline
\end{tabular}

$$
\text { 5-2 }
$$


CETL reviewed the cost information provided by Shaw in their final report. Additional details were requested to aid in the evaluation. Shaw provided a copy of a paper they had presented at the WM'03 conference, which is the source of the above information (see also Appendix B). All major tasks appear to all have been addressed. However, there is no further cost breakdown. For example, there are no details, only lump sum amounts, for:

- equipment costs

- cost of reagents

- cost of utilities

In addition, no details are provided about:

- $\quad$ the number and type of workers, level of effort and hourly rates

- the amount of remote monitoring versus on-site time

- depreciation

- a contingency

- the amount allowed for maintenance and downtime

- analytical costs

and there is no discussion that remoteness of the site has been factored into the cost estimate.

The format of the bioremediation cost estimate is different from that provided by the other vendors and the baseline technology. This makes it more difficult to make comparisons. The best that can be done with the information that is available is to compare the cost on a $\$ / \mathrm{ft}^{3}$ basis. Most of the numbers appear low, although it is not clear if the components that make up each are comparable. For example, the bioremediation cost element "Premobilization", $\$ 0.39 / \mathrm{ft}^{3}$, could be compared to the baseline cost element "Field Work Preparation", $\$ 1.19 / \mathrm{ft}^{3}$. Likewise the bioremediation cost element "Soil Management", $\$ 0.51 / \mathrm{ft}^{3}$, could be compared to the baseline cost element "Excavation", $\$ 1.67 / \mathrm{ft}^{3}$.

If it is assumed that there is no overlap between the baseline and the Shaw cost estimate, then the total cost would be similar to that shown in Table 5-3.

Even under this scenario, the treatment cost would be less than the baseline.

It is recommended that, prior to further studies, Shaw provide additional details to support their cost estimate.

\subsection{SOIL WASHING}

The following costs breakout (Table 5-4) was taken from the Earthline Soil Washing Treatability Study Final Report dated January 2003. Complete details are provided in Appendix B. These are just the field costs, and exclude planning, document preparation, engineering, etc. The costs have been adjusted for a soil volume of 2,682,000 cubic feet.

$5-3$

Volume V Vendor Studies Evaluation and Ranking 
Table 5-3. Bioremediation + Baseline Cost Projection.

\begin{tabular}{|l|r|r|}
\hline \multicolumn{1}{|c|}{ Task } & $\begin{array}{c}\text { Cost, } \\
\mathbf{1 0 0 0}\end{array}$ & $\mathbf{\$} \mathbf{f t}^{\mathbf{3}}$ \\
\hline Field Work Preparation (e.g.. field planning) & $\$ 3,199$ & $\$ 1.19$ \\
\hline $\begin{array}{l}\text { Field Work (e.g. mobilization, site prep, infrastructure, logistics, } \\
\text { demob) }\end{array}$ & $\$ 3,276$ & $\$ 1.22$ \\
\hline Waste Characterization (e.g. belt detector system, data collection) & $\$ 2,069$ & $\$ 0.77$ \\
\hline $\begin{array}{l}\text { Excavation (e.g. road grader forming windrows, picking up with } \\
\text { paddlewheel scraper) }\end{array}$ & $\$ 4,480$ & $\$ 1.67$ \\
\hline Bioremediation & $\$ 14,941$ & $\$ 5.57$ \\
\hline Backfill Treated Soil & $\$ 3,136$ & $\$ 1.17$ \\
\hline $\begin{array}{l}\text { Packaging for Disposal (e.g. material handling, burrito wraps, } \\
\text { loading into trucks) }\end{array}$ & $\$ 463$ & \\
\hline Transportation (e.g. hauling to NTS for disposal) & $\$ 274$ & $\$ 0.17$ \\
\hline Disposal (e.g. disposal fee) & $\$ 576$ & $\$ 0.21$ \\
\hline TOTAL OF ABOVE & $\$ 32,414$ & $\$ 12.08$ \\
\hline
\end{tabular}

Table 5-4. Soil Washing Cost Projection.

\begin{tabular}{|l|r|r|}
\hline \multicolumn{1}{|c|}{ Task } & \multicolumn{1}{|c|}{$\begin{array}{c}\text { Cost, } \\
\mathbf{1 0 0 0} \text { 's }\end{array}$} & $\mathbf{\$ / \mathbf { f t } ^ { \mathbf { 3 } }}$ \\
\hline Field Work Preparation (e.g.. field planning) & $\$ 3,199$ & $\$ 1.19$ \\
\hline $\begin{array}{l}\text { Field Work (e.g. mobilization, site prep, infrastructure, logistics, } \\
\text { demob) }\end{array}$ & $\$ 3,276$ & $\$ 1.22$ \\
\hline Waste Characterization (e.g. belt detector system, data collection) & $\$ 2,069$ & $\$ 0.77$ \\
\hline $\begin{array}{l}\text { Excavation (e.g. road grader forming windrows, picking up with } \\
\text { paddlewheel scraper) }\end{array}$ & $\$ 4,480$ & $\$ 1.67$ \\
\hline Wash Soil & $\$ 23,613$ & $\$ 8.80$ \\
\hline Backfill Treated Soil & $\$ 2,494$ & $\$ 1.17$ \\
\hline Packaging for Disposal & $\$ 365$ & $\$ 0.17$ \\
\hline Transportation (e.g. hauling to NTS for disposal) & $\$ 262$ & $\$ 0.10$ \\
\hline Disposal (e.g. disposal fee) & $\$ 605$ & $\$ 0.21$ \\
\hline TOTAL OF ABOVE & $\$ 40,363$ & $\$ 15.32$ \\
\hline
\end{tabular}

* Unit cost estimate in the Earthline Final Report was $\$ 13.23 \mathrm{f} \mathrm{t}^{3}$. This value has increased because of updated treatment costs from Bechtel Nevada for the baseline treatment, some components of which are also required for the soil washing treatment.

CETL reviewed the cost information provided by Earthline Technologies in their final report. Additional details were requested to aid in the evaluation. Earthline provided this with the understanding that the material be kept confidential. Readers may contact Earthline directly if they desire to see this information. The summary of the level of effort and tasks appear to be reasonable and well thought out. The overall cost appears to be reasonable based on comparisons that can be made. And appropriate factors such as the following were considered when developing the cost estimate:

- remote location

Volume V Vendor Studies Evaluation and Ranking 
- $\quad$ power from temporary diesel generator

- transportation of water and chemicals to the site

The line items used to develop the cost estimate appear to be complete:

Capital improvements

mobilization

demobilization

startup

operations

maintenance

treated soil analysis

stockpiling of treated soils

backfill by Bechtel Nevada

And the description of the soil treatment process was in accordance with the process demonstrated at the bench scale (physical screening, chemical extraction using stirred tank reactors, L/S separation, UF and NF membrane systems). Reasonable qualifiers were used to adjust the initial estimates (10\% contingency, operations at $80 \%$ of capacity).

The design basis was a plant with capacity of $20 \mathrm{tph}$. To process the $1,200,000 \mathrm{ft}^{3}$ of soil at the Clean Slate II site would require 90 weeks of four 10-hour days (about 21 months). To minimize the length of time on-site, an around-the-clock operation may be more amenable for the soils on the Tonapah Test Range (TTR). This could potentially shorten the treatment time to around 5 months. Cost would need to be adjusted for shift premiums and possible overtime. Heap leaching could possibly benefit from less on-site time, although this was not discussed by Earthline. And cost for treatment using heap leaching would be less (around $\$ 2 / \mathrm{ft}^{3}$ less). Application of heap leaching in the hot, arid, remote NTS climate may be difficult.

\subsection{FLOTATION}

The following cost breakout was taken from the URS Plutonium Oxide Removal from Soil by High Capacity Flotation System Final Report dated September 2002. Complete details are provided in Appendix B. These are just the field costs, and exclude planning, document preparation, engineering, etc. The costs have been adjusted for a soil volume of 2,682,000 cubic feet.

CETL reviewed the cost information provided by URS Corporation in their final report. For the cost estimate $15 \%$ waste was assumed, but it should be remembered that this waste only contains $30-35 \%$ of the plutonium and that additional treatment or processing would be required to meet performance goals. The $200 \mathrm{gpm}$ system is larger than needed and, as a result, equipment cost may be lower (I get that a $200 \mathrm{gpm}$ system has a capacity of 14,054,000 ft3/year, about ten times the size indicated). Cost for utilities and reagents were reasonable. The rate for operators is around $\$ 30 /$ hour, which is probably adequate. 
Table 5-5. High Capacity Flotation C ost Projection.

\begin{tabular}{|l|r|r|}
\hline \multicolumn{1}{|c|}{ Task } & \multicolumn{1}{c|}{$\begin{array}{c}\text { Cost, } \\
\mathbf{1 0 0 0} \mathbf{s}\end{array}$} & $\mathbf{\$ / \mathbf { f t } ^ { 3 }}$ \\
\hline Field Work Preparation (e.g.. field planning) & $\$ 3,199$ & $\$ 1.19$ \\
\hline $\begin{array}{l}\text { Field Work (e.g. mobilization, site prep, infrastructure, logistics, } \\
\text { demob) }\end{array}$ & $\$ 3,276$ & $\$ 1.22$ \\
\hline Waste Characterization (e.g. belt detector system, data collection) & $\$ 2,069$ & $\$ 0.77$ \\
\hline $\begin{array}{l}\text { Excavation (e.g. road grader forming windrows, picking up with } \\
\text { paddlewheel scraper) }\end{array}$ & $\$ 4,480$ & $\$ 1.67$ \\
\hline Packaging for Disposal & $\$ 1,824$ & $\$ 0.04$ \\
\hline Transportation (e.g. hauling to NTS for disposal) & $\$ 1,310$ & $\$ 0.63$ \\
\hline Disposal (e.g. disposal fee) & $\$ 3,026$ & $\$ 0.01$ \\
\hline Equipment Depreciation & $\$ 98$ & $\$ 0.15$ \\
\hline Water Cost & $\$ 1687$ & $\$ 0.33$ \\
\hline Power Cost & $\$ 22$ & $\$ 0.68$ \\
\hline Chemical Reagent & $\$ 391$ & $\$ 0.49$ \\
\hline Operators & $\$ 883$ & $\$ 1.13$ \\
\hline TOTAL OF ABOVE & $\$ 22,265$ & $8.30^{*}$ \\
\hline
\end{tabular}

* Unit cost estimate in the URS Corporation Final Report was $\$ 6.48 \mathrm{f} \mathrm{t}^{3}$. This value has increased because of updated treatment costs from Bechtel Nevada for the baseline treatment, some components of which are also required for the soil washing treatment.

The process described is for an around the clock operation, but there are no adjustments for shift premiums. There is also no time budgeted for supervisor or oversight time. The depreciation is reasonable as is the level of effort for the operators. There is no contingency for maintenance and downtime. No analytical or monitoring costs are mentioned. It is unclear what the equipment cost includes (e.g., power generator, building, staging area for workers, etc.)

$5-6$ 


\subsection{SUMMARY OF THE CRITERIA EVALUATION AND OF PREVIOUS RELATED STUDIES}

\subsection{SUMMARY OF THE CRITERIA EVALUATION}

The numerical scoring results of the three technologies are provided in Table 6-1. A summary is provided of scores for each criterion, corresponding goal, weighted value of each criterion based on goal value, and a total score for each technology based on a maximum of 100 percent. The bioremediation technology demonstrated by Shaw had the highest score of 69 percent, followed by Earthline's Soil Washing system with a score of 64 percent, and the URS flotation system with a score of 42 percent.

Conclusions from the laboratory testing, presented as strengths and weaknesses, as summarized in Table 6-1. It should be noted that the flotation system would require enhancement or coupling with other technology to meet the residual $\mathrm{Pu}$ in soil standards. An the on-site time required for any of these technologies may make implementation at the TTR difficult.

Table 6-1. Technology Strengths and Weaknesses.

\begin{tabular}{|c|l|l|}
\hline Technology & \multicolumn{1}{|c|}{ Strength } & \multicolumn{1}{|c|}{ Weakness } \\
\hline Bioremediation & $\begin{array}{l}\text { Treatment meets preliminary } \\
\text { remediation goals } \\
\text { With utility and resource planning the } \\
\text { system can be operated in remote areas }\end{array}$ & $\begin{array}{l}\text { Requires that soil moisture } \\
\text { content be maintained at } \\
\text { approximately 15 percent } \\
\text { Process requires close } \\
\text { monitoring }\end{array}$ \\
\hline Soil Washing & $\begin{array}{l}\text { Treatment meets preliminary } \\
\text { remediation goals }\end{array}$ & $\begin{array}{l}\text { Leachate recycling process } \\
\text { needs to be demonstrated. } \\
\text { and operate in remote areas }\end{array}$ \\
\hline High Capacity & $\begin{array}{l}\text { System can be operated in campaigns } \\
\text { to lessen possible schedule } \\
\text { interruptions from Air Force site use }\end{array}$ & $\begin{array}{l}\text { System is mobile and can be operated } \\
\text { in remote areas }\end{array}$ \\
$\begin{array}{l}\text { System can be operated in campaigns } \\
\text { to lessen possible schedule } \\
\text { interruptions from Air Force site use }\end{array}$ & $\begin{array}{l}\text { Does not meet preliminary } \\
\text { remediation goals without } \\
\text { enhancements or coupling } \\
\text { with another treatment } \\
\text { system. }\end{array}$ \\
\hline
\end{tabular}

6-1 


\subsection{SUMMARY OF PREVIOUS RELATED STUDIES}

Three soils from the Nevada Test Site were evaluated using the following five technologies. A brief summary of the pilot scale results of each of these studies is provided below. All fell short of consistently reducing the mass (volume) of contaminated soil. Performance of one field study is also summarized. Further details and the report references are included in Volume 1.

Of the pilot scale studies that have been performed, only processes based on particle size appear promising. (Laboratory bench scale flotation and bioremediation studies were also encouraging). However, since the particle size distribution and plutonium distribution are not constant, the effectiveness of this process varies from site to site and even within a site. No chemical extraction studies on plutonium-contaminated soils from the NTS have been performed. The data indicate that mass reduction based on particle size separation would need to be joined with another technology to be able to consistently reduce the mass of contaminated soil.

\section{PARAMAG}

The PARAMAG process consisted on an attrition scrubber, a hydraulic particle size separator, a conventional screen and a high-intensity cylindrical magnet, which was the main component of the separation process. The best run of the three soils lowered the amount of plutonium in the soil from 298 down to $207 \mathrm{pCi} / \mathrm{g}$. This "clean soil" was $73 \%$ of the initial soil mass. Good mass reduction was obtained but the removal of plutonium was poor.

Advanced Processing Technologies, Inc. (APT)

The APT process uses an air-sparged hydrocyclone (ASH). The ASH injects numerous small air bubbles into a high velocity swirl flow of soil slurry to separate fine particles from the soil mass. Results varied from soil to soil. One of the better runs lowered the amount of plutonium in the soil from 423 down to $278 \mathrm{pCi} / \mathrm{g}$. This "clean soil" was $69 \%$ of the initial soil mass. Good mass reduction was obtained but the removal of plutonium was poor.

Lockheed Environmental Systems and Technolgies (LESAT) Process

The LESAT process used a variety of technologies in an attempt to separate plutonium from contaminated soil. Components included an attrition scrubber, a two-cell mineral jig, an spiral classifier, a Wilfley shaking table, a Falcon concentrator and a hydrocyclone. Only separation by particle size using the spiral classifier worked somewhat well. One of the better runs lowered the amount of plutonium in the soil from 190 down to $6 \mathrm{pCi} / \mathrm{g}$. This clean soil was $17 \%$ of the initial soil mass. Removal of plutonium was good but mass reduction was not.

Other processes which were based on particle separation by density (mineral jug and shaking table) were not successful. The results from the tests performed with the concentrator were inconclusive.

Nuclear Remediation Technologies (NRT)

Volume V Vendor Studies Evaluation and Ranking 
The NRT dry process used particle sizing, low-intensity magnetic separation and high intensity magnetic separation. No concentration of radioactivity was observed.

\section{Scientific Ecology Group (SEG) Process}

The SEG process used an attrition scrubber, a mineral jig, vibrating screens, and a multigravity separator (MGS). The performance of the SEG process was variable. One of the better runs lowered the amount of plutonium in the soil from 742 down to $220 \mathrm{pCi} / \mathrm{g}$. This "clean soil" was $94 \%$ of the initial soil mass. Good removal of plutonium and good mass reduction were obtained. However, the mass balance for plutonium was very poor and calls into question the results. In another run the specific activity of plutonium in the tailings was higher that in the feed. The significant variation in results and the poor mass balance are concerns that would need to be resolved.

\section{Segmented Gate}

Poor results were obtained in a field test performed at the Clean Slate 2 site: only $61 \%$ of the plutonium activity ended up in the "concentrate" with a volume reduction of 2:1 (weight of feed to weight of clean).

These results of the current studies are encouraging because they indicate significant improvement over that obtained in these earlier pilot and field studies.

6-3 


\subsection{CONCLUSIONS AND RECOMMENDATIONS}

Based on the results of bench testing of technologies for the removal of $\mathrm{Pu}$ from soils at NTS, two technologies are considered to be viable treatment alternatives to the baseline approach of excavate, transport and dispose. Both the Shaw bioremediation technology and the Earthline soil washing technology met the criteria and goals established for the project, and preliminary testing demonstrates the potential for significant volume reduction of $\mathrm{Pu}$ contaminated soils at a substantial cost savings.

All three technologies tested exhibited strengths and weaknesses within the parameters at the NTS. The URS Flotation technology was not as streamlined as the others for NTS soils and the waste volume reduction was not demonstrated. The Shaw and Earthline technologies both demonstrated similar reduction percentages in waste volume. The Shaw bioremediation system will require a large volume of water and continuous operation. The Earthline soil washing system will require a large volume of water and will generate a secondary waste stream that will require treatment/disposal.

It is recommended that, pending review of more detailed information to support the cost estimate, the Shaw system be considered for a pilot scale demonstration at the NTS. Parallel with or prior to this effort, it would also be useful to perform laboratory studies to determine if sulfuric acid leaching can perform as well as the bioremediation process. A chemical based process would be much simpler than the biological based Shaw process. The Earthline system should first demonstrate effective Pu removal from recycled leachate prior to advancing to a pilot scale test. And concerns raised by technical team members should be addressed and resolved prior to a pilot scale test. Larger scale testing under true site conditions will reduce technology deployment uncertainties and allow a site-specific evaluation of system requirements. No further studies are recommended for the URS flotation technology.

$7-1$ 


\subsection{REFERENCES AND BIBLIOGRAPHY}

${ }^{1}$ Origins of the Nevada Test Site, United State Department of Energy, DOE/MA-0518, December 2000.

${ }^{2}$ United States Nuclear Tests, July 1945 through September 1992, DOE/NV-209 (Rev.14). US DOE Nevada Operations Office, December 1994.

${ }^{3}$ Cho, Eung Ha, et. al., Soil Volume Reduction Technologies, Evaluation of Current Technologies, DOE Cooperative Agreement DE-FC26-98FT40396, Deployment Leading to Implementation, Final Report, submitted by West Virginia University to US DOE National Energy Technology Laboratory, July 2000.

${ }^{4}$ Final Environmental Impact Statement for the Nevada Test Site and Off-Site Location in the State of Nevada, United States Department of Energy, EIS Report, DOE/EIS -0243. Available on-line at: http://nepa.eh.doe.gov/eis/eis0243/eis0243 toc.html

51996 Baseline Environmental Management Report, Nevada Test Site and Tonopah Test Range, US DOE Office of Environmental Management, 1996. Available on-line at: http://www.em.doe.gov/bemr96/nvts.html

${ }^{6}$ Cost/Risk/Benefit Analysis of Alternative Cleanup Requirements for PlutoniumContaminated Soils On and Near the Nevada Test Site, DOE/NV-399, US DOE Nevada Operations Office, May 1995.

${ }^{7}$ Murarik, T.M., "Characterization, Liberation and Separation of Plutonium at the Nevada Test Site: Safety Shot Residues", Proceedings of the Soil Decon '93: Technology Targeting Radionuclides and Heavy Metals, June 16 and 17, 1993, Gatlinburg, TN, ORNL-6769, Oak Ridge National Laboratory, Oak Ridge, TN, September 1993.

${ }^{8}$ Misra, M., et. al., "Characterization and Physical Separation of Radionuclides from Contaminated Soils," Proceedings of the Soil Decon '93: Technology Targeting Radionuclides and Heavy Metals, June 16 and 17, 1993, Gatlinburg, TN, ORNL6769, Oak Ridge National Laboratory, Oak Ridge, TN, September 1993.

${ }^{9}$ Papelis, et. al., Evaluation of Technologies for Volume Reduction of PlutoniumContaminated Soils from the Nevada Test Site, DOE/NV/10845-57, US DOE Nevada Operations Office, June 1996. Available on-line at: http://208.200.37.252/pdf/z01017a.pdf or at: http://plutoniumerl.actx.edu/pusoil.html

$8-1$ 
${ }^{10}$ Murari, T.M., et.al., "Characterization Studies And Indicated Remediation Methods for Plutonium Contaminated Soils at the Nevada Test Site", Spectrum '92, Boise, Idaho, August 23-27, 1992.

${ }^{11}$ Misra, et.al., A Cost Effective Approach for Volume Reduction of PlutoniumContaminated Soils," University of Nevada-Reno.

${ }^{12}$ Data provided by Sean Crawford (USDOE Nevada Operations Office) to Steve Hoeffner (Clemson University) on January 23, 2001. Data is from studies performed by University of Nevada-Reno and by IT Corporation around 1996. The IT data was included as an attachment to a memorandum from J.R. McKinley to L. Wille on August 26, 1996, Subject: Volume Reduction Study.

${ }^{13}$ Jerger, J.E., E.S. Alperin, R.G. Holmes. Biologically-Mediated Removal and Recovery of Plutonium from Contaminated Soil, WM'03 Conference, February 23-27, 2003, Tucson, Arizona. 
APPENDIX A 
Table A-1. Vendor Technology Treatability Study Scoring.

\begin{tabular}{|c|c|c|c|c|c|}
\hline \multirow[b]{2}{*}{ Criterion } & \multirow[b]{2}{*}{ Critical Measure } & \multirow[b]{2}{*}{ Scoring Rationale } & \multicolumn{3}{|c|}{ Score $(1=$ poor, $5=$ excellent $)$} \\
\hline & & & $\begin{array}{l}\text { Bio- } \\
\text { remediation }\end{array}$ & $\begin{array}{l}\text { Soil } \\
\text { Washing }\end{array}$ & $\begin{array}{l}\text { High } \\
\text { Capacity } \\
\text { Flotation }\end{array}$ \\
\hline \multirow{4}{*}{$\begin{array}{l}\text { Project Reduction } \\
\text { Potential }\end{array}$} & $\begin{array}{l}\text { Schedule risk with respect } \\
\text { to baseline }\end{array}$ & $\begin{array}{l}\text { 1. Causes Program to miss programmatic or milestones } \\
\text { established by agreements } \\
\text { 2. Can be implemented with in baseline, but poses significant } \\
\text { challenge to baseline schedule, cost, and risk } \\
\text { 3. Can be implemented within baseline with moderate risk/cost } \\
\text { to schedule } \\
\text { 4. Can be implemented within baseline with minimal risk } \\
\text { 5. Same time or less than baseline }\end{array}$ & 3 & 4 & 2 \\
\hline & $\begin{array}{l}\text { Reduce volume of soil } \\
\text { requiring packaging } \\
\text { transportation and disposal }\end{array}$ & $\begin{array}{l}\text { 1. } \text { Soil volume reduction }<70 \% \text { (economically not viable) } \\
\text { 2. Projected soil volume reduction }+/-70 \\
\text { 3. Projected soil volume reduction } 70-80 \\
\text { 4. Projected soil volume reduction } 80-90 \\
\text { 5. Projected soil volume reduction } 90+\end{array}$ & 3 & 4 & 1 \\
\hline & $\begin{array}{l}\text { Avoid (minimize) issues } \\
\text { related to waste disposition } \\
\text { requirements (No orphaned } \\
\text { waste streams) }\end{array}$ & $\begin{array}{l}\text { 1. Produces minimal secondary waste with acceptable } \\
\text { disposition } \\
\text { 2. Produces minimal secondary waste, but has uncertainties } \\
\text { about disposition (treatment) } \\
\text { 3. Produces minimal secondary waste, but has a defined } \\
\text { disposition path difficult to implement } \\
\text { 4. Produces minimal secondary waste, but has a defined } \\
\text { disposition path, demonstrated technically, just cost } \\
\text { 5. Produces no secondary waste for which there are issues with } \\
\text { disposition path cost }\end{array}$ & 4 & 2 & 3 \\
\hline & & $\begin{array}{ll} & \text { Criterion Score } \\
\end{array}$ & 3.3 & 3.3 & 2.0 \\
\hline $\begin{array}{l}\text { Minimize Soil } \\
\text { Volume that has to } \\
\text { be handled }\end{array}$ & $\begin{array}{l}\text { Enabling }-\mathrm{Pu} \text { in treated } \\
\text { soils must be } \leq 1000 \\
\text { pCi/gm }\end{array}$ & $\begin{array}{l}\text { 1. Does not treat soils to } \leq 1000 \mathrm{pCi} / \mathrm{gm} \\
\text { 5. Does treat soils to } \leq 1000 \mathrm{pCi} / \mathrm{gm}\end{array}$ & 5 & 5 & 1 \\
\hline
\end{tabular}


Table A-1. Vendor Technology Treatability Study Scoring.

\begin{tabular}{|c|c|c|c|c|c|}
\hline \multirow[b]{2}{*}{ Criterion } & \multirow[b]{2}{*}{ Critical Measure } & \multirow[b]{2}{*}{ Scoring Rationale } & \multicolumn{3}{|c|}{ Score $(1=$ poor, $5=$ excellent $)$} \\
\hline & & & $\begin{array}{l}\text { Bio- } \\
\text { remediation }\end{array}$ & $\begin{array}{l}\text { Soil } \\
\text { Washing }\end{array}$ & $\begin{array}{l}\text { High } \\
\text { Capacity } \\
\text { Flotation }\end{array}$ \\
\hline $\begin{array}{l}\text { Minimize Soil } \\
\text { Volume that has to } \\
\text { be handled } \\
\text { (continued) }\end{array}$ & $\begin{array}{l}\text { Volume Reduction - } \\
\text { nominally, } 70 \% \text { is the } \\
\text { minimum effective } \\
\text { reduction }\end{array}$ & $\begin{array}{l}\text { 1. Requires same material handling as baseline, achieves } \\
\text { marginal volume reduction and increases project } \\
\text { performance to limits } \\
\text { 2. Reduction of treatment and disposal material has high risk } \\
\text { for technology and for project performance } \\
\text { 3. Same as baseline for material handling, achieves moderate } \\
\text { return of material for treatment and disposal but has } \\
\text { moderate technology or project performance risk } \\
\text { 4. Same baseline material handling, achieves significant } \\
\text { reduction of material for treatment and disposal with low risk } \\
\text { to project performance parameters } \\
\text { 5. Removes and recovers Pu in minimal volume for with no } \\
\text { required excavation/processing }\end{array}$ & 3 & 4 & 1 \\
\hline & & $\begin{array}{ll} & \text { Criterion Score } \\
\end{array}$ & 4.0 & 4.5 & 1.0 \\
\hline $\begin{array}{l}\text { Minimize DOE ER } \\
\text { Costs for the project }\end{array}$ & $\begin{array}{l}\text { Soil excavation and } \\
\text { handling }\end{array}$ & $\begin{array}{l}\text { 1. Extensive handling initial and subsequent (tilling) that has } \\
\text { high onsite operational requirement and causes high worker } \\
\text { exposure } \\
\text { 2. Moderate handling initial and subsequent (tilling) that has } \\
\text { moderate onsite operational requirement and causes } \\
\text { moderate worker exposure } \\
\text { 3. Uses baseline excavation and handling requires supplemental } \\
\text { operation but they can be performed/monitored with modest } \\
\text { effort/exposure } \\
\text { 4inimal excavating or uses baseline and requires handling } \\
\text { that produces modest operational requirement and/or worker } \\
\text { exposure } \\
\text { Avoids excavating or uses baseline and requires handling } \\
\text { that produces minimal operational requirement and/or worker } \\
\text { exposure }\end{array}$ & 3 & 2 & 2 \\
\hline
\end{tabular}


Table A-1. Vendor Technology Treatability Study Scoring.

\begin{tabular}{|c|c|c|c|c|c|}
\hline \multirow[b]{2}{*}{ Criterion } & \multirow[b]{2}{*}{ Critical Measure } & \multirow[b]{2}{*}{ Scoring Rationale } & \multicolumn{3}{|c|}{ Score $(1=$ poor, $5=$ excellent $)$} \\
\hline & & & $\begin{array}{l}\text { Bio- } \\
\text { remediation }\end{array}$ & $\begin{array}{l}\text { Soil } \\
\text { Washing }\end{array}$ & $\begin{array}{l}\text { High } \\
\text { Capacity } \\
\text { Flotation }\end{array}$ \\
\hline \multirow[b]{2}{*}{$\begin{array}{l}\text { Minimize DOE ER } \\
\text { Costs for the project } \\
\text { (continued) }\end{array}$} & $\begin{array}{l}\text { Soil treatment and leachate } \\
\text { recovery }\end{array}$ & $\begin{array}{l}\text { 1. Process requires baseline excavation and handling plus } \\
\text { extensive on site work (staff) with extensive utility } \\
\text { requirements } \\
\text { 2. Enhancement would require recurring staffing (for } \\
\text { operations) and supplies, utilities, equipment } \\
\text { 3. Enhancement could be achieved, but would require personnel } \\
\text { presence on site and a recurring (or continual) supply of } \\
\text { resources } \\
\text { 4. Enhancement can be achieved with minimal site presence } \\
\text { (staff, installed or operated equipment), facilities, utilities } \\
\text { 5. Only marginal additional increases above the baseline } \\
\text { grade/load/go in line with minimal process and/or time input }\end{array}$ & 3 & 2 & 2 \\
\hline & Leachate drying & $\begin{array}{l}\text { 1. Process yields a waste for which disposition path is } \\
\text { problematic and additional processing or high-cost disposal } \\
\text { required. } \\
\text { Technical risks would be increased } \\
\text { 2. Leachate produced requires processing with some technical } \\
\text { risk to achieve disposition (process or "expensive" form of } \\
\text { waste - TRU) } \\
\text { 3. Process yields leachate (product) that takes processing with } \\
\text { minimal technical risk (drying, neutralization) and has a } \\
\text { clean disposition path } \\
\text { 4. Process yields leachate (product) that requires minimal } \\
\text { processing and technical risk. Some small volume may be } \\
\text { expensive } \\
\text { Process yields waste forms acceptable for disposition in } \\
\text { available facilities at reasonable cost (NTS disposal) }\end{array}$ & 4 & 2 & 3 \\
\hline
\end{tabular}


Table A-1. Vendor Technology Treatability Study Scoring.

\begin{tabular}{|c|c|c|c|c|c|}
\hline \multirow[b]{2}{*}{ Criterion } & \multirow[b]{2}{*}{ Critical Measure } & \multirow[b]{2}{*}{ Scoring Rationale } & \multicolumn{3}{|c|}{ Score $(1=$ poor, $5=$ excellent $)$} \\
\hline & & & $\begin{array}{l}\text { Bio- } \\
\text { remediation }\end{array}$ & $\begin{array}{l}\text { Soil } \\
\text { Washing }\end{array}$ & $\begin{array}{l}\text { High } \\
\text { Capacity } \\
\text { Flotation }\end{array}$ \\
\hline \multirow[t]{2}{*}{$\begin{array}{l}\text { Minimize DOE ER } \\
\text { Costs for the project } \\
\text { (continued) }\end{array}$} & $\begin{array}{l}\text { Material assay and } \\
\text { packaging }\end{array}$ & $\begin{array}{l}\text { 1. Requires complete assay and packaging } \\
\text { 2. Combination of complexities for assay, analytical, packaging } \\
\text { are feasible but complex } \\
\text { 3. Uses in filed analytical to confirm simple requirements to } \\
\text { package. May have some special packaging requirements } \\
\text { 4. Uses in field analytical, mostly simple (by volume). Simple } \\
\text { packaging may require minimal special waste assay and } \\
\text { packaging } \\
\text { 5ssay can be done on site or by process knowledge (with } \\
\text { periodic confirmation) and packaged simply in bulk }\end{array}$ & 3 & 3 & 2 \\
\hline & Transportation & $\begin{array}{l}\text { 1. Large volume of } \mathrm{Pu} \text { soil remain to be shipped in bulk and } \\
\text { process generates } 1 \text { or more other streams that require } \\
\text { complex transportation } \\
\text { 2. Modest volume of } \mathrm{Pu} \text { contaminated soils - significant } \\
\text { secondary waste streams (mixed, TRU) } \\
\text { 3. Volume of } \mathrm{Pu} \text { contaminated soils moderately reduced ( }>70 \text { to } \\
\text { ) and a modest amount of secondary waste } \\
\text { 4. Significantly reduced } \mathrm{Pu} \text { in soils, minimal to no other } \\
\text { secondary waste } \\
\text { 5. Minimal volume of } \mathrm{Pu} \text { contaminated soils, suitable to ship in } \\
\text { bulk }\end{array}$ & 4 & 3 & 2 \\
\hline
\end{tabular}


Table A-1. Vendor Technology Treatability Study Scoring.

\begin{tabular}{|c|c|c|c|c|c|}
\hline \multirow{3}{*}{ Criterion } & \multirow[b]{2}{*}{ Critical Measure } & \multirow[b]{2}{*}{ Scoring Rationale } & \multicolumn{3}{|c|}{ Score $(1=$ poor, $5=$ excellent $)$} \\
\hline & & & $\begin{array}{l}\text { Bio- } \\
\text { remediation }\end{array}$ & $\begin{array}{l}\text { Soil } \\
\text { Washing }\end{array}$ & $\begin{array}{l}\text { High } \\
\text { Capacity } \\
\text { Flotation }\end{array}$ \\
\hline & Disposal & $\begin{array}{l}\text { 1. Process yields significant volume of waste requiring } \\
\text { disposal/disposition and generation of secondary waste with } \\
\text { complex disposition requirements } \\
\text { 2. Process yields major waste reductions and significant } \\
\text { secondary waste generation for waste disposition } \\
\text { 3. Process yields moderate volume reduction with } \\
\text { disposal/disposition at NTS. Some waste is of moderate } \\
\text { volume and complexity for disposition }\end{array}$ & 4 & 3 & 2 \\
\hline & & $\begin{array}{ll} & \text { Criterion Score }\end{array}$ & 3.5 & 2.5 & 2.2 \\
\hline \multirow{3}{*}{$\begin{array}{l}\text { DOE Custodial } \\
\text { Responsibilities }\end{array}$} & $\begin{array}{l}\text { Decrease Pu level to below } \\
\text { applicable limits }\end{array}$ & 1. $<1000 \mathrm{pCi} / \mathrm{gm}$ in residuals - enabling & & & \\
\hline & $\begin{array}{l}\text { Avoid/Minimize "Long- } \\
\text { term Monitoring/Legacy" } \\
\text { Responsibilties }\end{array}$ & $\begin{array}{l}\text { 1. Action would leave soils > regulatory limits and /or } \\
\text { monitoring/legacy responsibilities (ecological or waste) } \\
\text { 2. No soils above regulatory limits, but extensive monitoring } \\
\text { requirement/or legacy (ecological or waste) } \\
\text { 3. No soils above regulatory limits but regular (infrequent) } \\
\text { monitoring for ecological and/or waste issues } \\
\text { 4. No soils above regulatory limits, but minimal (event } \\
\text { triggered) monitoring for ecological and/or waste issues } \\
\text { 5. Responsibilities limited to only "deed" liability }\end{array}$ & 4 & 3 & 1 \\
\hline & & $\begin{array}{ll}\text { Criterion Score } \\
\end{array}$ & 4.0 & 3.0 & 1.0 \\
\hline
\end{tabular}


Table A-1. Vendor Technology Treatability Study Scoring.

\begin{tabular}{|c|c|c|c|c|c|}
\hline \multirow[b]{2}{*}{ Criterion } & \multirow[b]{2}{*}{ Critical Measure } & \multirow[b]{2}{*}{ Scoring Rationale } & \multicolumn{3}{|c|}{ Score $(1=$ poor, $5=$ excellent $)$} \\
\hline & & & $\begin{array}{l}\text { Bio- } \\
\text { remediation }\end{array}$ & $\begin{array}{l}\text { Soil } \\
\text { Washing }\end{array}$ & $\begin{array}{l}\text { High } \\
\text { Capacity } \\
\text { Flotation }\end{array}$ \\
\hline \multirow[t]{3}{*}{$\begin{array}{l}\text { Minimize the risks } \\
\text { of transportation } \\
\text { accidents }\end{array}$} & $\begin{array}{l}\text { Transportation of primary } \\
\text { waste to disposal }\end{array}$ & $\begin{array}{l}\text { 1. Large volume of Pu soils and/or Pu soils with increased } \\
\text { concentrations being transported from Safe Shots to disposal } \\
\text { 2. Minimally reduced volume of Pu soils and/or Pu soils } \\
\text { significantly increased concentrations being transported from } \\
\text { Safe Shots to disposal } \\
\text { 3. Moderately reduced volume of Pu soils and/or Pu soils with } \\
\text { moderately increased concentrations being transported from } \\
\text { Safe Shots to disposal } \\
\text { 4. Significantly reduced volume of } \mathrm{Pu} \text { soils and/or Pu soils with } \\
\text { minimally increased concentrations being transported from } \\
\text { Safe Shots to disposal } \\
\text { Maximully reduced volume of Pu soils and/or Pu soils with } \\
\text { minimal or no increase in concentrations being transported } \\
\text { from Safe Shots to disposal }\end{array}$ & 3 & 4 & 3 \\
\hline & $\begin{array}{l}\text { Disposition of secondary } \\
\text { waste }\end{array}$ & $\begin{array}{l}\text { 1. Large volume of "difficult waste" (liquid TRU or mixed) } \\
\text { 2. Significant volume of waste with significant exposure } \\
\text { potential } \\
\text { 3. Moderate volume/moderate exposure potential } \\
\text { 4. Small volume with low exposure potential } \\
\text { 5. None }\end{array}$ & 3 & 3 & 3 \\
\hline & & $\begin{array}{ll} & \text { Criterion Score } \\
\end{array}$ & 3.0 & 3.5 & 3.0 \\
\hline \multirow[t]{2}{*}{$\begin{array}{l}\text { Minimize the } \\
\text { potential for uptake } \\
\text { exposure of workers }\end{array}$} & Exposure above baseline & $\begin{array}{l}\text { 1. At work limits - significant mitigation required } \\
\text { 2. Significant } \\
\text { 3. Moderate } \\
\text { 4. Marginal and exposure } \\
\text { 5. At or near baseline }\end{array}$ & 4 & 3 & 3 \\
\hline & $\begin{array}{l}\text { Increment due to processing } \\
\text { exposure }\end{array}$ & See Above & & & \\
\hline
\end{tabular}


Table A-1. Vendor Technology Treatability Study Scoring.

\begin{tabular}{|c|c|c|c|c|c|}
\hline \multirow{3}{*}{ Criterion } & \multirow[b]{2}{*}{ Critical Measure } & \multirow[b]{2}{*}{ Scoring Rationale } & \multicolumn{3}{|c|}{ Score $(1=$ poor, $5=$ excellent $)$} \\
\hline & & & $\begin{array}{l}\text { Bio- } \\
\text { remediation }\end{array}$ & $\begin{array}{l}\text { Soil } \\
\text { Washing }\end{array}$ & $\begin{array}{l}\text { High } \\
\text { Capacity } \\
\text { Flotation }\end{array}$ \\
\hline & $\begin{array}{l}\text { Increment due to modified } \\
\text { waste form/composition }\end{array}$ & $\begin{array}{l}\text { 1. High assimulation form with high content (fine, dry) } \\
\text { particulates easily airborne } \\
\text { 2. Moderately assimulation form with high content (fine, dry) } \\
\text { particulates easily airborne } \\
\text { 3. Wet soil or slurry, not easily airborne, moderate content } \\
\text { 4. Wet soil or slurry, not easily airborne, low content } \\
\text { 5. Stabilized form, low content }\end{array}$ & 4 & 3 & 3 \\
\hline & & $\begin{array}{ll} & \text { Criterion Score } \\
\end{array}$ & 4.0 & 3.0 & 3.0 \\
\hline $\begin{array}{l}\text { Maximize Process } \\
\text { Simplicity }\end{array}$ & $\begin{array}{l}\text { No Intermediate Scoring } \\
\text { Factor Used }\end{array}$ & $\begin{array}{l}\text { 1. Inherently complex process, high on site O\&M, low } \\
\text { compatability with isolated arid environment } \\
\text { 2. Significant process complexities, significant on site O\&M, } \\
\text { significant compatibility issues, isolated, arid environment } \\
\text { 3. Moderately complex, moderate O\&M, medium compatibility } \\
\text { issues with environment } \\
\text { 4. Low complexity, periodic to moderate O\&M, and reasonably } \\
\text { compatible with isolated/arid environment } \\
\text { 5. Inherently simple process, low (on site) O\&M, compatible } \\
\text { with isolated/arid environment }\end{array}$ & 3 & 3 & 2 \\
\hline & & $\begin{array}{ll} & \text { Criterion Score } \\
\end{array}$ & 3.0 & 3.0 & 2.0 \\
\hline \multirow[t]{2}{*}{$\begin{array}{l}\text { Optimize Process } \\
\text { System Portability }\end{array}$} & $\begin{array}{l}\text { No Intermediate Scoring } \\
\text { Factor Used }\end{array}$ & $\begin{array}{l}\text { 1. New and different for each site with no equipment reuse. } \\
\text { Need utility installation or reliable external supply at each } \\
\text { site, cannot reuse communication and controls, limits on } \\
\text { personnel significant } \\
\text { 2. Minimal transfer of equipment between sites, utility } \\
\text { installation and or supply, minimal communication and } \\
\text { controls reuse, minimal personnel reuse } \\
\text { 3. Modest } \\
\text { 4. Significant } \\
\text { 5. Load and go portability, self-supply utilities (solar) } \\
\text { relocatably communication and controls, reuse same } \\
\text { operations personnel }\end{array}$ & 3 & 3 & 2 \\
\hline & & $\begin{array}{ll}\text { Criterion Score } \\
\end{array}$ & 3.0 & 3.0 & 2.0 \\
\hline
\end{tabular}


Table A-1. Vendor Technology Treatability Study Scoring.

\begin{tabular}{|c|c|c|c|c|c|}
\hline \multirow[b]{2}{*}{ Criterion } & \multirow[b]{2}{*}{ Critical Measure } & \multirow[b]{2}{*}{ Scoring Rationale } & \multicolumn{3}{|c|}{ Score $(1=$ poor, $5=$ excellent $)$} \\
\hline & & & $\begin{array}{l}\text { Bio- } \\
\text { remediation }\end{array}$ & $\begin{array}{l}\text { Soil } \\
\text { Washing }\end{array}$ & $\begin{array}{l}\text { High } \\
\text { Capacity } \\
\text { Flotation }\end{array}$ \\
\hline $\begin{array}{l}\text { Minimize Impact on } \\
\text { Air Force } \\
\text { Operations }\end{array}$ & $\begin{array}{l}\text { No Intermediate Scoring } \\
\text { Factor Used }\end{array}$ & $\begin{array}{l}\text { 1. Schedule duration long or at project baseline limits, extensive } \\
\text { range clearance needed, schedule for implementation is } \\
\text { restrictive } \\
\text { 2. Schedule duration long (relative to baseline or other } \\
\text { enhancements), significant external range clearance needed, } \\
\text { schedule for implementation may have some restrictions } \\
\text { 3. Schedule duration moderate (relative to project baseline or } \\
\text { other enhancements), moderate range clearance needed, } \\
\text { schedule for implementation not highly restrictive } \\
\text { 4. Schedule duration is only marginally above project baseline } \\
\text { limits, minimal range clearance needed, schedule for } \\
\text { implementation is very flexible } \\
\text { Minimal schedule duration to complete, minimal range } \\
\text { clearance needed, schedule for implementation is very } \\
\text { flexible }\end{array}$ & 2 & 3 & 3 \\
\hline & & $\begin{array}{ll} & \text { Criterion Score } \\
\end{array}$ & 2.0 & 3.0 & 3.0 \\
\hline
\end{tabular}


APPENDIX B 


\section{Bioremediation Cost Information Provided by Shaw Environmental and Infrastructure, Inc.}

From page 13 of the Treatability Testing Report for the Removal of Plutonium from Nevada Test Site Area Y Soil Using Biological Treatment, August 12, 2003

The overall objectives including a clean soil plutonium concentration less than 1000 $\mathrm{pCi} / \mathrm{g}$ and a significant soil volume reduction greater than $70 \%$ were achieved based on the test results (Hoeffner, 2001). The estimated cost for full-scale application of the technology is less than $\$ 10$ per cubic foot compared to the baseline technology cost estimate of $\$ 18$ per cubic foot (Jerger, 2003). This work clearly demonstrates that the science of metals bioremediation technology is highly suited to the treatment of Pu in soil. Pilot scale testing will further define the engineering aspects of the technology and provide accurate materials and operating costs for the process.

From page 4 and 5 of the WM'03 Conference paper Biologically-Mediated Removal and Recovery of Plutonium from Contaminated Soil, February 2003,

The full-scale process operation is based on 25,000 cubic yards (19,100 cubic meters) of soil. The soil will be treated in batches for 90 days. The soil leaching will be conducted in four leach beds approximately 48 feet (15 meters) wide, 400 feet (120 meters) long and 12 to 14 feet (3.6 to 4.3 cubic meters) deep (Figure 1). An aeration system consisting of a blower and a slotted pipe network will be placed in a sand layer covering the bottom to pull air through the soil. The soil will be mixed with sulfur, sulfur-oxidizing bacteria, and inorganic nutrients. Each leach bed will receive approximately 1500 cubic yards $(18,400$ cubic meters) of soil.

When soil $\mathrm{pH}$ is less than 2 , the leach beds will be flooded and drained three times to remove solubilized Pu. Approximately 86,000 gallons (325,000 liters) of water will be required for a single pore volume flush per leach bed. pit. The leachate will be directed to the SRB bioreactor at a rate of $40 \mathrm{gpm}(150 \mathrm{lpm})$ (Figure 1). Treated water will be recycled to the pits for additional leaching. The SRB reactor will yield 163 tons of sludge (filter cake) that will be mixed with 10 percent lime to yield a final stabilized sludge mass of 174 tons that is ready for disposal. Volume reduction is greater than 90 percent, but limited by the constraint of not producing a transuranic waste.

Treated soil will be spread over the site or disposed based on client or regulatory requirements. Assuming no special disposal regulations/requirements are imposed, the final soil batch will be limed to neutralize $\mathrm{pH}$, left in the treatment cell, and used to receive recycled water for evaporation. The total treatment time for 24,000 cubic yards $(18,400$ cubic meters) of soil will be 14 months. The full-scale treatment economics indicate that the process costs are favorable (Table III).

Two waste streams will be generated during soil treatment. Aqueous waste will contain very low levels of Pu and other metals, sulfate, and some sulfide. This water will be recycled and finally applied to the last soil treatment batches and left to evaporate. The sulfate concentration in the soil will increase by an estimated two to three thousand $\mathrm{mg} / \mathrm{kg}$ after the water evaporates. Sludge from the clarifier and filter press will contain 
10 to 15 times the level of radioactivity compared to the untreated soil. This sludge will be dewatered to the extent feasible and the resulting filter cake will be stabilized with lime and packed into containers for disposal at a low-level radioactive waste facility.

Table III. Full-Scale Treatment Process Economics

\begin{tabular}{|c|c|c|}
\hline Task & Description & Cost \\
\hline Premobilization & & $\$ 250,000$ \\
\hline Site Preparation & $\begin{array}{l}\text { Site survey and layout, office and support trailers, tools, electrical } \\
\text { service, site monitoring instruments, water trucks, personnel } \\
\text { transportation, labor }\end{array}$ & $\$ 640,000$ \\
\hline $\begin{array}{l}\text { Leach Bed } \\
\text { Construction }\end{array}$ & Excavation and construction, aeration system, blower installation & $\$ 630,000$ \\
\hline $\begin{array}{l}\text { Soil } \\
\text { Management }\end{array}$ & $\begin{array}{l}\text { Excavator, loader, dump truck, water truck, pug mill, equipment } \\
\text { mob/demob, labor }\end{array}$ & $\$ 330,000$ \\
\hline Chemicals & $\begin{array}{l}\text { Sulfur, nitrogen, ethanol, polymer, lime, caustic, bacterial inocula (SOB } \\
\text { and SRB) }\end{array}$ & $\$ 780,000$ \\
\hline $\begin{array}{l}\text { Leachate } \\
\text { Treatment } \\
\text { Equipment }\end{array}$ & Tanks, lime silo, polymer/flocculation skid, sulfide scrubber skid & $\$ 50,000$ \\
\hline $\begin{array}{l}\text { Leachate } \\
\text { Treatment } \\
\text { Skids }\end{array}$ & $\begin{array}{l}\text { Tanks, pumps, bioreactor, filter press, pug mill, lime feeder, piping, } \\
\text { instrumentation, electrical, controls, installation/fabrication, painting, } \\
\text { engineering, designing, procurement procedures and plans }\end{array}$ & $\$ 210,000$ \\
\hline $\begin{array}{l}\text { Leachate } \\
\text { Treatment } \\
\text { Installation }\end{array}$ & $\begin{array}{l}\text { Secondary containment, skid mob/demob, feed and leachate basins, } \\
\text { leachate basin cover }\end{array}$ & $\$ 140,000$ \\
\hline Operation & Maintenance, electrical, labor, analytical & $\$ 580,000$ \\
\hline $\begin{array}{l}\text { Total Project } \\
\text { Cost }\end{array}$ & & $\begin{array}{r}\$ 3,610,00 \\
0\end{array}$ \\
\hline $\begin{array}{l}\text { Cost per cubic } \\
\text { yard }\end{array}$ & & $\$ 150$ \\
\hline Cost per ton & & $\$ 120$ \\
\hline
\end{tabular}




\section{Soil Washing Cost Information Provided by Earthline Technologies}

From page 15 and Table 8 of Nevada Test Site Soil Washing Treatability Study Final

Report, January 2003

The cost of soil washing using the conventional soil washing approach is estimated to be $\$ 13.23 / \mathrm{ft} 3$; therefore, this option provides $\$ 6.14 \mathrm{M}$ savings over the baseline cost of $\$ 18.35 / \mathrm{ft} 3$ for the NTS Clean Slate 3 site. Using the heap leach approach, Earthline estimates the soils could be washed at a cost of $\$ 11.04 / \mathrm{ft} 3$. Therefore, the heap leach option cost savings are estimated to be $\$ 8.77 \mathrm{M}$ over the baseline cost. A cost comparison of the two soil washing options against the Baseline technology is provided in Appendix B, Table 8 .

Both cost estimates assume the soil washing operation would occur in a remote location and includes the cost of power using a temporary diesel generator and transportation of water and chemicals to the NTS site. The cost estimate also assumes Earthline's scope of work would include constructing the landfill and/or providing the soil plant with all the required capital improvements, mobilization, demobilization, startup, operations and maintenance, treated soil analysis, and stockpiling treated soils for the conventional soil washing approach. Earthline assumes the feed soils would be stockpiled adjacent to the soil washing process. Backfilling treated soil would be by others but is included in the life cycle analysis for cost comparison (ref. Appendix B, Table8 for more cost detail).

A process optimization and pilot study should be performed at the NTS site. A detailed flow sheet, mass balance, and cost benefit analysis would be completed as part of the pilot study. 
Table 8 - Cost Comparison for NTS Clean Slate 3 Site $\left(1,200,000 \mathrm{ft}^{3}\right.$ Soil)

\section{Baseline Esimated Costs}

\begin{tabular}{|c|c|}
\hline Activity Description & Cost (\$) \\
\hline Field Work Preparation (e.g.. field planning) & 130,000 \\
\hline $\begin{array}{l}\text { Field Work (e.g. mobilization, site prep, infrastructure, } \\
\text { logistics, demob) }\end{array}$ & $1,199,000$ \\
\hline $\begin{array}{l}\text { Waste Characterization (e.g. belt detector system, } \\
\text { data collection) }\end{array}$ & 722,000 \\
\hline $\begin{array}{l}\text { Excavation (e.g. road grader forming windrows, } \\
\text { picking up with paddlewheel scraper) }\end{array}$ & $1,594,000$ \\
\hline $\begin{array}{l}\text { Packaging for Disposal (e.g. material handling, burrito } \\
\text { wraps, loading into trucks) }\end{array}$ & $5,439,000$ \\
\hline Transportation (e.g. hauling to NTS for disposal) & $3,904,000$ \\
\hline Disposal (e.g. disposal fee) & $9,027,000$ \\
\hline Total Cost & $22,015,000$ \\
\hline
\end{tabular}

$\operatorname{Cost/ft3}$
18.35

\section{Soil Wahing Option Cost}

\begin{tabular}{|c|c|}
\hline Activity Description & Cost (\$) \\
\hline Field Work Preparation (e.g.. field planning) & 130,000 \\
\hline $\begin{array}{l}\text { Field Work (e.g. mobilization, site prep, infrastructure, } \\
\text { logistics, demob) }\end{array}$ & $1,199,000$ \\
\hline $\begin{array}{l}\text { Waste Characterization (e.g. belt detector system, } \\
\text { data collection) }\end{array}$ & 722,000 \\
\hline $\begin{array}{l}\text { Excavation (e.g. road grader forming windrows, } \\
\text { picking up with paddlewheel scraper) }\end{array}$ & $1,594,000$ \\
\hline Wash Soil $^{1}$ & $10,565,000$ \\
\hline $\begin{array}{l}\text { Backfill Treated Soil }{ }^{2} \\
\text { Packaging for Disposal (e.g. material handling, burrito } \\
\text { wraps, loading into trucks) }\end{array}$ & $\begin{array}{l}1,115,800 \\
163,170\end{array}$ \\
\hline Transportation (e.g. hauling to NTS for disposal) ${ }^{3}$ & 117,120 \\
\hline Disposal (e.g. disposal fee) ${ }^{3}$ & 270,810 \\
\hline Total Cost & $15,876,900$ \\
\hline & \\
\hline
\end{tabular}

Savings Over Baseline
Soil Wahing Heap Leaching Option Cost

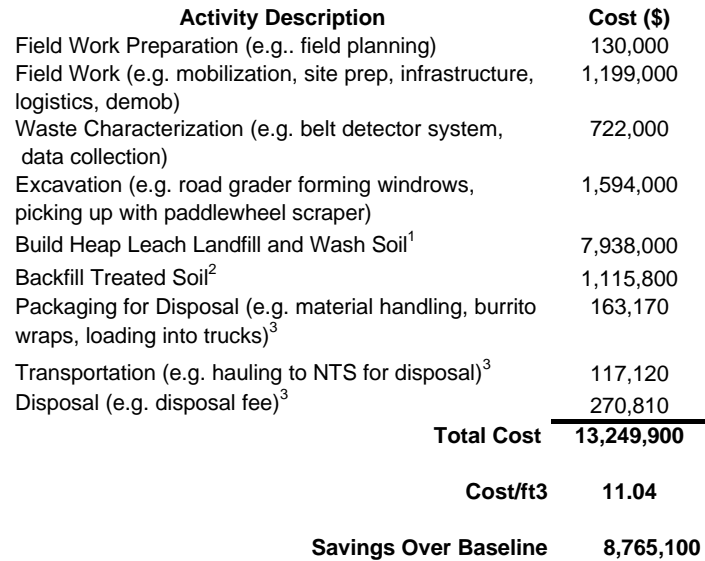

1. Soil Washing Cost Estmate includes construction of Heap Leach Landfill and/or Soil Plant Capital Improvements, Mobilization, Start-up, Demobilzation, Water, Chemicals, Supplies, Soil Plant Maintenance and Operations, Labor and Treated Soil Analysis.

2. Backfill Treated Soil Cost estimated to be $70 \%$ of excavtion cost

3. Packaging, Transportation, and Disposal Cost based upon 3\% of Baseline Cost for Secondary Waste. 
Flotation Cost Information Provided by URS Corporation

From page 16 of Plutonium Oxide Removal from Soil by High Capacity Flotation

System Final Report, September 2002.

\section{APPENDIX}

Cost Estimate of High Capacity Flotation Technology Versus Baseline Technology

Baseline Technology

\begin{tabular}{|c|c|c|}
\hline Item & $\begin{array}{r}\text { Cost Per } \\
\text { Cubic Feet (1) } \\
\end{array}$ & $\begin{array}{r}\text { Total } \\
\text { Cost } \\
\end{array}$ \\
\hline Field Preparation & $\$ 0.108$ & $\$ 130$ \\
\hline Field Work & $\$ 0.999$ & $\$ 1,199$ \\
\hline Waste Characterization & $\$ 0.602$ & $\$ 722$ \\
\hline Excavation & $\$ 1.331$ & $\$ 1,597$ \\
\hline Packaging for Disposal & $\$ 4.533$ & $\$ 5,439$ \\
\hline Transportation & $\$ 3.253$ & $\$ 3,904$ \\
\hline Disposal & $\$ 7.523$ & $\$ 9,027$ \\
\hline Total Baseline & $\$ 18.348$ & 22,018 \\
\hline
\end{tabular}

High Capacity Flotation Technology

\begin{tabular}{lrr} 
Item & $\begin{array}{r}\text { Cost Per } \\
\text { Cubic Feet (1) }\end{array}$ & $\begin{array}{r}\text { Total } \\
\text { Cost }\end{array}$ \\
\cline { 2 - 3 } Field Preparation & & \\
Field Work & $\$ 0.108$ & $\$ 130$ \\
Waste Characterization & $\$ 0.999$ & $\$ 1,199$ \\
Excavation & $\$ 0.602$ & $\$ 722$ \\
Packaging for Disposal (2) & $\$ 1.331$ & $\$ 1,597$ \\
Transportation (2) & $\$ 0.680$ & $\$ 816$ \\
Disposal (2) & $\$ 0.488$ & $\$ 586$ \\
Equipment Depreciation (3) & $\$ 1.128$ & $\$ 1,354$ \\
Water Cost (4) & $\$ 0.037$ & $\$ 44$ \\
Power Cost (5) & $\$ 0.629$ & $\$ 755$ \\
Chemical Reagent (6) & $\$ 0.008$ & $\$ 10$ \\
Operators (7) & $\$ 0.146$ & $\$ 175$ \\
& $\$ 0.329$ & $\$ 395$ \\
Total High Capacity & & \\
& & $\mathbf{\$ 7 , 7 8 2}$
\end{tabular}

\section{Notes \& Explanations}

(1) Based on total 1200,000 cubic feet of soils

(2) $1,200,000 \times 15 \%=180,000$ cubic feet as waste

(3) Using a 200 gpm system as example:

system capacity $=200 \times 3.785 \times 0.2 \times 60 \times 24 \times 365 / 72$.

system cost

1093075 (Cubic Feet Per Year)

yearly depreciation cost @ 10 Year SLw/o residual $\$ 400,000$

$\$ 40,000$

depreciation cost per cubic feet processed

$\$ 0.037$

(3) National cost range $=\$ 0.8-\$ 2.5 / 100$ gallons, assuming NTS cost at $\$ 5.00 / 100$ gallons, assuming $10 \%$ evaporation rate and $40 \%$ moisture in waste/cleaned soils

$(1,200,000 \times 72.8 / 0.2 \times .1 / 3.785 / 100 \times 5+1,200,000 \times 0.4 \times 28 / 3.785 \times 5 / 100) / 10$

755

(4) $30 \mathrm{hp}$ for a $200 \mathrm{gpm}$ system, assuming $\$ 0.07 / \mathrm{kwh}$ at NTS

$(30 \times 746 / 1000 \times 24 \times 365 \times 0.07) / 1000=$

(5) $0.1-1 \mathrm{~kg} /$ ton soil, take $1 \mathrm{~kg} /$ ton soil, $\$ 1 / \mathrm{lb}$ and 13.7 cubic feet/ton

175

(6) 2 operators per shift at 3 shift per day, cost per operator $=\$ 60,000 /$ year

$(60000 \times 2 \times 3 \times 1200000 / 1093075) / 1000$ 


\title{
Evaluation of Remediation Technologies for Plutonium Contaminated Soils at the Nevada Test Sits (NTS)
}

\section{Cooperative Agreement \#DE-FC26-00NT40841}

\author{
Volume VI
}

References and Bibliography

Date Issued October 13, 2003 


\section{BACKGROUND INFORMATION}

1. Information about the Nevada Test Site

2. The Need for Volume Reduction of the Plutonium-Contaminated Soils

3. Characterization of the Plutonium-Contaminated Soils

4. Characterization of the Plutonium-Contaminated Soils at the Nevada Test Site

5. Estimated Cost the Treat and Dispose of the Contaminated Soils

6. General information on Treatment Technologies for Radioactively Contaminated Soils.

7. Information on Treatment of Nevada Test Site Plutonium-Contaminated Soils

General Overviews and Multiple Technology Reviews

Magnetic Separation

Soil Washing/Chemical Extraction

Segmented Gate

Flotation

Bioremediation

Precision Excavation/Vacuum

\section{Information about the Nevada Test Site}

Final Environmental Impact Statement for the Nevada Test Site and Off-Site Location in the State of Nevada, United States Department of Energy, EIS Report, DOE/EIS -0243. Available on-line at: http://nepa.eh.doe.gov/eis/eis0243/eis0243_toc.html

1996 Baseline Environmental Management Report, Nevada Test Site and Tonopah Test Range, US DOE Office of Environmental Management, 1996. Available on-line at:

\section{http://www.em.doe.gov/bemr96/nvts.html}

Origins of the Nevada Test Site, United State Department of Energy, DOE/MA-0518, December 2000.

United States Nuclear Tests, July 1945 through September 1992, DOE/NV-209

(Rev.14). US DOE Nevada Operations Office, December 1994.

2. The Need for Volume Reduction of the Plutonium-Contaminated Soils

NTS Needs Statement Need Code NV04-00101-04S http://www.nv.doe.gov/programs/envmgmt/STCG/pdf/NV04-0101-05S.pdf 


\section{Characterization of the Plutonium-Contaminated Soils}

General

EPA, "Characterization Protocol for Radioactive Contaminated Soils" (1992),

Publication 9380.1-10FS

Sequential Extraction

Loyland S.M., LaMont S.P., Herbison S.E., and Clarl S. B. (2000b) "Actinides

Partitioning to an Acidic, Sandy Lake Sediment," Radiochimica Acta, 88, 793-798.

Loyland S.M., LaMont S.P., and Clarl S.B. (2001) "Plutonium Partitioning to Colloidal and Particulate Matter in Acidic, Sandy Sediment: Implications for Remediation Alternatives and Plutonium Migration," Environmental Science and Technology, 35, 2295-2300.

Schultz M., Burnett W. and Inn K. (1998a) "Evaluation of a Sequential Extraction Method for Determining Actinide Fraction in Soils and Sediments," Journal Environmental Radioactivity, 40, 155-174.

Schult M., Inn K., Lin Z., Burnett W., Smith G., Biegalski S., and Filliben J. (1998b) "Identification of Radionuclide Partitioning in Soils and Sediments: Determination of Optimum Conditions for the Exchangeable Fraction of the NIST Standard Sequential Extraction Protocol," Journal of Applied Radiation and Isotopes, 49, 1289-1293.

Schultz M., Burnett W., Inn K., Lin Z., Smith G., (1998c)"Geochemical Partitioning of Actinides Using Sequential Chemical Extraction: Comparison to Stable Elements," Journal of Radioanalytical and Nuclear Chemistry, 234, 251-256.

Smith, G.E. (1998) "Fraction of Actinide Elements in Sediments Via and Optimized Protocol for Sequential Chemical Extractions," Master Thesis, Florida State University, Tallahassee, Florida.

Litaor, M.I., Ibrahim, S.A. "Plutonium Association with Selected Solid Phases in Soils of Rocky Flats, Colorado, Using Sequential Extraction Technique"

Clark, S.B., Kurosaki, H., Loyland, S.M., Navratil, J.D., (2000), "Development of a Flow-through Reactor Method for Sequential Leaching of Soils and Sediments", Extended Abstracts Volume 2, 550, NRC5 $5^{\text {th }}$ International Conference on Nuclear and Radiochemistry, Pontresina, Switzerland

Schultz, M.K., (1996), "Partitioning of Uranium, Americium, and Plutonium in Irish Sea Sediment by Sequential Chemical Extractions", Master Thesis submitted to the Department of Oceanography, College of Arts and Sciences, Florida State University 


\section{Characterization of the Plutonium-Contaminated Soils at the Nevada Test Site}

Murarik, T.M., et.al., "Characterization Studies And Indicated Remediation Methods for Plutonium Contaminated Soils at the Nevada Test Site", Spectrum '92, Boise, Idaho, August 23-27, 1992.

Murarik, T.M., "Characterization, Liberation and Separation of Plutonium at the Nevada Test Site: Safety Shot Residues", Proceedings of the Soil Decon '93: Technology Targeting Radionuclides and Heavy Metals, June 16 and 17, 1993, Gatlinburg, TN, ORNL-6769, Oak Ridge National Laboratory, Oak Ridge, TN, September 1993.

Misra, M., et. al., "Characterization and Physical Separation of Radionuclides from Contaminated Soils," Proceedings of the Soil Decon '93: Technology Targeting Radionuclides and Heavy Metals, June 16 and 17, 1993, Gatlinburg, TN, ORNL-6769, Oak Ridge National Laboratory, Oak Ridge, TN, September 1993.

"Transuranics in Desert Ecosystems, Nevada Applied Ecology Group (1977) NVO-181, United States Department of Energy, Nevada Operations Office, Las Vegas, Nevada

Laux, B., (1975) Nevada Applied Ecology Group Progress Report - "The Radioecology of Plutonium and Other Transuranics in Desert Environments" NVO-153, United States Energy Research and Development Administration, Nevada Operations Office, Las Vegas, Nevada

Oyeyemi, Olayinka and Smith, David. Autoradiography of soil samples from NTS using Alpha and Beta Detectives. Livermore, CA: Glenn T.S. Institute for Transuranic Science.

Fowler, E.B., Essington, E.H., (1973-1974) "Nevada Applied Ecology Group Soils Element Activities", Los Alamos Scientific Laboratory "The Radioecology of Plutonium and Other Transuranics in Desert Environments" Nevada Applied Ecology Group Progress Report (1975) NVO-153, 7-9, 11-12, 1-26

Church, B.W., Medling, E.S.*, USAEC, Nevada Operations Office, Brady D.N., Reynolds Electrical \& Engineering Co., Inc., "A Different Look at Area 13 Fidler Survey Data" 231, "The Radioecology of Plutonium and Other Transuranics in Desert Environments" Nevada Applied Ecology Group Progress Report (1975) NVO-153; *Graduate student, San Diego State University

Gilbert, R.O., Eberhardt, L.L., Fowler, E.B.*, Romney, E.M., Essington, E.H.*, Kinnear, J.E., Battelle Memorial Institute, Pacific Northwest Laboratory, Richland, Washington, "Statistical Analysis of ${ }^{239-240} \mathrm{PU}$ and ${ }^{241} \mathrm{AM}$ Contamination of Soil and Vegetation on NAEG Study Sites, 339, *Los Alamos Scientific Laboratory, Los Alamos, New Mexico 


\section{Estimated Cost the Treat and Dispose of the Contaminated Soils}

Cost/Risk/Benefit Analysis of Alternative Cleanup Requirements for Plutonium-Contaminated Soils On and Near the Nevada Test Site, DOE/NV-399, US DOE Nevada Operations Office, May 1995.

Talmage, Sylvia S. and Betty D. Chilton, Cleanup Procedures at the Nevada Test Site and Other Radioactively Contaminated Sites Including Representative Costs of Cleanup and Treatment of Contaminated Areas, ORNL-6317, NVO/AEIC-306, Oak Ridge National Laboratory, Oak Ridge, TN, September 1987.

\section{General information on Treatment Technologies for Radioactively Contaminated Soils.}

Ijaz, Talaat, et.al., Summary of Remediation Options for Plutonium Contaminated Soils, Radioactive Waste Management and Env. Res., vol. 22, pp. 49-77, 1999.

International Atomic Energy Agency IAEA (1999) "Technologies for Remediation of Radioactively Contaminated Sites”, IAEA-TECDOC-1086

Remediation of Radioactively Contaminated Soils, Los Alamos National Laboratory, available at:

$$
\text { http://www-emtd.lanl.gov/TD/Remediation/radiosoils.html }
$$

Misra, M. and R.J. Mehta, Remediation Heavy Metals, Radionuclides, and Organic Pollutants from Soils, JOM, pp. 45-53, September 1995.

Misra, M., et.al., Heavy Metal Contaminated Soils Project. Physical Separation. Topical Report for Centrifugal Gravity and Gravo-magnetic Concentration Technology. Final Report. Prepared for US Department of Energy, Office of Technology Development, April 1995.

Heavy Metals Contaminated Soil Project Technical Summary, DOE/EM-0129P, National Technology Transfer Center, Wheeling, WV, 1994. Available on-line at: www.nttc.edu/env/Heavy Metals/heavy metals/chap1.html

Kung, K.S., et.al., Chemical Extraction of Plutonium and Americium from Contaminated Rocky Flats Soil, Radiochimica Acta, vol. 80, pp. 13-21, 1998.

Wagner, J. (1997) "New and Innovative Technologies for Mixed Waste Treatment", University of Michigan School of Natural Resources and Environment for EPA Office of Solid Waste Permits and State Programs Division

EPA, "Technology Screening Guide for Radioactively Contaminated Sites" (1996), EPA 402-R-96-017, November

4 
OAK National Laboratory. Proceedings of Soil Decon'93: Technology Targeting Radionuclides and Heavy Metals, Gatlinburg, Tennessee: OAK National Laboratory; 1993 June.

Kung, K.S., Lu, N., Triay, L.R., Motyl, K.M., Roushey, W.J., (1997) “Chemical Extraction of Plutonium and Americium from Contaminated Rocky Flats Soil"

Gombert, Dirk. Evaluation of soil washing for radiological contaminated soils. Idaho National Engineering Laboratory; 1994 March.

Lu, N., et.al., Removal of Plutonium-239 and Americium-241 from Rocky Flats Soil by Leaching, Environ. Sci. Technol., vol. 32, pp. 370-374, 1998.

Negri, M.C., Selective Removal of Plutonium 238 From a Canal Sediment Using a Carbonate-Chelnat Soil Washing Technology (ACT*DE*CONSM), Journal of Hazardous Materials, vol. 66, pp. 99-118, 1999.

\section{Information on Treatment of Nevada Test Site Plutonium-Contaminated Soils}

General Overviews and Multiple Technology Reviews

Cho, Eung Ha, et. al., Soil Volume Reduction Technologies, Evaluation of Current Technologies, DOE Cooperative Agreement DE-FC26-98FT40396, Deployment Leading to Implementation, Final Report, submitted by West Virginia University to US DOE National Energy Technology Laboratory, July 2000.

Wallace, A., Romney, E.M., "Feasibility and Alternate procedures for Decontamination and Post-Treatment Management of Pu-Contaminated Areas in Nevada"*, University of California, Laboratory of Nuclear Medicine and Radiation Biology, Los Angeles, CA, 255, 251-328, "The Radioecology of Plutonium and Other Transuranics in Desert Environments" Nevada Applied Ecology Group Progress Report (1975) NVO-153 *Republished with minor changes from an original report prepared for the NAEG in September, 1974, UCLA-12-973

Papelis, et. al., Evaluation of Technologies for Volume Reduction of Plutonium-Contaminated Soils from the Nevada Test Site, DOE/NV/10845-57, US

DOE Nevada Operations Office, June, 1996. Available on-line at: here or at: http://plutonium-erl.actx.edu/pusoil.html

Note: this site (http://plutonium-erl.actx.edu/) is very extensive

Magnetic Separation

Schake, A. R., et. al., "Magnetic Separation for Environmental Remediation." Report No. LA-UR-94-3373, CONF-940301—44, Los Alamos National 
Laboratory, Los Alamos, NM. 1994.

Soil Washing/Chemical Extraction

Integrated Demonstration, Plutonium in Soils, Final Report submitted by Scientific

Ecology Group, STD-R-58-001, US Department of Energy, Las Vegas, Nevada

Misra, M., et.al., Application of Physical Beneficiation Techniques for Separation of Radionuclides from Contaminated Soils, 1995 SME Annual Meeting, March 6-9, 1995, Denver, Colorado - View PDF

Misra, et.al., A Cost Effective Approach for Volume Reduction of PlutoniumContaminated Soils," University of Nevada-Reno.

Misra, M. and R.K. Mehta, Physical Separation of Radionuclides from Contaminated Soils. University of Nevada-Reno.

DOE/MEMP Summary Report of the Pilot Test on Nevada Test Site Soils

\section{Segmented Gate}

Summary Report, Segmented Gate System, Summary of Lessons Learned

From Applications at Seven DOE Sites, Accelerated Site Technology

Deployment, U.S. Department of Energy, February 2001

ThermoNUtech's Segmented Gate System at Tonapah Test Range, Clean Slate 2, Tonapah, Nevada, Federal Remediation Technologies Roundtable, 1999. Available on-line at: http://bigisland.ttclients.com/frtr/00000180.html

Flotation

Mehta, R.K., et.al., Triboelectrification Assisted Air Classification Process for Removal of Radionuclides from Contaminated Soils, Chapter 32 of Hydrocarbon Contaminated Soils, Volume 5. From the Proceedings of the 1994 Ninth Annual Conference on Contaminated Soils, held at the University of Massachusetts at Amherst, Kostecki, P.T., et.al., (eds), 1995.

Chai, Cheng-Dong, Flotation Separation of Radionuclides from Contaminated Nevada Test Site (NTS) Soil, Thesis, University of Nevada-Reno, 1995.

Cho, E.H., et.al., Carrier Flotation for the Removal of Radionuclides from Contaminated Soils, Minerals and Metallurgical Processing, pp. 27-31, August, 1997.

Misra, M. et.al., Selective Flotation of Ultra Fine Radionuclides from Johnston Atoll Coral Sand, 1996 SME Annual Meeting, March 11-14, 1996, Phoenix, Arizona.

Bioremediation

Metals Bioremediation Project, Final Report, IT Project No. 767685, IT

6

Volume VI References and Bibliography

Cooperative Agreement \#DE-FC26-00NT40841

October 13, 2003 
Corporation, Knoxville, TN, 1997.

Environmental News, (2001) "Microbes Show Promise for Bioremediating Plutonium", August, 314A

Rusin, P.A., et.al., Solubilization of Plutonium Hydrous Oxide by Iron-Reducing Bacteria, Environ. Sci. Technol., vol. 28, pp. 1686-1690, 1994.

Groudev, S.N., et.al., Bioremediation of a Soil Contaminated with Radioactive Elements, Hydrometallurgy, vol. 59, pp. 311-318, 2001.

Bryan N., Livens F., and Horrill A. (1994) "Biogeochemical Behavior of Plutonium and Geochemical Modeling of Soil Solution," Journal of Radioanalytical and Nuclear Chemistry, 182, 2, 359-366.

Precision Excavation/Vaccum

Orcutt, J.A., Cleanup and Treatment (CAT) Test: A Land Area Decontamination Project Utilizing a Vacuum Method of Soil Removal, DOE/NV/00410-70, USDOE, Las Vegas, Nevada, August 1982. 


\section{BIBLIOGRAPHY}

Hoeffner, Steve, Navratil, J.D., Torrao, G., Carlino, Robert, "Characterization of Radioactive Contaminated Soils from the Nevada Test Site" Proceedings of the 9th Biennial International Conference on Nuclear and Hazardous Waste Management, Reno, Nevada, August 4 - 8, 2002.

Hoeffner, Steve, Navratil, J.D., Carlino, Robert, Smalley, Richard, "Remediation Methods for Plutonium Contaminated Soils at the Nevada Test Site" Poster presentation at the Subsurface Contaminants Focus Area Midyear Review Conference, Salt Lake City, Utah, March 5-7, 2002.

Hoeffner, Steve, Navratil, J.D., Torrao, G., Smalley, Richard, Carlino, Robert, "Lesson Learned Evaluation of Remediation Technologies for Plutonium Contaminated Soil" Proceedings of the WM'02 Conference, Tucson, Arizona, February 24-28, 2002.

Hoeffner, Steve, Navratil, J.D., Torrao, G., "Remediation Methods for Contaminated Soils at the Nevada Test Site." Proceedings of the $13^{\text {th }}$ Annual Technical Information Exchange Workshop, Albuquerque, New Mexico, November 12-15, 2001.

Hoeffner, Steve L., Navratil, J.D., Torrao, G., Smalley, Richard, "Evaluation of Remediation Methods for Plutonium Contaminated Soil." Proceedings of Industry Partnerships for Environmental Science and Technology Conference, Morgantown, WV, October 30-November 1, 2001.

Hoeffner, Steve, Navratil, J.D., Smalley, Richard, "Advances in Treatment Methods for Radioactive Contaminated Soils" Proceedings of the $8^{\text {th }}$ International Conference on Radioactive Waste Management and Environmental Remediation (ICEM '01), Bruges, Belgium, September 30October 4, 2001.

NNSA, (2001) "Proceedings from the Remediation of Radioactive Surface Soils Workshop", August 14-15, 2001, U.S. Department of Energy National Nuclear Security Administration, Nevada Operations Office

Torrao, Guilhermina, Hoeffner, Steve, and Navratil, James. Technical Evaluation of Remediation Technologies for Plutonium Contaminated Soils at the Nevada Test Site. $25^{\text {th }}$ Actinide Separations Conference. Boise, Idaho. May 14-18, 2001.

Hoeffner, Steve, Navratil, J.D., Smalley, Richard, "Technical Evaluation of Remediation Technologies for Plutonium-Contaminated Soils." Poster presentation at the Subsurface Contaminants Focus Area Midyear Review Conference, Atlanta, Georgia, March 20-22, 2001.

Hoeffner S., Navratil J., and Smalley R. (2000) “Technical Evaluation of Remediation Technologies for Plutonium Contaminated Soil," Proceedings of Industry Partnerships for Environmental Science and Technology Conference, Morgantown, MV. 


\section{References and Bibliography for Evaulation of Remediation Technologies for Plutonium Contaminated Soils at the Nevada Test Site (NTS)}

\begin{tabular}{|c|c|c|c|}
\hline Ref.\# & Title & Author & File Name \\
\hline $1+1$ & $\begin{array}{l}\text { Final Environmental Impact Statement for the Nevada Test Site } \\
\text { and Off-Site Location in the State of Nevada }\end{array}$ & "DOE & "1-1-eis-024.pdf \\
\hline $1-2$ & 1996 Baseline Environmental Mgt Report & DOE & 1-2-nvts.pdf \\
\hline $1-3$ & Origins of the Nevada Test Site & $\mathrm{DOE}$ & N/A \\
\hline $1-4$ & US Nuclear Tests July 45 - Sept.1992 & DOE & $\mathrm{N} / \mathrm{A}$ \\
\hline $2-1$ & NTS Needs Statement & DOE & 2-1-Site Need Statement.pdf \\
\hline $3-1$ & Characterization Protocol for Radioactive Contaminated Soils" & EPA & $3-1-$ \\
\hline $3-2$ & Actinides Partitioning to an Acidic Sandy Lake Sediment & Loyland S.M., LaMont S.P., Clarl S.B. & 3-2-Actinides Partitioning.pdf \\
\hline $3-3$ & $\begin{array}{l}\text { Plutonium Partitioning to Colloidal and Particulate Matter } \\
\text { in Acidic, Sandy Sediment }\end{array}$ & Loyland S.M., LaMont S.P., Clarl S.B. & $\mathrm{N} / \mathrm{A}$ \\
\hline $3-4$ & $\begin{array}{l}\text { Evaluation of a Sequential Extraction Method for Determining } \\
\text { Actinide Fraction in Soils and Sediments }\end{array}$ & Schultz M., Burnett W., Inn K. & $\mathrm{N} / \mathrm{A}$ \\
\hline $3-5$ & $\begin{array}{l}\text { Identification of Radionuclide Partitioning in Soils and Sediments: } \\
\text { Determination of Optimum Conditions for the Exchangeable } \\
\text { Fraction of the NIST Standard Sequential Extraction Protocol }\end{array}$ & $\begin{array}{l}\text { Schultz M., Inn K., Lin Z., Burnett W., } \\
\text { Smith G., Biegalski S., and Filliben J. }\end{array}$ & $\mathrm{N} / \mathrm{A}$ \\
\hline $3-6$ & $\begin{array}{l}\text { Geochemical Partitioning of Actinides Using Sequential } \\
\text { Chemical Extraction: Comparison to Stable Elements" }\end{array}$ & $\begin{array}{l}\text { Schultz M., Burnett W., Inn K., Lin Z., } \\
\text { Smith G. }\end{array}$ & $\mathrm{N} / \mathrm{A}$ \\
\hline $3-7$ & $\begin{array}{l}\text { Fraction of Actinide Elements in Sediments Via and Optimized } \\
\text { Protocol for Sequential chemical Extractions }\end{array}$ & Smith G.E. & $\mathrm{N} / \mathrm{A}$ \\
\hline $3-8$ & $\begin{array}{l}\text { Plutonium Association with Selected Solid Phases in Soils of } \\
\text { Rocky Flats, Colorado, Using Sequential Extraction Technique }\end{array}$ & Litaor, M.I., Ibrahim, S.A. & $\begin{array}{l}\text { 3-8-Plutonium Association } \\
\text { with Selected Solid.pdf }\end{array}$ \\
\hline $3-9$ & $\begin{array}{l}\text { Development of a Flow-through Reactor Method for Sequential } \\
\text { Leaching Soils and Sediments }\end{array}$ & $\begin{array}{l}\text { Clark, S.B., Kurosaki, H., Loyland, S.M. } \\
\text { Navratil, J.D. }\end{array}$ & $\mathrm{N} / \mathrm{A}$ \\
\hline $3-10$ & $\begin{array}{l}\text { Partitioning of Uranium, Americium, and Plutonium in Irish Sea } \\
\text { Sediment by Sequential Chemical Extractions }\end{array}$ & Schultz, M.K. & $\mathrm{N} / \mathrm{A}$ \\
\hline $4-1$ & $\begin{array}{l}\text { Characterization Studies and Indicated Remediation Methods } \\
\text { for Plutonium Contaminated Soils at the Nevada Test Site }\end{array}$ & Murarik, T.M., et.al & $\mathrm{N} / \mathrm{A}$ \\
\hline $4-2$ & $\begin{array}{l}\text { Characterization, Liberation and Separation of Plutonium at the } \\
\text { Nevada Test Site: Safety Shot Residues }\end{array}$ & Murarik, T.M. & $\begin{array}{l}\text { 4-2-Characterization, Liberation, and } \\
\text { Separation.pdf }\end{array}$ \\
\hline $4-3$ & $\begin{array}{l}\text { Characterization and Physical Separation of Radionculides from } \\
\text { Contaminated Soils }\end{array}$ & Misra, M., et.al & $\begin{array}{l}\text { 4-3-Characterization and Physical } \\
\text { Separation.pdf }\end{array}$ \\
\hline $4-4$ & Transuranics in Desert Ecosystems & DOE & $\begin{array}{l}\text { 4-4-NTS Tru in Desert } \\
\text { Ecosystems.pdf }\end{array}$ \\
\hline $4-5$ & $\begin{array}{l}\text { The Radioecology of Plutonium and Other Transuranics in } \\
\text { Desert Environments }\end{array}$ & Laux, B. & $\begin{array}{l}\text { 4-5-NTS The Radioecology } \\
\text { of Plutonium.pdf }\end{array}$ \\
\hline
\end{tabular}




\section{References and Bibliography for Evaulation of Remediation Technologies for Plutonium Contaminated Soils at the Nevada Test Site (NTS)}

\begin{tabular}{|c|c|c|c|}
\hline Ref. \# & Title & Author & File Name \\
\hline $4-6$ & $\begin{array}{l}\text { Autoradiography of Soil Samples from NTS using Alpha and } \\
\text { Beta Detectives. }\end{array}$ & Oyeyemi, Olayinka and Smith, David & 4-6-Autoradiography of Soil Samples.pdf \\
\hline $4-7$ & Nevada Applied Ecology Group Soils Element Activities & Fowler, E.B., Essington, E.H. & 4-7-Nevada Applied Ecology Group.pdf \\
\hline $4-8$ & A Different Look at Area 13 Fidler Survey Data & Church, B.W., Medling, E.S. & 4-8-A Different Look at Area 13.pdf \\
\hline $4-9$ & $\begin{array}{l}\text { Statistical Analysis of PU and AM Contamination } \\
\text { of Soil and Vegetation on NAEG Study Sites }\end{array}$ & Gilbert, R.O., Eberhardt, L.L., Fowler, E.B. & $\begin{array}{l}\text { 4-9-Statistical Analysis of } \\
\text { 239-240 Pu.pdf }\end{array}$ \\
\hline $5-1$ & $\begin{array}{l}\text { Cost/Risk/Benefit Analysis of Alternative Cleanup Requirements } \\
\text { for Plutonium-Contaminated Soils On and Near the Nevada Test } \\
\text { Site }\end{array}$ & DOE & 5-1-Cost/Risk.pdf \\
\hline $5-2$ & $\begin{array}{l}\text { Cleanup Procedures at the Nevada Test Site and Other } \\
\text { Radioactively Contamined Sites, Including Representative Costs } \\
\text { of Cleanup and Treatment of Contaminated Areas }\end{array}$ & Talmage, Sylvia S. and Chilton, Betty D. & $\begin{array}{l}\text { 5-2-ORNL Cleanup } \\
\text { Procedures at the Nevada } \\
\text { Test NTS1.pdf }\end{array}$ \\
\hline $6-1$ & $\begin{array}{l}\text { Summary of Remediation Options for Plutonium Contaminated } \\
\text { Soils, Radioactive Waste Management and Env. Res. }\end{array}$ & ljaz, Talaat, et.al & $\begin{array}{l}\text { 6-1-Summary of Remediation } \\
\text { Options.pdf }\end{array}$ \\
\hline $6-2$ & $\begin{array}{l}\text { Technologies for Remediation of Radioactively Contaminated } \\
\text { Sites }\end{array}$ & International Atomic Energy Agency IAEA & $\mathrm{N} / \mathrm{A}$ \\
\hline $6-3$ & Remediation of Radioactively Contaminated Soils & Los Alamos National Laboratory & 6-3-LA Heap Leach.pdf \\
\hline $6-4$ & $\begin{array}{l}\text { Remediation Heavy Metals, Radionuclides, and Organic } \\
\text { Pollutants from Soils }\end{array}$ & Misra, M. and Mehta, R.J. & $\begin{array}{l}\text { 6-4-Remediation Heavy } \\
\text { Metals.pdf }\end{array}$ \\
\hline $6-5$ & $\begin{array}{l}\text { Heavy Metal Contaminated Soils Project. Physical Separation. } \\
\text { Topical Report for Centrifugal Gravity and Gravo-magnetic } \\
\text { Concentration Technology }\end{array}$ & Misra, M., et.al & $\begin{array}{l}\text { 6-5-Heavy Metal Contamin- } \\
\text { ated Soils Project.pdf }\end{array}$ \\
\hline $6-6$ & Heavy Metals Contaminated Soil Project Technical Summary & $\mathrm{DOE}$ & $\mathrm{N} / \mathrm{A}$ \\
\hline $6-7$ & $\begin{array}{l}\text { Chemical Extraction of Plutonium and Americium from } \\
\text { Contaminated Rocky Flats Soil, Radiochimica Acta }\end{array}$ & Kung, K.S., et.al & $\mathrm{N} / \mathrm{A}$ \\
\hline $6-8$ & New and Innovative Technologies for Mixed Waste Treatment & Wagner, J. & $\begin{array}{l}\text { 6-8-New Mixed Waste Treatment } \\
\text { Technology.pdf }\end{array}$ \\
\hline $6-9$ & $\begin{array}{l}\text { Technology Screening Guide for Radioactively Contaminated } \\
\text { Sites }\end{array}$ & EPA & 6-9-Guide.pdf \\
\hline $6-10$ & $\begin{array}{l}\text { Proceedings of Soil Decon '93: Technology Targeting } \\
\text { Radionuclides and Heavy Metals }\end{array}$ & OAK National Laboratory & $\mathrm{N} / \mathrm{A}$ \\
\hline $6-11$ & $\begin{array}{l}\text { Chemical Extraction of Plutonium and Americium from } \\
\text { Contaminated Rocky Flats Soil }\end{array}$ & $\begin{array}{l}\text { Kung, K.S., Lu, N., triay, L.R., Motyl, K.M. } \\
\text { Roushey, W.J. }\end{array}$ & $\begin{array}{l}\text { 6-11-Chemical Extraction of } \\
\text { Plutonium.pdf }\end{array}$ \\
\hline $6-12$ & Evaluation of Soil Washing for Radiological Contaminated Soils & Gombert, Dirk & $\mathrm{N} / \mathrm{A}$ \\
\hline $6-13$ & $\begin{array}{l}\text { Removal of Plutonium-239 and Americium-241 from Rocky } \\
\text { Flats Soil by Leaching }\end{array}$ & Lu, N., et.al & $\mathrm{N} / \mathrm{A}$ \\
\hline
\end{tabular}




\section{References and Bibliography for Evaulation of Remediation Technologies for Plutonium Contaminated Soils at the Nevada Test Site (NTS)}

\begin{tabular}{|c|c|c|c|}
\hline Ref. \# & Title & Author & File Name \\
\hline 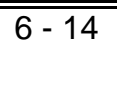 & $\begin{array}{l}\text { Selective Removal of Plutonium } 238 \text { from a Canal Sediument } \\
\text { Using a Carbonate-Chelnat Soil Washing Technology }\end{array}$ & Negri, M.C. & $\begin{array}{l}\text { 6-14-Selective Removal of } \\
\text { Plutonium 238.pdf }\end{array}$ \\
\hline $7-1$ & $\begin{array}{l}\text { Soil Volume Reduction Technologies, Evaluation of Currnet } \\
\text { Technologies }\end{array}$ & Cho, Eung Ha., et.al & 7-1-July 2000.pdf \\
\hline $7-2$ & $\begin{array}{l}\text { Feasibility and Alternate Procedures for Decontamination and } \\
\text { Post-Treatment Management of Pu-Contamined Areas in } \\
\text { Nevada }\end{array}$ & Wallace, A., Romney, E.M. & $\begin{array}{l}\text { 7-2-Feasibility and Alternate } \\
\text { Procedures.pdf }\end{array}$ \\
\hline $7-3$ & $\begin{array}{l}\text { Evaluation of Technologies for Volume Reduction of Plutonium- } \\
\text { Contaminated Soils from the Nevada Test Site }\end{array}$ & Papelis, et.al & 7-3-Abstract.pdf \\
\hline $7-4$ & Magnetic Separation for Environmental Remediation & Schake, A.R., et.al & $\begin{array}{l}\text { 7-4-Magnetic Separation for } \\
\text { Environmental Remediation. } \\
\text { pdf }\end{array}$ \\
\hline $7-5$ & Integrated Demonstration, Plutonium in Soils & Scientific Ecology Group & $\begin{array}{l}\text { 7-5-Integrated Demonstration, } \\
\text { Plutonium in Soils1.pdf }\end{array}$ \\
\hline $7-6$ & $\begin{array}{l}\text { Application of Physical Beneficiation Techniques for } \\
\text { Separation of Radionuclides from Contaminated Soils }\end{array}$ & Misra, M., et.al & $\begin{array}{l}\text { 7-6-Application of Physical } \\
\text { Benefication Techniques.pdf }\end{array}$ \\
\hline $7-7$ & $\begin{array}{l}\text { A Cost Effective Approach for Volume Reduction of Plutonium } \\
\text { Contaminated Soils }\end{array}$ & Misra, et.al & 7-7-A Cost Effective Approach.pdf \\
\hline $7-8$ & Physical Separation of Radionuclides from Contaminated Soils & Misra, M. and Mehta, R.K. & $\begin{array}{l}\text { 7-8-Physical Separation of } \\
\text { Radionuclides.pdf }\end{array}$ \\
\hline $7-9$ & $\begin{array}{l}\text { Segmented Gate System, Summary of Lessons Learned } \\
\text { from Applications at Seven DOE Sites }\end{array}$ & DOE & $\begin{array}{l}\text { 7-9-SGS Segmented Gate } \\
\text { System_Summary Report.pdf }\end{array}$ \\
\hline $7-10$ & Segmented Gate System at Tonapah Test Range & ThermoNUtech & 7-10-Segmented Gate System.pdf \\
\hline $7-11$ & $\begin{array}{l}\text { Trioelectrification Assisted Air Classification Process for } \\
\text { Removal of Radionuclides from Contaminated Soils }\end{array}$ & Mehta, R.K., et.al & $\begin{array}{l}\text { 7-11-Triboelectrification } \\
\text { Chapter 32.pdf }\end{array}$ \\
\hline $7-12$ & $\begin{array}{l}\text { Flotation Separation of Radionuclides from Contamined Nevada } \\
\text { Test Site (NTS) Soil }\end{array}$ & Chai, Cheng-Dong & $\begin{array}{l}\text { 7-12-Flotation Separation } \\
\text { of Radionuclides.pdf }\end{array}$ \\
\hline $7-13$ & $\begin{array}{l}\text { Carrier Flotation for the Removal of Radionuclides from } \\
\text { Contaminated Soils }\end{array}$ & Cho, E.H., et.al & $\begin{array}{l}\text { 7-13-Carrier Flotation for the } \\
\text { Removal of Radionuclides.pdf }\end{array}$ \\
\hline $7-14$ & $\begin{array}{l}\text { Selective Flotation of Ultra Fine Radionuclides from Johnston } \\
\text { Atoll Coral Sand }\end{array}$ & Misra, M., et.al & $\begin{array}{l}\text { 7-14-Selective Flotation of } \\
\text { Ultra Fine Radionuclides.pdf }\end{array}$ \\
\hline $7-15$ & Metals Bioremediation Project & IT & N/A \\
\hline $7-16$ & Microbes Show Promise for Bioremediating Plutonium & Environmental News & $\mathrm{N} / \mathrm{A}$ \\
\hline $7-17$ & $\begin{array}{l}\text { Solubilization of Plutonium Hydrous Oxide by Iron-Reducing } \\
\text { Bacteria }\end{array}$ & Rusin, P.A., et.al & $\begin{array}{l}\text { 7-17-Solubilization of Pluton- } \\
\text { ium Hydrous Oxide by Iron- } \\
\text { Reducing Bacteria.pdf }\end{array}$ \\
\hline
\end{tabular}




\section{References and Bibliography for Evaulation of Remediation Technologies for Plutonium \\ Contaminated Soils at the Nevada Test Site (NTS)}

\begin{tabular}{|c|c|c|c|}
\hline Ref. \# & Title & Author & File Name \\
\hline $7-18$ & $\begin{array}{l}\text { Bioremediation of a Soil Contaminated with Radioactive } \\
\text { Elements }\end{array}$ & "Groudev, S.N., et.al & $\begin{array}{l}7-18-\text { Bioremediation of a } \\
\text { Soil Contaminated with } \\
\text { Radioactive Elements.pdf }\end{array}$ \\
\hline $7-19$ & $\begin{array}{l}\text { Biogeochemical Behavior of Plutonium and Geochemical } \\
\text { Modeling of Soil Solution }\end{array}$ & Bryan, N., Livens, F., and Horrill A. & $\begin{array}{l}\text { 7-19-Biogeochemical } \\
\text { Behavior of Plutonium.pdf }\end{array}$ \\
\hline $7-20$ & $\begin{array}{l}\text { Cleanup and Treatment (CAT) Test: A Land Area Decontamin- } \\
\text { ation Project Utilizing a Vacuum Method of Soil Removal }\end{array}$ & DOE & $\begin{array}{l}\text { 7-20-Cleanup and Treatment } \\
\text { (CAT)1.pdf }\end{array}$ \\
\hline
\end{tabular}

